\begin{abstract}
Title of Document:

WATER IMMERSION BALLASTED

PARTIAL GRAVITY FOR LUNAR AND

MARTIAN EVA SIMULATION

John Richard Mularski

Master of Science, 2007

Directed By:

Associate Professor David Akin

Department of Aerospace Engineering
\end{abstract}

The University of Maryland Space Systems Laboratory is developing the capability to simulate partial gravity levels for human operational activities through the use of ballast on body segments in the underwater environment. This capability will be important as NASA prepares to return to the Moon by the end of the next decade. This thesis discusses various forms of partial gravity simulation used in the past, and discusses applications for ballasted underwater simulations. Primary application of this technique is for static or quasistatic activities, such as collecting basic anthropometric data on reach envelopes or postural control, as well as accumulating an experience base on partial gravity habitat and vehicle design and operations. The research conducted investigated collecting postural stability data through the use of a controlled disturbance to the ballasted subject. 


\title{
WATER IMMERSION BALLASTED PARTIAL GRAVITY FOR LUNAR AND MARTIAN EVA SIMULATION
}

\author{
By \\ John Richard Mularski \\ Thesis submitted to the Faculty of the Graduate School of the \\ University of Maryland, College Park, in partial fulfillment \\ of the requirements for the degree of \\ Master of Science \\ 2007
}

Advisory Committee:

Associate Professor David Akin, Chair

Associate Professor Robert Sanner

Visiting Professor Mary Bowden 
(C) Copyright by

Space Systems Laboratory

University of Maryland

2007 


\section{Dedication}

This paper is dedicated to my parents for all of their help and support. 


\section{Acknowledgements}

I would like to thank everyone at the SSL for all the help they have provided during my time here. I would especially like to thank my test subjects Agnieszka, Liz, Ali, and Tim as well as my lead safety diver Dave. I would also like to thank my adviser Dr. Akin for helping me develop this project and guiding me through. 


\section{Table of Contents}

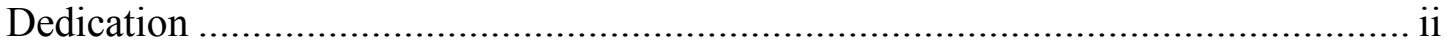

Acknowledgements................................................................................. iii

Table of Contents.................................................................................... iv

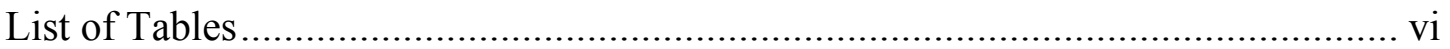

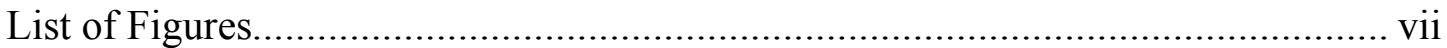

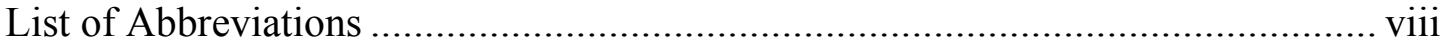

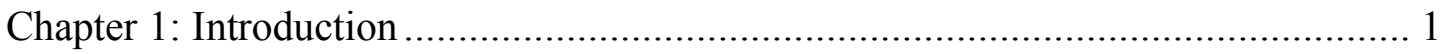

Chapter 2: Background Material and Literature Review ......................................... 3

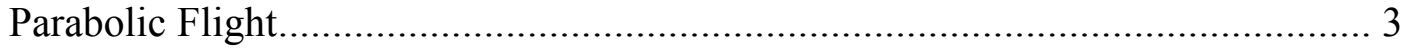

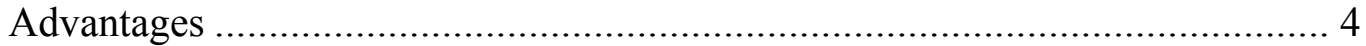

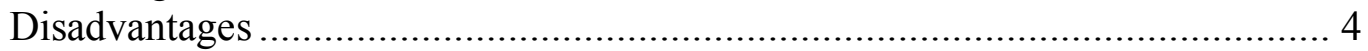

Previous Research .............................................................................. 5

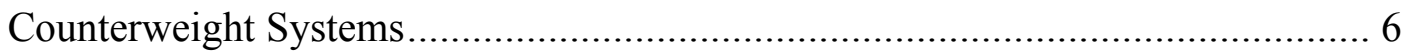

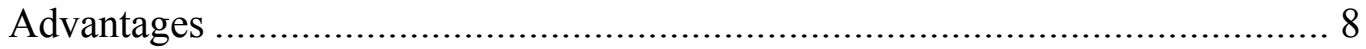

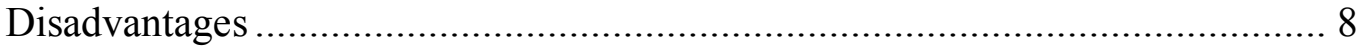

Previous Research ........................................................................... 9

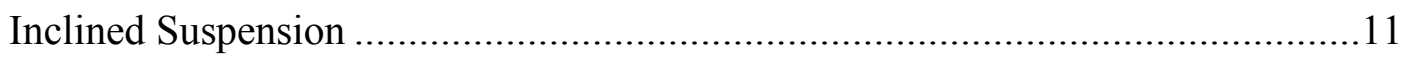

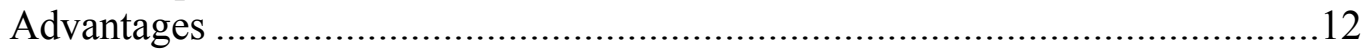

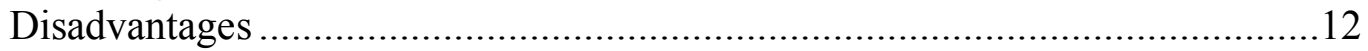

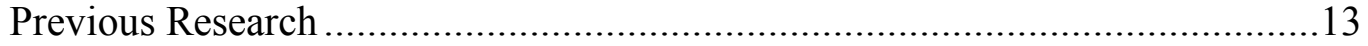

Water Immersion ................................................................................... 14

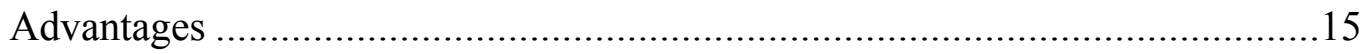

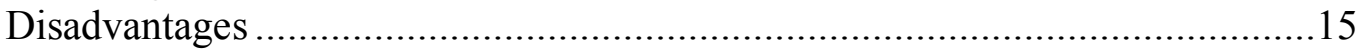

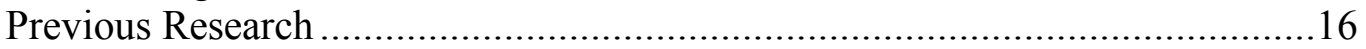

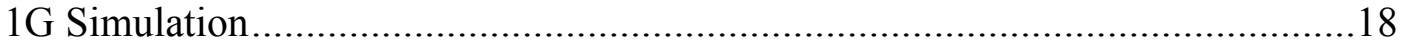

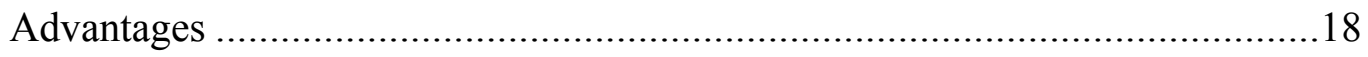

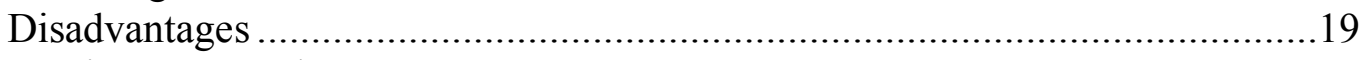

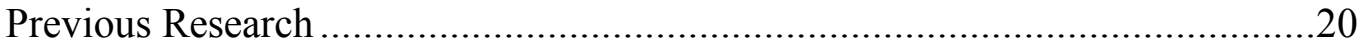

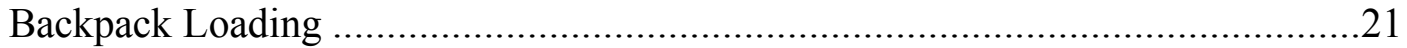

Chapter 3: Partial Gravity System Design \& Development......................................23

Ballast System Development...........................................................................25

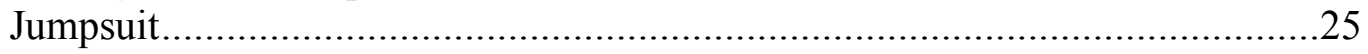

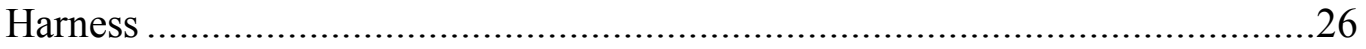

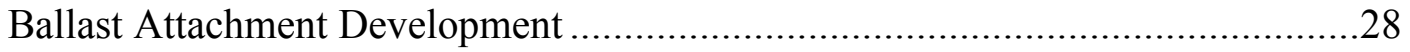

Hard Plate System ..................................................................................28

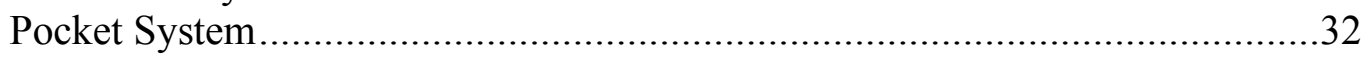

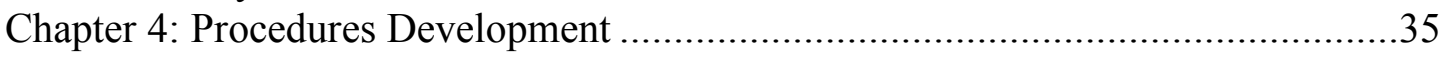

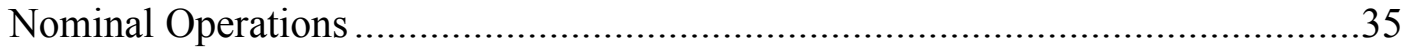

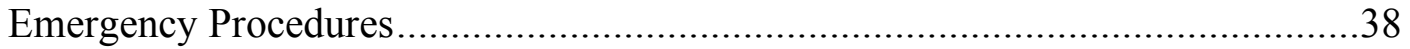

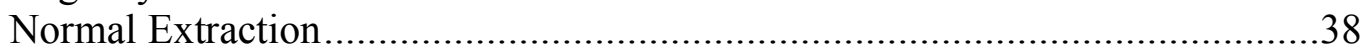

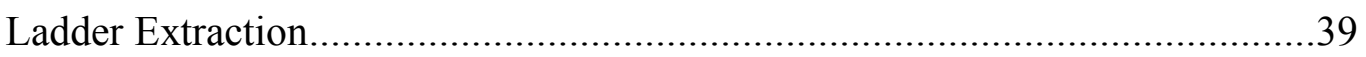

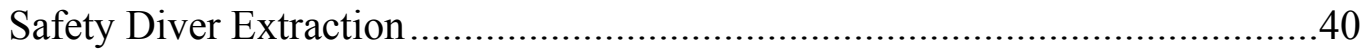

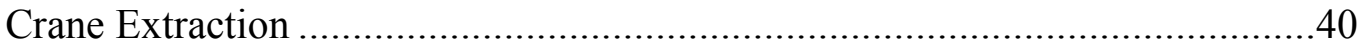


Chapter 5: Experimental Procedures \& Hardware ...................................................42

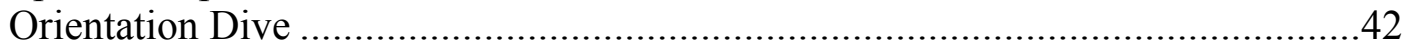

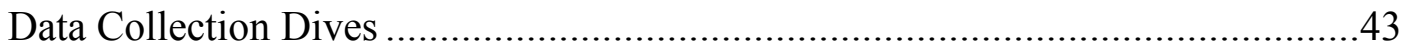

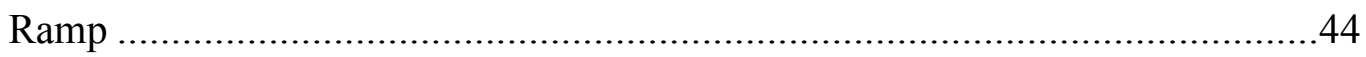

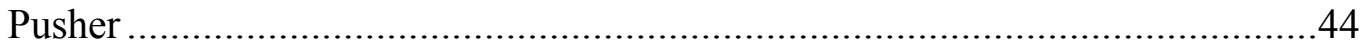

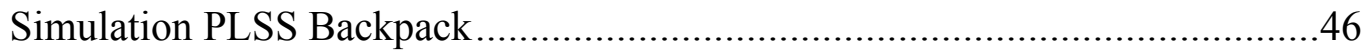

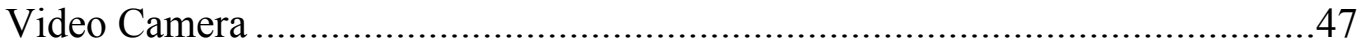

Experimental Procedures......................................................................48

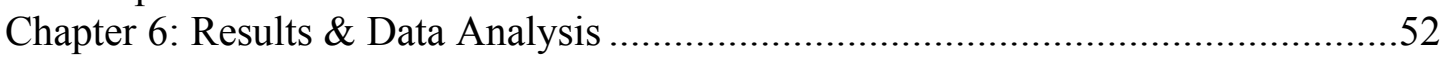

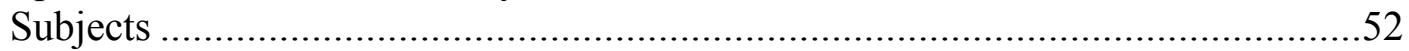

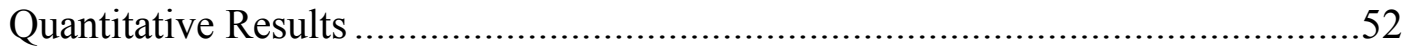

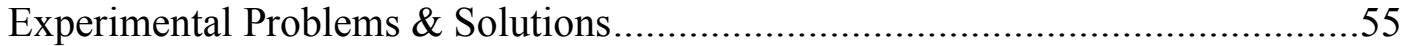

Data Analysis Problems \& Solutions .........................................................59

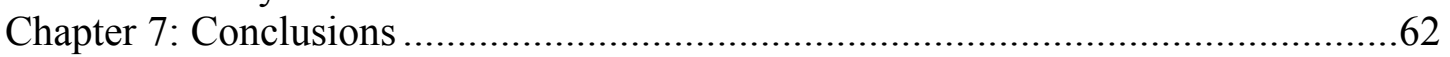

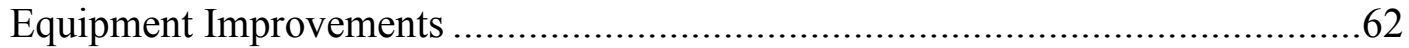

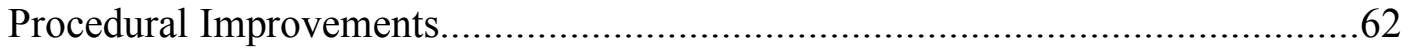

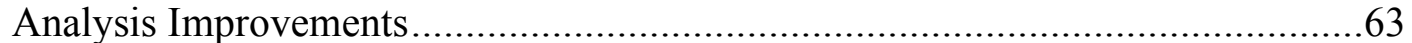

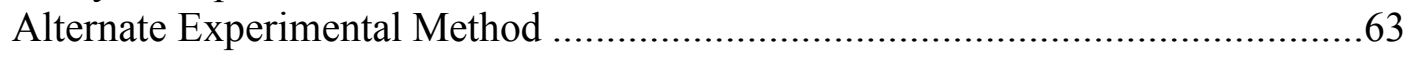

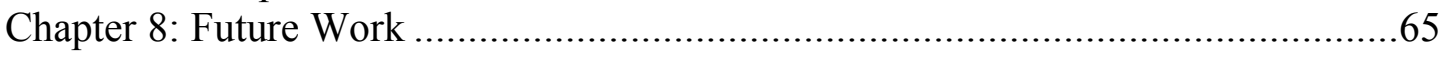

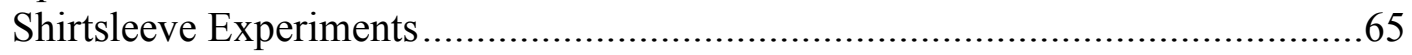

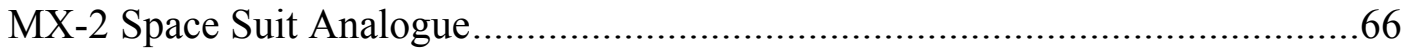

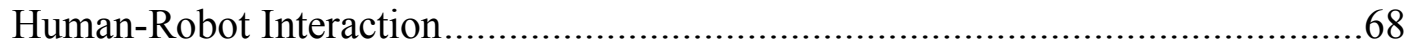

Appendix A: Pusher Experiment Data................................................................69

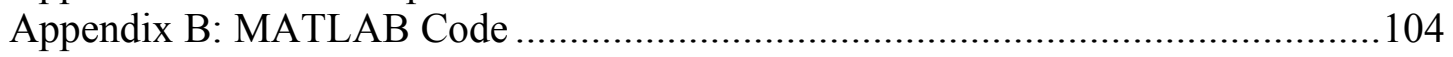

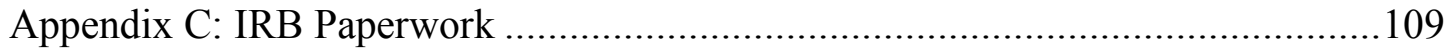

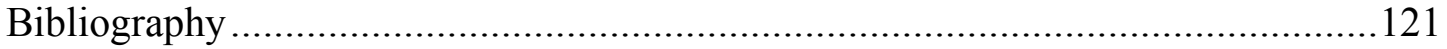




\section{List of Tables}

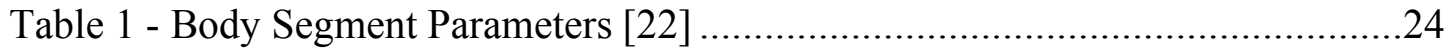

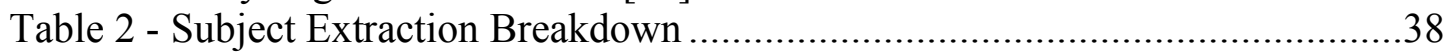

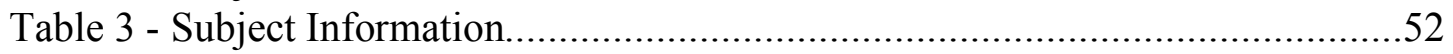

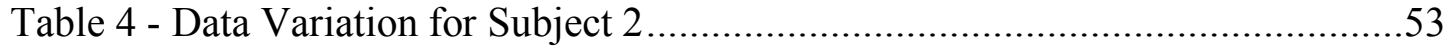

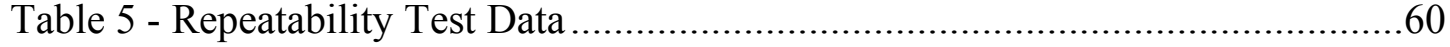




\section{List of Figures}

Figure 1 - Parabolic Flight Trajectory [1] .................................................. 4

Figure 2 - Apollo Parabolic Flight EVA Training [3] .......................................... 5

Figure 3 - Apollo Counterweight EVA Training [6] .......................................... 7

Figure 4 - Example of a Counterweight System [7] .......................................... 7

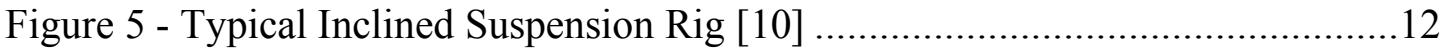

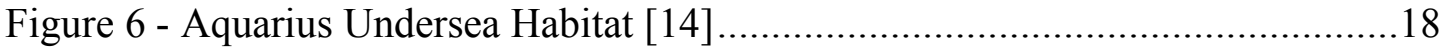

Figure 7 - 1 G Lunar Simulation [15] ............................................................... 19

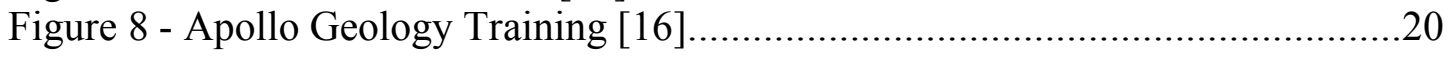

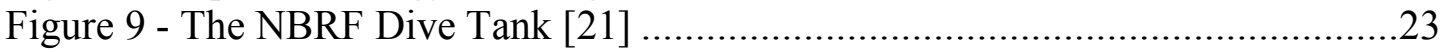

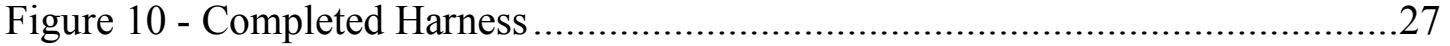

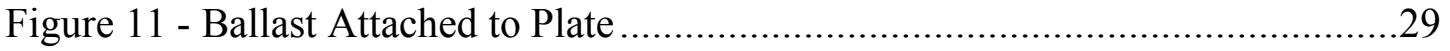

Figure 12 - Ballast Plate Attached to Restraint .......................................................29

Figure 13 - Hard Plate Retainer with Quick Adjustment Buckle...............................30

Figure 14 - Partial Gravity Test with Hard Plate System......................................... 31

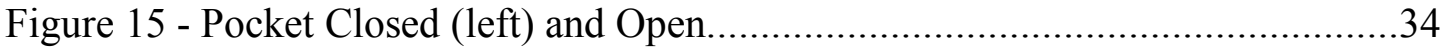

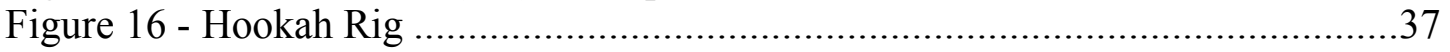

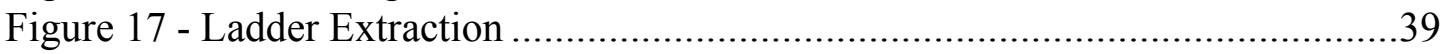

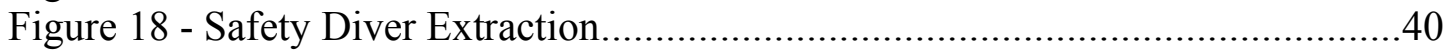

Figure 19 - Crane Extraction ............................................................................ 41

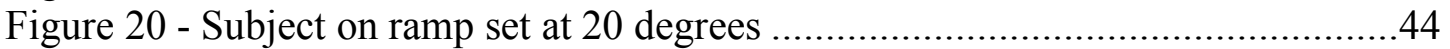

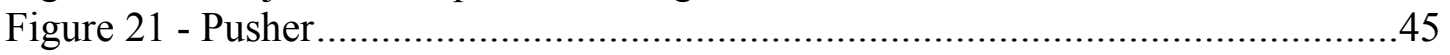

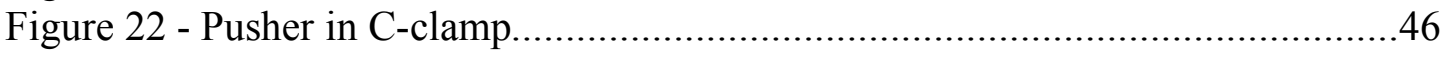

Figure 23 - Simulation PLSS Backpack ..........................................................4

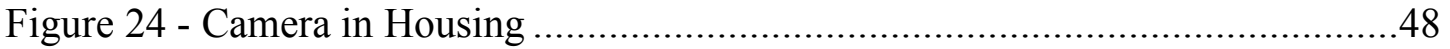

Figure 25 - Diver Adjusting Ballast..................................................................50

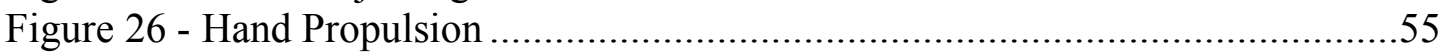

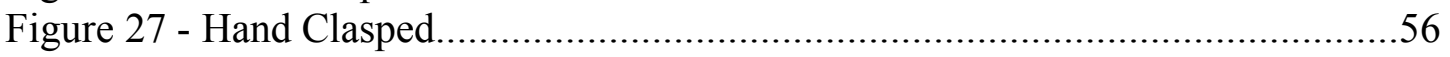

Figure 28 - Photo Used in Repeatability Test ................................................61

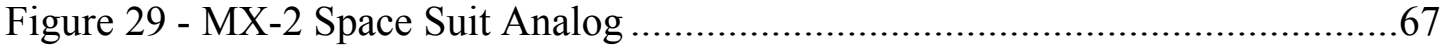

Figure 30 - Ranger \& MX-2 Working Together .................................................68 


\section{List of Abbreviations}

BAT - Beam Assembly Teleoperator

CG - Center of Gravity

EVA - ExtraVehicular Activity

FFM - Full Face Mask

FMARS - Flashline Mars Arctic Research Station

MIT - Massachusetts Institute of Technology

NASA - National Aeronautics \& Space Administration

NBRF - Neutral Buoyancy Research Facility

NEEMO - NASA Extreme Environment Operations

NOAA - National Oceanic \& Atmospheric Administration

PLSS - Portable Life Support System

RATS - Research And Technology Studies

SSL - Space Systems Laboratory 


\section{Chapter 1: Introduction}

The Moon is the Earth's nearest neighbor and the only other planetary body that humans have walked on. The United States is planning on returning to the Moon by the end of the next decade, but by then it will have been almost 50 years since Gene Cernan left the Moon's surface. By this point, almost everyone who was involved in the Apollo program will have retired. In order to successfully return to the Moon and prepare ourselves for Mars we must relearn how to work effectively in a reduced gravity environment. It is important to gain this knowledge as early as possible in the design process, so that "lessons learned" can be effectively applied throughout the Lunar and Martian surface infrastructure. Knowledge of how humans move and work in a reduced gravity field will be applied to the design of everything from habitats to space suits.

Designing systems that maximize the productivity of astronauts during this next phase of planetary exploration is more important than ever. Apollo had the advantage of send newly hardware to the Moon for every mission. This allowed for an incremental learning process. After each mission astronaut feedback could be used to refine the equipment and procedures for the next mission. NASA's building block approach will not allow this to the same extent, as equipment from previous missions will be reused carrying forward any faults in its design.

There are several ways to gain the required knowledge. These methods included reviewing the Apollo debriefings, interviewing Apollo astronauts and engineers, and simulating the partial gravity environment on Earth. Among the various simulation 
methods are parabolic flight, counterweight systems, $1 \mathrm{G}$ testing and water-immersion. Water-immersion simulation was chosen for the simulations in this thesis.

Chapter 2 will explain why this choice was made by discussing the benefits and drawbacks to various methods to simulate partial gravity as well as a look at some past experiments in this field. Chapter 3 will discuss the design and development of the system used in this thesis. This chapter will include the various trade studies as well as "lessons learned" through the development process. Chapter 4 will focus on the basic safety procedures including their development and validation. Experimental procedures and equipment will be covered in chapter 5 . The data from these experiments will be presented in chapter 6. Chapter 7 will contain data analysis and conclusions. The future work section will be contained in chapter 8 . 


\section{Chapter 2: Background Material and Literature Review}

Several methods have been used to study how humans react to partial gravity environments. Each of the methods discussed in this chapter has advantages and drawbacks. They are each useful for researching certain aspects of work in partial gravity. Each method will be useful in preparing for the first human mission to the Moon in nearly half a century. The methods discussed are parabolic flight, counterweight systems, inclined suspension, $1 \mathrm{G}$ simulation, and water immersion. After a discussion of simulation techniques, techniques for distributing loads in a backpack will be discussed as an introduction to the experiment carried out for this thesis.

\section{Parabolic Flight}

Parabolic flight is a method to generate reduced gravity conditions by flying a roller coaster style pattern as seen in Figure 1. As the aircraft transitions from a nose high path to a nose low path the apparent gravity in the aircraft is reduced. If the aircraft accelerates towards the Earth at the same rate as gravity, then the occupants feel weightless. The aircraft can also choose any partial gravity level including Lunar and Martian gravities. The aircraft creates true partial gravity in that an accelerometer placed in the aircraft will read just as it would if placed on another planetary body. 


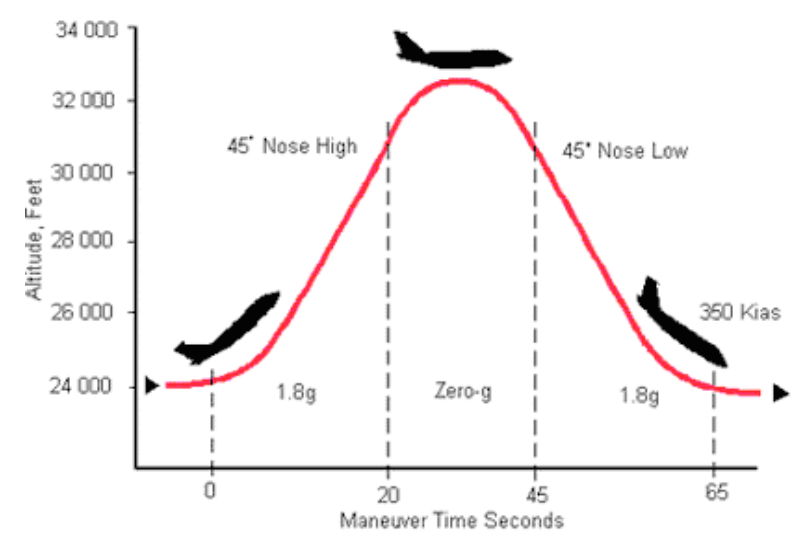

Figure 1 - Parabolic Flight Trajectory [1]

NASA and the US Air Force have been using parabolic flight to investigate space flight since the mid-1950's. [2] During the Apollo program parabolic flight was used to help train the crew for surface operations. The astronauts found the training to be useful to acquaint them with the feel of the experimental equipment they would be handling. [4]

\section{$\underline{\text { Advantages }}$}

The primary advantage of parabolic flight is that it creates true partial gravity. It is the highest fidelity mission simulator for partial gravity. The actual flight hardware can be used in parabolic flight tests, which has two primary advantages. First it allows the astronauts to become familiar with feel of the actual hardware. They can see how easy it is to move and use. Secondly parabolic flight allows engineers and astronauts to ensure that all of the interfaces work correctly in the actual gravity environment.

\section{$\underline{\text { Disadvantages }}$}

The disadvantages of parabolic flight include limitations on mass, volume, and time among others. The tests occur inside of an aircraft, which restricts the size and mass of the equipment that can be used. As can be seen in Figure 2, in their pressure suits the 
astronauts reach almost to the top of the aircraft cabin. Time is also limited during these tests. When flying parabolas to simulate lunar gravity the reduced gravity lasts approximately 28 seconds before the plane must pull up. [2] This precludes testing an entire ExtraVehicular Activity (EVA), which may last as long as 8 hours.

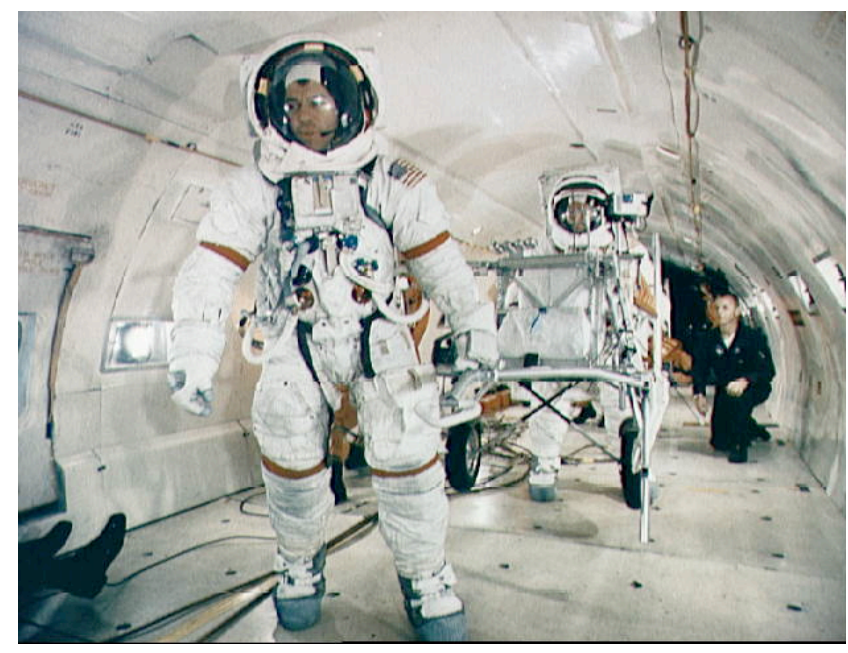

Figure 2 - Apollo Parabolic Flight EVA Training [3]

At the end of the parabola when the plane pulls up the occupants are subjected to almost twice the normal force of gravity. This creates two problems that must be dealt with. First all of the personnel and equipment must be positioned to endure the pull out force. This maneuvering may cut into an already short test period. And second, the change from low to high gravity causes some personnel to become nauseous, leading to lost testing time. Lastly parabolic testing is expensive. The Apollo era tests were conducted in a $\mathrm{KC}-135 \mathrm{~A}$, which is a modified Boeing airliner. This large aircraft is costly to operate limiting those organizations that can independently conduct parabolic testing.

\section{Previous Research}

During her doctoral work at the Massachusetts Institute of Technology (MIT) Dava Newman conducted partial gravity research aboard NASA's KC-135. The parabolic 
flight tests were used to calibrate data taken during water immersion trials at the National Aeronautics and Space Administration (NASA) Ames Research Center. The parabolic tests consisted of two subjects running on a treadmill. The treadmill was run at a range of speeds. The tests were run at two different gravity levels: lunar and Martian. During the treadmill tests data was collected on the biomechanics of running and walking in reduced gravities. This data included stride frequency, peak force, contact time and aerial time. This research found that peak force and stride frequency decreased as the gravity level decreased. The stride length increased as the gravity level decreased and the contact time was unaffected. [5] NASA conducted lunar gravity simulations using parabolic flight as well. Their tests were mainly aimed at testing specific hardware under lunar gravity as shown in Figure 2.

\section{$\underline{\text { Counterweight Systems }}$}

Counterweight systems simulate partial gravity by offsetting part of the subject's weight through the use of springs, weights or pneumatics. A counterweight system was used during the Apollo program to allow the astronauts to run through complete tasks in simulated partial gravity an example of which can be seen in Figure 3. 


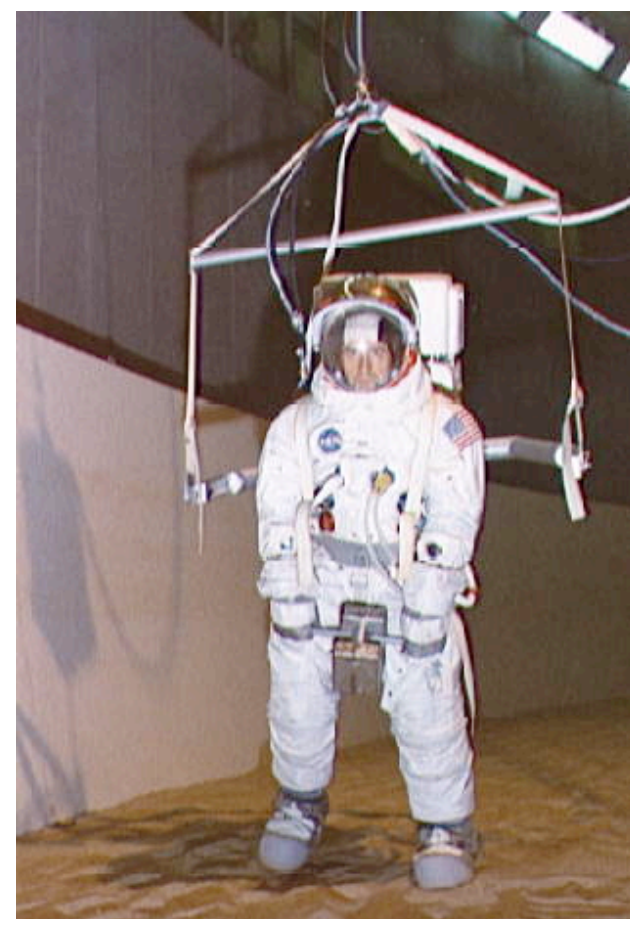

Figure 3 - Apollo Counterweight EVA Training [6]

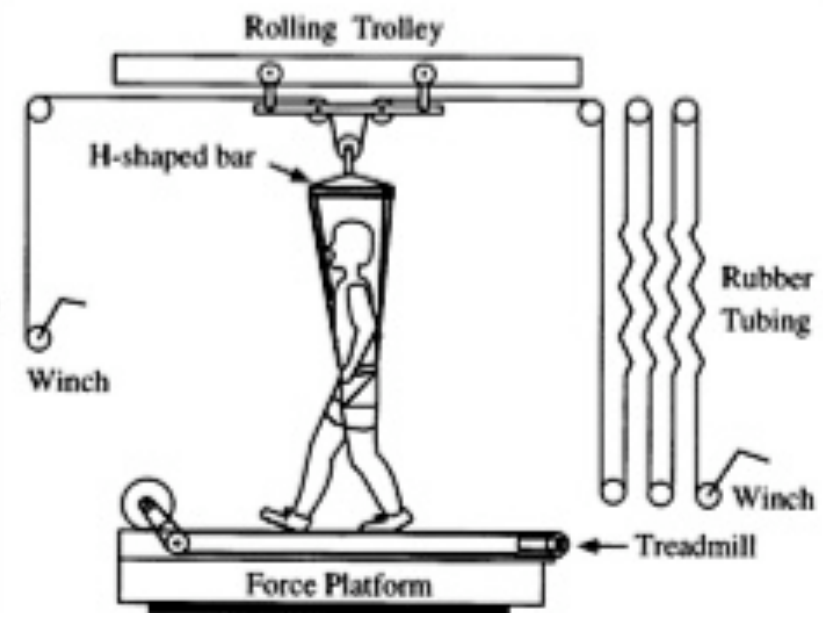

Figure 4 - Example of a Counterweight System [7]

Figure 4 depicts a typical design for a counterweight system consisting of a harness attached to a support point, which can move to maintain the force directly above the subject. This keeps the suspension force vector in direct opposition to the local gravity vector. The simplest way to keep the suspension point above the subject is to have it affixed to an overhead trolley, which is pulled by the subject. The trolley will naturally 
seek the lowest energy position, which is directly above the subject. To keep the effects of the disturbing force the trolley creates low, it must be designed to slide as easily as possible. Methods that have been used to move the suspension point include overhead cranes, air bearing trolleys, and magnetic bearings.

\section{$\underline{\text { Advantages }}$}

Counterweight systems remove the severe time and space constraints inherent to parabolic simulations. Counterweight tests can run as long as the stamina of the test subject allows. This allows full tasks and EVAs to be simulated without interruption. The size of the simulation area is constrained only by the ability to move the overhead suspension point. This can range from a small test area with a linear monorail to a virtually unlimited test area as allowed by the truck-mounted suspension point.

\section{Disadvantages}

The use of a harness and suspension rig places some limitations on the simulations that can be conducted. In order to allow rotational degrees of freedom a complex gimbaled harness must be constructed. Even with this harness rotation is usually limited. The next drawback also involves the harness. As seen in Figure 3 the harness is typically attached at or near the subject's center of gravity. This means that the subject's limbs are not being counterweighted to provide a fully accurate simulation. Another drawback involves the overhead suspension point, which requires all tasks to be setup such that the subject does not pass under or enter into any mockups. This prevents testing of ingress/egress testing of enclosed spacecraft or rovers. The dynamics of the system are 
also affected. If springs are used the upward force is typically not constant and if motors are used the force may be delayed due to the control system implemented.

\section{$\underline{\text { Previous Research }}$}

Much of the research that has been conducted using counterweight systems has focused on the use of suspension and treadmills to investigate the mechanics of running in reduced gravity. The use of the treadmill reduces the need for a large overhead rig to move with the subject. The suspension point only needs to move to account for variations in the subject's location on the treadmill. The treadmill also allows the subject to run without stopping or changing direction as long as the subject's endurance lasts.

A study conducted at the University of California, Berkeley by Griffin, Tolani, and Kram looked at the way energy is conserved when walking in reduced gravity. As a person walks they convert gravitational potential energy into horizontal kinetic energy through the motion of their center of gravity. This reduces the amount of energy a person must expend to walk. They hypothesized that the recovery of mechanical energy would decrease and the maximum recovery of energy would occur at a lower walking speed as gravity was reduced. They tested their hypothesis using the equipment shown in Figure 4. The experiment only offset the gross body weight using a lower body harness, so it did not account for the dynamics of the moving limbs. Data was collected using a 2-axis force sensor mounted under the treadmill. The sensor measured vertical and horizontal ground reaction forces. The results of the experiment proved both points of their hypothesis. [7] 
Christopher Carr conducted research at MIT to investigate how spacesuit legs contribute to energy recovery during walking and running. This research was conducted using a lower body exoskeleton with a rigid knee. This fixed exoskeleton acted like a spring much in the same way that the pressurized tube of a spacesuit leg does. Both the exoskeleton and the space suit leg seek to remain in a fully straight orientation. Carr's research focused on the energy recovery, the metabolic energy required to walk/run, and the walk/run transition point. The results were described using three quantities: Froude number, specific resistance, and cost of transport. The Froude number is a nondimensional way of representing velocity and is defined as:

$$
F_{r}=\frac{v^{2}}{g \bullet L}
$$

Where $\mathrm{v}$ is velocity, $\mathrm{g}$ is the gravity level, and $\mathrm{L}$ is the subject's leg length.

Specific resistance is the efficiency of motion per unit distance in units of:

$$
\frac{J}{N \cdot m}
$$

Cost of transport is the energy expended to carry a unit mass a unit distance with units:

$$
\frac{J}{k g \bullet m}
$$

The results of his research showed that the cost of transportation, specific resistance, and the Froude number of the run-walk transition were all decreased with the use of the exoskeleton and energy recovery was increased. This implies that the exoskeleton and therefore a space suit can be beneficial for transportation in reduced gravities. The reduced Froude number of transition shows that humans would be more likely to run when in a reduced gravity environment. [8] 
NASA, in support of the constellation program, is using a suspension system to test how far an astronaut can walk back in the event of a rover breakdown. This research allows engineers to size the thermal system of the suits to handle the increased heat generated due to a sustained run. The test is being conducted using the MK III space suit over a 10 km distance. [9]

\section{Inclined Suspension}

Inclined suspension simulates partial gravity by rotating the floor such that the component of gravity perpendicular to the floor is equal to the desired gravity. The angle required is calculated from the following:

$$
\theta=\cos ^{-1}\left(g_{\text {Desired }}\right)
$$

Where theta is the angle between the local horizontal and the inclined surface and the desired gravity is a fraction of 1 . In the case of the Moon, the desired gravity is $1 / 6$. For lunar gravity the floor is rotated 80.5 degrees from its normal orientation. Since the subject would naturally fall off of such a steep surface a harness is used to offset the rest of the gravitational force. This harness must be designed to support the entire body so that no unnatural torques are applied to the subject. It must also be designed to allow the legs to move unimpeded and independently. Figure 5 shows a typical inclined suspension rig from the Apollo era. 


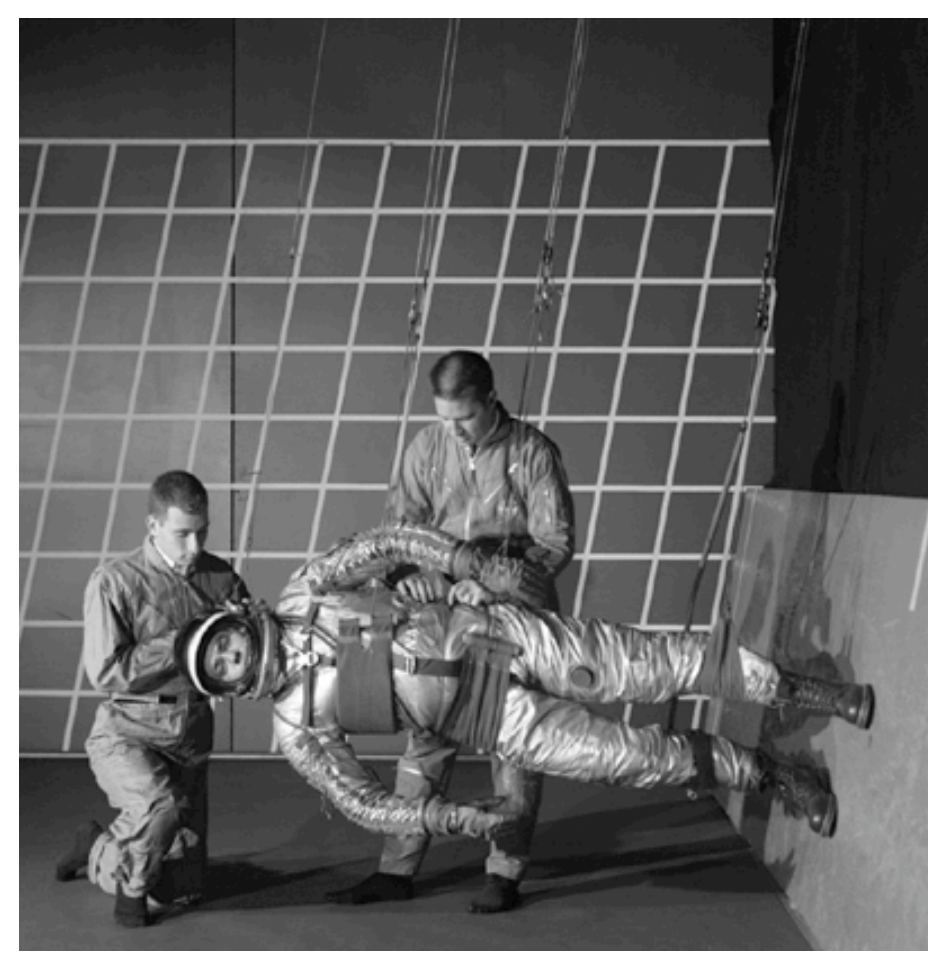

Figure 5 - Typical Inclined Suspension Rig [10]

\section{$\underline{\text { Advantages }}$}

When the inclined platform is curved so that it forms a closed circuit the subject has an unlimited distance that can be traversed while staying in a relatively small area. This allows testing of walkback distances and metabolic rates. Walkback distances were the constraining factor when using the Apollo lunar rover and this is not likely to change if a similar rover is used in the future. This will be an important test for future spacesuit designs.

\section{Disadvantages}

The harnesses typically used for inclined suspension tests do not allow for much rotation from a standing posture; this limits tests mainly to mobility studies. Even for the limited positions they allow the harnesses required for inclined suspension are extremely 
complex. As can be seen in Figure 5 the left and right leg must be balanced independently so that the subject can walk. To prevent interference the high leg is in a sling while the lower leg is attached to a rod that runs up the back. The suspension lines typically run from the subject up to a fixed point above. This introduces a pendulum dynamic that would not be found in true partial gravity. As the subject moves away from the platform the lines no longer pull directly parallel to the platform. The shorter the suspension lines the larger this effect becomes, so typically large towers are built to support the subject.

\section{$\underline{\text { Previous Research }}$}

NASA has conducted research using inclined simulators. One study looked at the mobility effects of lunar versus Earth gravity and a pressurized space suit versus an unpressurized space suit. The study had the subjects complete general motions such as walking, running, jumping, and climbing. For the walking and running tests the subjects selected their own velocities. They were told to select a comfortable pace. The subjects could not obtain maximum possible running velocity due to the short traverse distance of 20 feet allowed by the simulator. The maximum velocity obtained by the subjects while running in lunar gravity was approximately $50 \%$ of that obtained in Earth gravity. The authors attribute the reduction to reduced traction due to the reduced normal force. Pressurizing the space suit reduced the speed under both gravity levels by approximately $25 \%$. During the jumping trials, as expected the subjects could jump higher and farther in lunar gravity than in Earth gravity. The height was $6-7$ times higher for jumping straight up and the subjects jumped twice as far horizontally in a standing broad jump. The unpressurized suit reduced the height by $10 \%-15 \%$ when compared to street clothes 
and pressurizing the suit further reduced the altitude by $30 \%$. The climbing tests involved a ladder, a staircase, and a pole. The subjects were capable of ascending and descending the stairs easily in lunar gravity, but could not see the stairs while descending requiring careful concentration. While in Earth gravity one subject attempted to climb the stairs. The subject was successful with the unpressurized suit, but unable to climb even one step with the suit pressurized. The subjects were able to climb the ladder under all suit conditions in lunar gravity, but modifications to their technique was required when the suit was pressurized. Due to the mobility of the suit it was difficult to grasp the rungs while the suit was pressurized. Instead the subjects grabbed on the back of the ladder uprights as with did not require them to roll their hands from the natural position of the suit. Climbing the ladder in Earth gravity with the suit pressurized was possible, but difficult and fatiguing. The subjects were unable to climb a pole in Earth gravity, but found the task easy in lunar gravity. [11]

\section{$\underline{\text { Water Immersion }}$}

Water Immersion uses the natural buoyancy of water to offset the force of gravity. This type of simulation can be used for simulating any gravity level less than 1-G. Foam or weights are added to mockups and subjects to achieve the desired gravity level. In water immersion testing a mockup's rotational characteristics must be checked in addition to its weight so that the mockup does not continually attempt to return to a "preferred" orientation. To achieve a rotationally neutral object, one that does not rotate when released, the center of buoyancy must be place coincidental with the center of gravity (CG). If this is not done the object will rotate so that the center of buoyancy is directly above the center of gravity. 


\section{$\underline{\text { Advantages }}$}

Water immersion systems allow for a self-contained test subject unlike either of the suspension techniques. This allows for a full six degree-of-freedom simulation and allows for entry into mockups to test airlock hatches and ingress/egress procedures. Ballast may be added to a subject in several locations allowing for a more accurate weighting than typically found in counterweight systems, which offset gross body weight. Any equipment mockups that are used in the simulation can also be weighted to achieve the desired gravity level allowing astronauts to train with equipment of realistic size and mass. This allows them to learn the best way to pick up an object and handle it. The duration of tests while limited by air supplies is significantly longer than that found in parabolic flight studies.

\section{$\underline{\text { Disadvantages }}$}

The major disadvantage in water immersion is due to the water itself. The water adds drag to all movements, so that static or slow moving tests are most accurately simulated. Static tests involving posture or stability are well suited to water immersion, as are slow moving tests such as ingress/egress studies. While underwater the human body is very close to neutral, so ballast must be added to achieve the desired gravity. While the apparent weight is correct the inertial mass is higher than would be encounter in actual reduced gravity. This added mass effects creates higher inertial forces that must be overcome during any dynamic testing. The water also adds a life support concern; the human body was not designed to operate underwater so equipment must be worn to sustain life. This requires that all subjects be certified to participate in dive operations 
and the use of safety divers to ensure the subjects have air at all times during the simulation.

\section{$\underline{\text { Previous Research }}$}

As was mentioned earlier, Dava Newman of MIT conducted research using water immersion as well as parabolic flights. The underwater trials consisted of six subjects running on an underwater treadmill. The subjects were ballasted to simulate five different gravity levels ranging from $0 \mathrm{G}$ to approximately $1 \mathrm{G}$. The subjects ran at three different speeds under each gravity condition. A $1 \mathrm{G}$ land based control was also performed. The data measured during these tests included stride frequency, contact time, peak force, and stride length. The same trends found in the parabolic flight data held for the water immersion research as well. The data however was not an exact match. The stride frequency was lower and the contact time was longer in the water immersion study than in the parabolic flights. These effects were attributed to the increased mass and inertia due to the ballast required for the water immersion study. [5]

Leslie Wickman and Bernadette Luna expanded upon the research conducted by Newman. They added a variable CG backpack to their study to investigate carrying additional loads in reduced gravity environments. Their study consisted of six subjects walking and running on treadmills in lunar, Martian, and Earth gravity levels. The Earth gravity trials were land based with the two reduced gravity trials conducted underwater. The maximum weight of the backpack was determined by the subject's comfort level. This weight consisted of $270 \%$ of the subject's 1 G-body weight in lunar gravity, $80 \%$ in Martian gravity, and $45 \%$ in the $1 \mathrm{G}$ trials. The data consisted of energetics results and 
mechanics results such as stride length and stride frequency. The mechanics results followed the same trends as found in the Newman data. The energetics results were used to extrapolate the amount of load that a human could carry for an eight-hour workday in each gravity level and to develop a model for energy expended. The maximum load for all day work was selected utilizing the subject's maximum oxygen uptake capacity. Other research has suggested that $35 \%$ to $50 \%$ of the maximum oxygen uptake is sustainable for an eight-hour workday. Utilizing this oxygen range, the data showed that for lunar gravity a person should be able to sustain a load factor of 2.7 while walking. Load factor is defined as the backpack mass plus the subject's body mass divided by their body mass. In others words they should be able to carry $170 \%$ of their body weight for one EVA. For Martian gravity this drops to $50 \%$ and in Earth gravity $20 \%$. Their energy model was developed using regression analysis. The parameters of the model included velocity, gravity level, load factor, body mass, and leg length. [12]

NASA has been conducting water immersion simulation studies through the NASA Extreme Environment Mission Operations (NEEMO) project. The NEEMO missions are intended to serve as an analog to long duration spaceflight. They take place at the National Oceanic and Atmospheric Administration (NOAA) Aquarius undersea habitat. The NOAA Aquarius is a 15 meter by 4.5 meter cylinder similar in size to the U.S. Lab module on the International Space Station (ISS). The habitat is located in 60 feet of water off the coast of Key Largo, FL. It is a pressurized habitat, so the pressure inside is slightly higher than the surrounding pressure keeping the water out. Research conducted during the NEEMO project has included telemedicine, surface robotics, and partial 
gravity EVA. Using hardhat diving equipment divers have carried out tasks with different CG conditions to determine stability. [13]

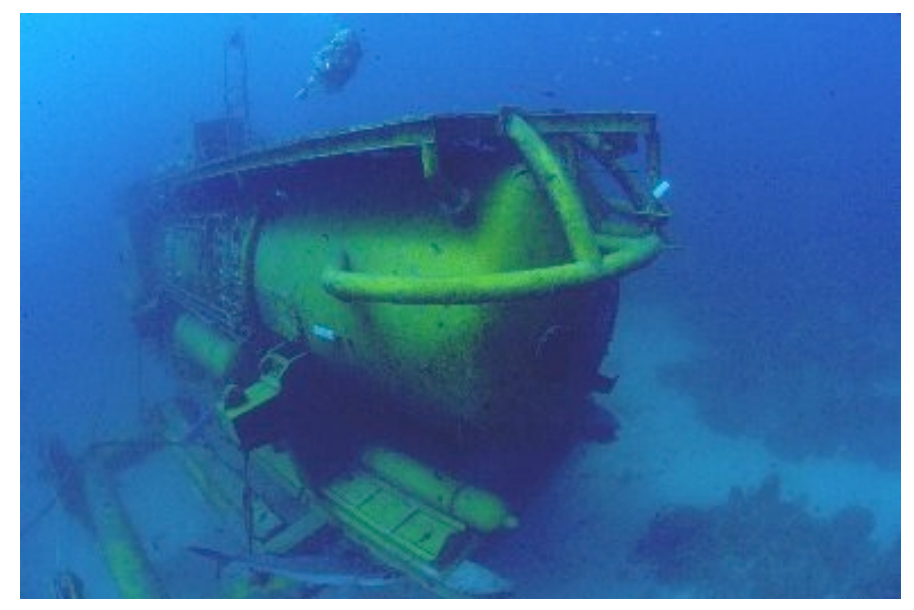

Figure 6 - Aquarius Undersea Habitat [14]

Aquarius images are copyright (C) 2007, University of North Carolina Wilmington. All rights reserved. Further reproduction prohibited.

\section{$\underline{1 G \text { Simulation }}$}

$1 \mathrm{G}$ simulation takes a completely different approach than all of the preceding methods. This method ignores reduced gravity entirely. Subjects use hardware that is similar to the real equipment in size and shape, but not in mass. Using $1 \mathrm{G}$ simulation eliminates all of the hardware attached to the subject to offload gravity. They are free to move about, but must contend with full gravity. These simulations are useful for procedures training and team building.

\section{$\underline{\text { Advantages }}$}

The major advantage to $1 \mathrm{G}$ simulation is the elimination of simulation hardware attached to the subject. The subject is not encumbered by a harness or cable system that limits 
their mobility. Special training in the use of simulation hardware is also not required. This allows subjects to concentrate on learning the task at hand.

\section{Disadvantages}

The disadvantage to $1 \mathrm{G}$ simulation is the lack of any attempt at partial gravity. This simulation is useful for mission training and task planning, but shows nothing about human capabilities in partial gravity. Fatigue may be a major factor in any $1 \mathrm{G}$ simulation especially if spacesuits are used as in Figure 7. Not only is the subject contending with their own body weight they also feel the full weight of the suit. For this reason lightweight mockups are sometimes used such as in Figure 8.

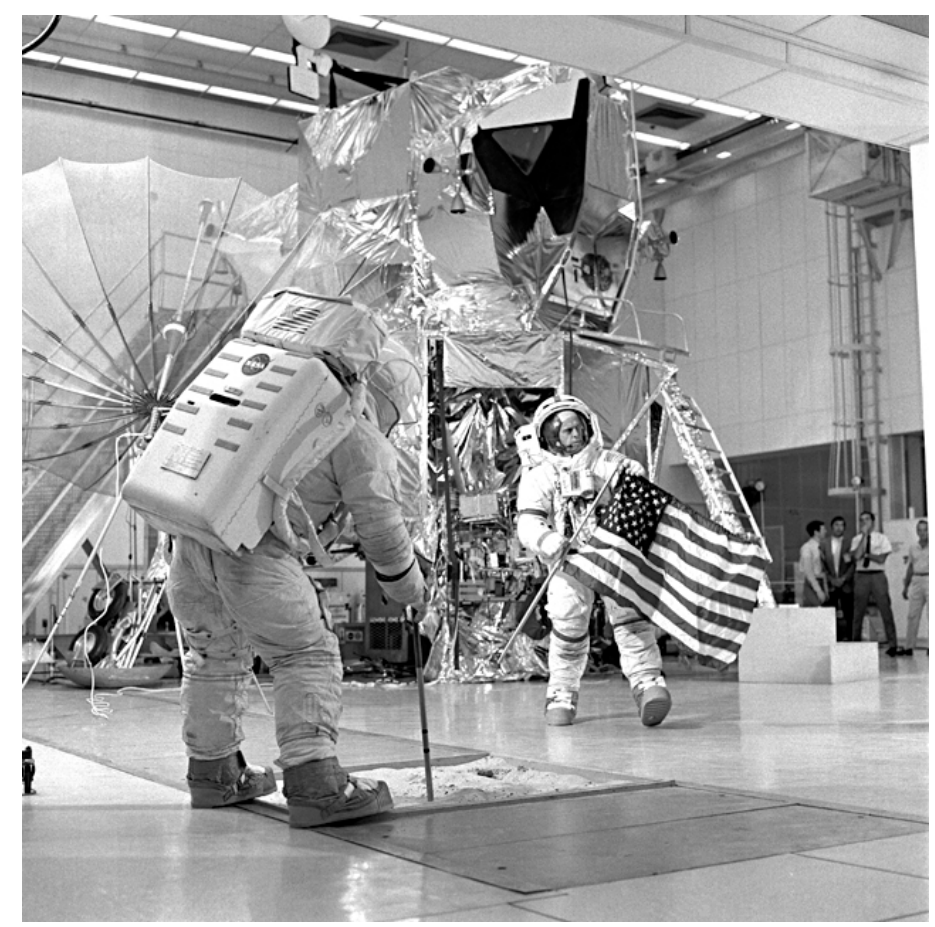

Figure 7 - 1 G Lunar Simulation [15] 


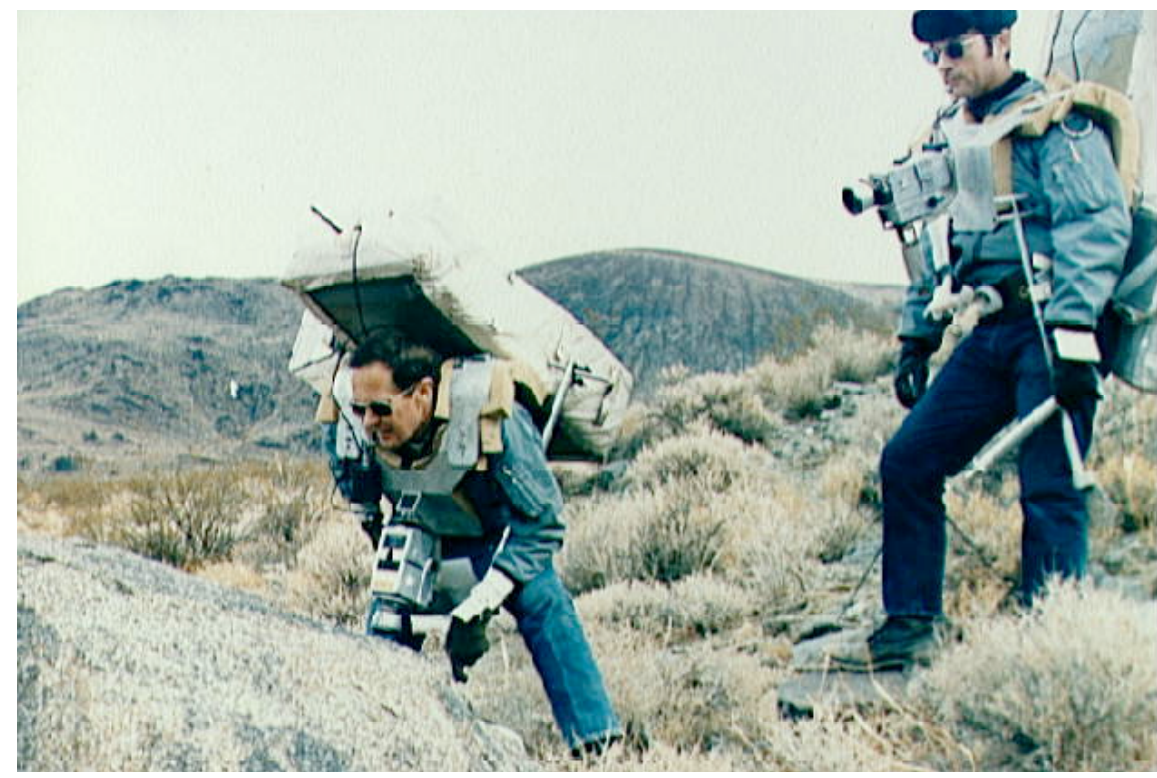

Figure 8 - Apollo Geology Training [16]

\section{$\underline{\text { Previous Research }}$}

Several organizations are currently conducting $1 \mathrm{G}$ simulations geared towards preparing for the next generation of planetary exploration. Among these are NASA and the Mars Society. The Mars Society is currently funding two simulations. One is called the Flashline Mars Arctic Research Station (FMARS) and is located on Devon Island near the Arctic Ocean. The simulation is based here because of the geologic and temperature similarities to Mars. The goal of the simulation is to conduct research with the same constraints found during a Mars surface mission. The Mars Society also runs Mars Desert Research Station in Utah. Simulations conducted here serve the purpose of fieldtesting equipment and procedures before they are utilized at the more remote simulation sites. [17] [18]

NASA is conducting its own simulations under a program called the Desert Research And Technology Studies (RATS). The Desert RATS brings together equipment and 
personnel from across NASA and its contractors to test them in an integrated field environment. In 2005 a series of tests were conducted combing two subjects working in pressurized space suits and a manned rover. This combination allowed for testing procedures that will be needed for two person EVA's on either the moon or Mars. This data will allow engineer to better timeline the tasks involved. Recharging stations were also used to increase the amount of time that could be spent in the field. This is likely to be a common occurrence in future exploration. Insights were gained into how the stations should be designed including the need for the station to support the subjects to reduce fatigue. The 2005 Desert RATS also was the first time since Apollo that two suited crew members worked simultaneously. [19]

\section{Backpack Loading}

The carriage of external loads has been looked at for subjects in Earth gravity. The results found in the literature do not seem to form a solid conclusion about the best place to locate the center of gravity of the pack. It seems intuitive that the load should be placed as close to the subject's back as possible to minimize the disturbance from their normal unloaded posture. What is not intuitive is whether that load should be placed high in the pack or low in the back or even somewhere in between. Research in the literature has shown both high and low CG packs to have advantages. The high CG pack

minimizes the amount the subject must lean forward to bring the combined CG of themselves and the pack over their feet. The low CG pack tends to reduce the amount sway seen in a standing subject as compared to a high CG. This is interpreted as a sign of 
greater stability. The downside of the low CG pack is that the subjects tend to lean such that the load is over the front half of the foot increasing the chance of injury to the foot. $[20]$ 


\section{Chapter 3: Partial Gravity System Design \& Development}

The first step in designing a partial gravity simulation is to decide the method that will be used from those listed in the previous chapter. At the Space Systems Laboratory (SSL) this was an easy decision. Parabolic flight is too costly and access to the proper aircraft is very limited. The two suspension techniques would have required the development of a complex simulation system, which is unnecessary because the SSL is located at a water immersion facility. The Neutral Buoyancy Research Facility (NBRF) is a 25-foot deep 50-foot diameter pool used for human factors and space robotics research, as shown in Figure 9. For this reason water immersion was the chosen method of simulation.

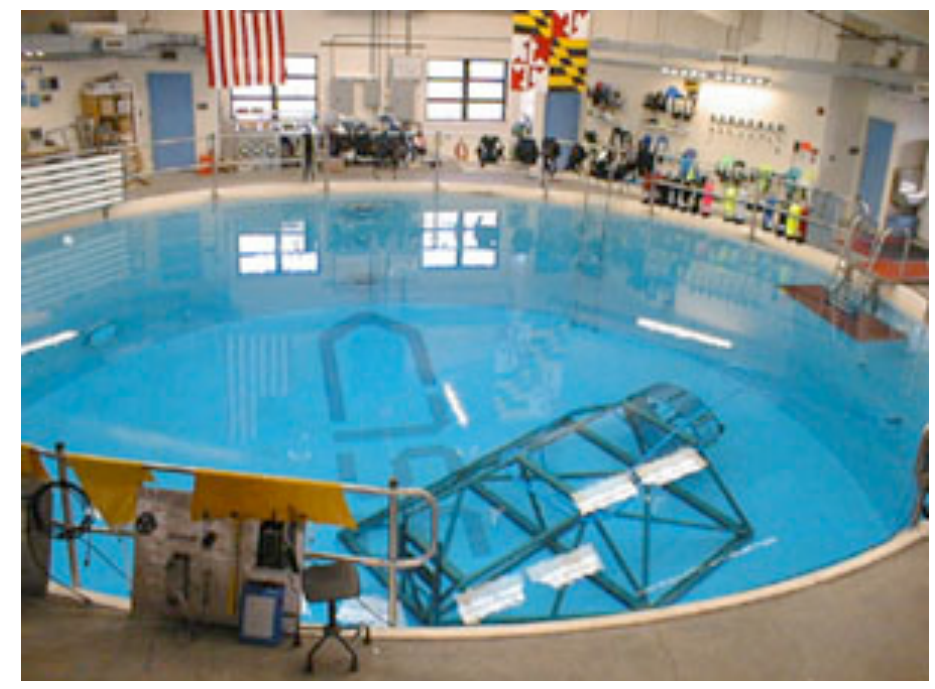

Figure 9 - The NBRF Dive Tank [21]

The human body has a density similar to that of water; because of this, ballast must be added to test subjects so that they have the correct apparent weight for the desired gravity level. The total ballast required is easily determined by taking a subject's Earth weight and multiplying it by the desired gravity level. Adding this amount of ballast to the subject would cause a scale to read correctly underwater, however the ballast cannot be 
added just anywhere. It needs to be correctly distributed on the subject so that their CG is maintained and body parts ballasted proportionally. The correct distribution is given body segment parameters. This is a set of data that shows the percent of the total mass that is contributed by each body part or segment. Distributing the ballast according to body segment parameters yields a subject with the correct center of gravity and who will react correctly when moving, bending, or performing other tasks. These parameters are different for each individual, but their measurement is outside the scope of this thesis. Instead a generic set of parameters published by de Leva are being used. [22] Utilizing every segment presented in this paper would generate an extremely accurate simulation, but would be completely impractical. Table 1 shows the breakdown of body segments. The two segments chosen for this research were the trunk and the thigh. These two segments account for $43.46 \%$ and $14.16 \%$ respectively. For Lunar gravity all of the other segments require approximately 2 pounds or less. This was considered low enough such that adding more segments would not significantly add to the accuracy of the simulation.

Table 1 - Body Segment Parameters [22]

\begin{tabular}{|c|c|c|c|}
\hline $\begin{array}{c}\text { Body } \\
\text { Segment }\end{array}$ & $\begin{array}{c}\text { \% of Body } \\
\text { Mass }\end{array}$ & $\begin{array}{c}\text { Lunar Ballast for } \\
\mathbf{1 7 5} \text { lb subject }\end{array}$ & $\begin{array}{c}\text { Mars Ballast for } \\
\mathbf{1 7 5} \text { lb subject }\end{array}$ \\
\hline Head \& Neck & 6.94 & 2.02 & 4.55 \\
\hline Trunk & 43.46 & 12.68 & 28.52 \\
\hline Upper Arm & 2.71 & 0.79 & 1.78 \\
\hline Forearm & 1.62 & 0.47 & 1.06 \\
\hline Hand & 0.61 & 0.18 & 0.40 \\
\hline Thigh & 14.16 & 4.13 & 9.29 \\
\hline Shank & 4.33 & 1.26 & 2.84 \\
\hline Foot & 1.37 & 0.40 & 0.90 \\
\hline
\end{tabular}

Once the segments were chosen the total mass of the subject still had to be accounted for by adding extra ballast to the chosen segments. The amount to add to each chosen segment was calculated by dividing the percentage contribution of each segment by the 
total contributed by the trunk and thighs. For example the trunk and thighs account for $57.62 \%$ of the body mass while the trunk alone contributes $43.46 \%$ therefore the trunk accounts for $75 \%$ of the simulated segments. For a $175 \mathrm{lb}$ subject $24 \mathrm{lbs}$ are placed on the trunk and $8 \mathrm{lbs}$ are placed on the thighs.

Now that the necessary amount of ballast has been calculated a way to attach it to the subject must be designed. The system must be designed to satisfy two important but competing objectives. The first objective is to maximize safety. Having a ballast system that is easy to release in the event of an emergency satisfies this objective. The second objective is that the ballast is secure. If the ballast is loosely sliding on the subject or spontaneously jettisoning this will be detrimental to the simulation's accuracy. The design of the system developed for this thesis can be broken into two segments: the ballast system and the ballast release mechanism.

\section{Ballast System Development}

The ballast system is the system that is physically worn by the subject and it supports the ballast release mechanism. During the development of the ballast system two basic concepts were considered: a jumpsuit and a harness.

\section{$\underline{\text { Jumpsuit }}$}

The jumpsuit was envisioned as a full body suit with pockets sewn in to hold ballast in the appropriate locations. The jumpsuit would have been created from a wetsuit, which is designed to be close fitting. The jumpsuit concept has several advantages that made it an attractive option. The primary advantage was the security with which the pockets would 
be held to the subject due to the form fitting nature of the suit. This also is the primary drawback of the concept. The form-fitting suit would be difficult to adjust to fit a range of body sizes. A solution to this problem would be to make multiple suits, but this would be prohibitive for cost and time reasons. The other disadvantages of the jumpsuit include the inability to adjust the pockets and its inherent buoyancy. The pockets would be sewn into the suit, which would preclude the ability to either resize or move the pockets relative to each other. Resizing of the pockets is important because if the pockets were too big the ballast would slide exerting a destabilizing force that could impact the data. If the pockets were on the small side this would limit either the mass of the subject or the gravity level that the system could handle. The use of a wetsuit as the jumpsuit would add buoyancy to the subject due to the material they are made from. This would require the addition of more ballast to compensate increasing the mass of the subject-system combination.

\section{$\underline{\text { Harness }}$}

The harness concept resembles a full-body harness of the type that would be found in rock climbing or fall-arrest gear. Like either of these systems the harness is adjustable to fit a wide range of subjects. The harness contains six adjustments to ensure a proper fit to the subject. There are three adjustments in the upper harness and three in the lower harness. The upper harness has an adjustment on each shoulder to raise and lower the torso ballast evenly. There is also a chest band that is tightened to ensure the torso ballast is held close to the body. The lower harness adjusts to the diameter of the subject's legs and has a waist adjustment. Another benefit of the harness comes from the fact that it is modeled after a rock climbing harness. This allows the subject to be lifted by the 
harness, an advantage that will be shown during the next chapter's discussion of emergency procedures. The third and final major advantage of the harness is due to its lack of inherent buoyancy. This reduces the ballast required when compared to the jumpsuit concept allowing for less mass to be carried by the subject. The completed harness is shown in Figure 10.

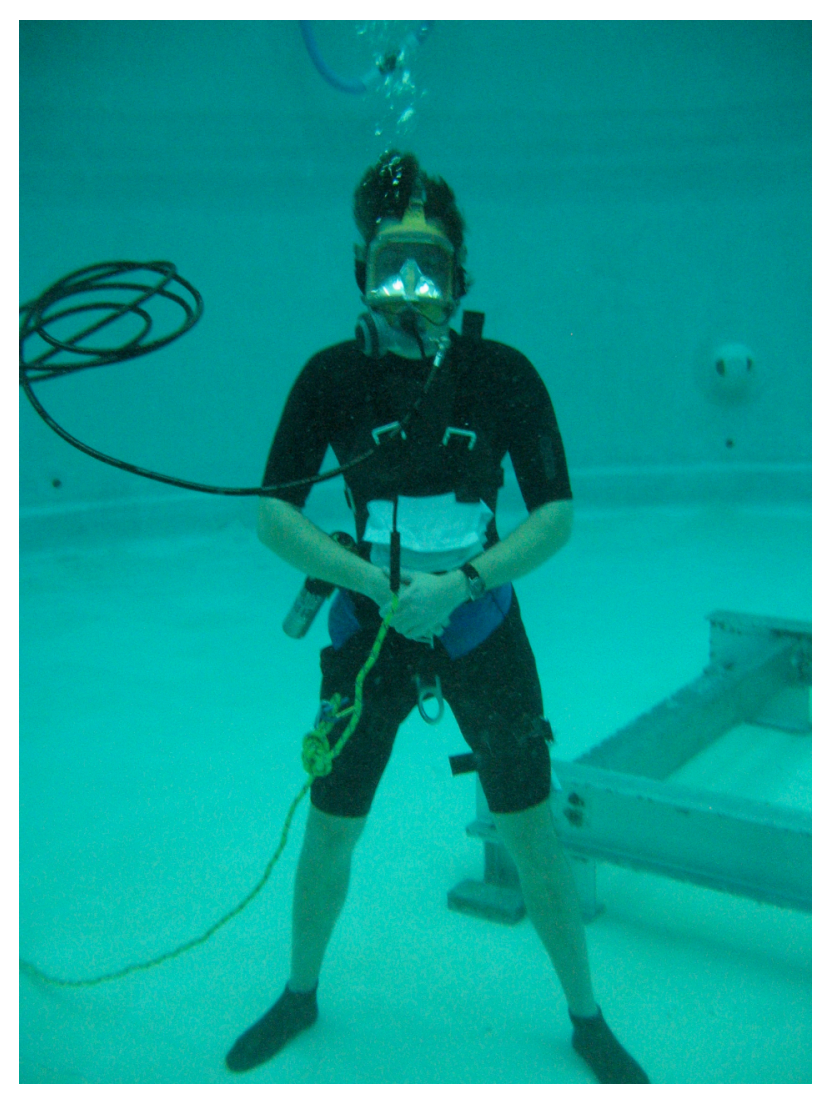

Figure 10 - Completed Harness

The large amount of adjustability has also proven to be a detriment in some cases. Some of the adjustments have a tendency to creep over time, which loosens the harness. The creep seems to be due primarily to the type of adjustment hardware chosen. Each of the adjustments uses a quick adjustment buckle similar to those found in skydiving harnesses. These were chosen for their ease of adjustability and proven security in their primary application. During testing it was discovered that if the extra webbing 
protruding from the attachment is not held tight to the subject the fittings tend to loosen. The creep is combated through careful donning of the harness and vigilance of the test director in keeping the free ends of the webbing secure. To help hold down the webbing ends elastic loops were added to the harness through which the webbing is fed.

\section{Ballast Attachment Development}

The ballast attachment is attached to the harness and is what physically holds the ballast in place on the subject. During the development of the ballast attachment two concepts were tested and evaluated: a hard plate system and a pocket system.

\section{$\underline{\text { Hard Plate System }}$}

The hard plate system was the first concept that was developed and tested. It consisted of a rigid metal plate to which weights were bolted shown in Figure 11. The plate had a tab on one end that was inserted into a webbing slot. The opposing end of the plate had a hole though which a clevis pin was inserted. Through the clevis pin was a hitch pin holding the plate in place. The plate and attachment mechanism are shown in Figure 12. When the hitch pin is pulled gravity causes the plate to slide off of the clevis pin, the tab slides out of the slot and the plate falls free. This system was envisioned as a way to rigidly attach the ballast to the subject while still allowing it to be easily removed in the event of an emergency. Once the concept was developed it was tested using a demonstration test rig as well as a human subject. 


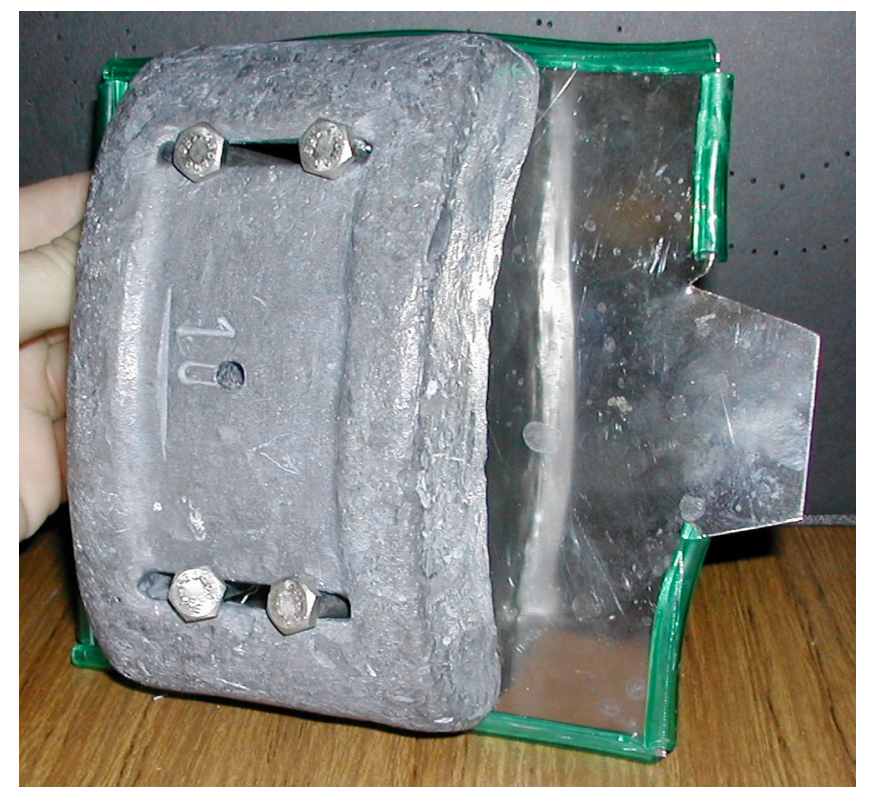

Figure 11 - Ballast Attached to Plate

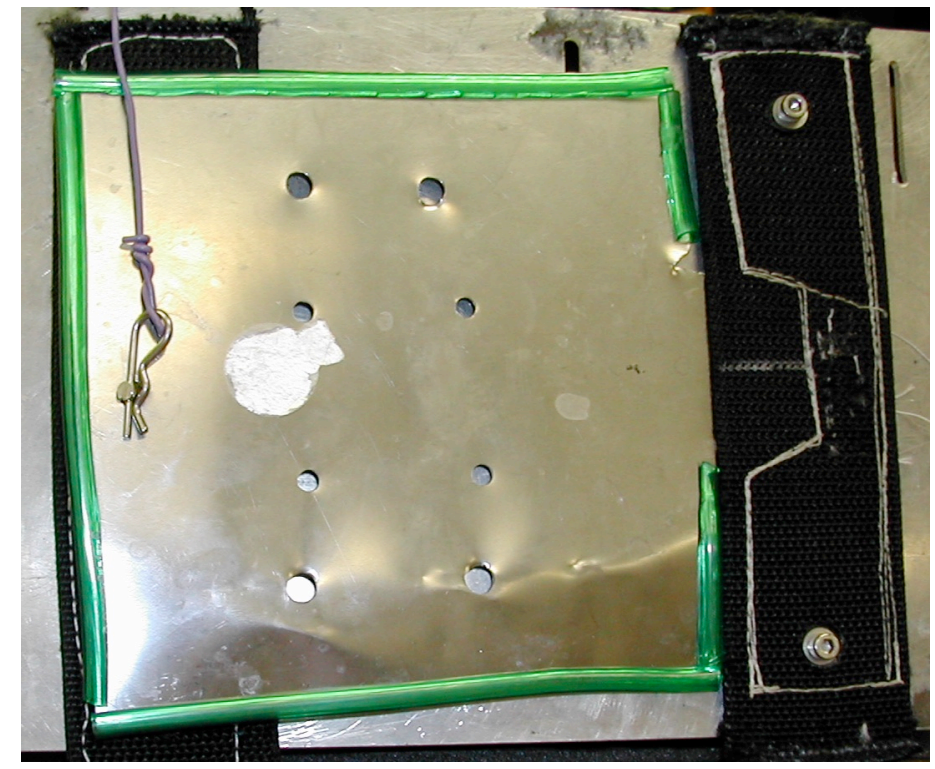

Figure 12 - Ballast Plate Attached to Restraint

The demonstration test rig consisted of a metal backing plate to which webbing was attached containing the slot and clevis pin as seen in Figure 12. The test rig was used underwater using two different ballast levels. The first test used a two-pound weight attached to the plate. The purpose of this test was to validate the basic concept and to ensure that the system behaved in a predictable manner before increasing the ballast. The 
test was conducted by clamping the backing plate to a mockup that was already residing in the dive tank. After the backing plate was secured the ballast plate was installed and the test diver floated above while the plate was released. This setup kept the test diver out of harms way during the test sequence. During the test the plate was easy to install and jettison and followed a predictable path once released. The one problem discovered during this test was that the plate followed a "falling leaf" pattern once released and would strike a subject in the legs if they were wearing this release system. This was thought to be due to the low weight being used and the high surface area of the plate. For this reason the release was tested with a heavier weight. For the second test session the plate was modified to hold one ten-pound weight. The ten-pound weight was tested in the same manner as the two-pound weight. The test confirmed that the "falling leaf" pattern was due to the low weight used during the previous test. The plate fell in a manner that was both predictable and safe for the test diver. The main problem uncovered during the test was that it was difficult to install the plate if the distance between the slot and the clevis pin was not precisely right. This problem was addressed by adding an adjustment between the clevis pin and the slot as shown in Figure 13.

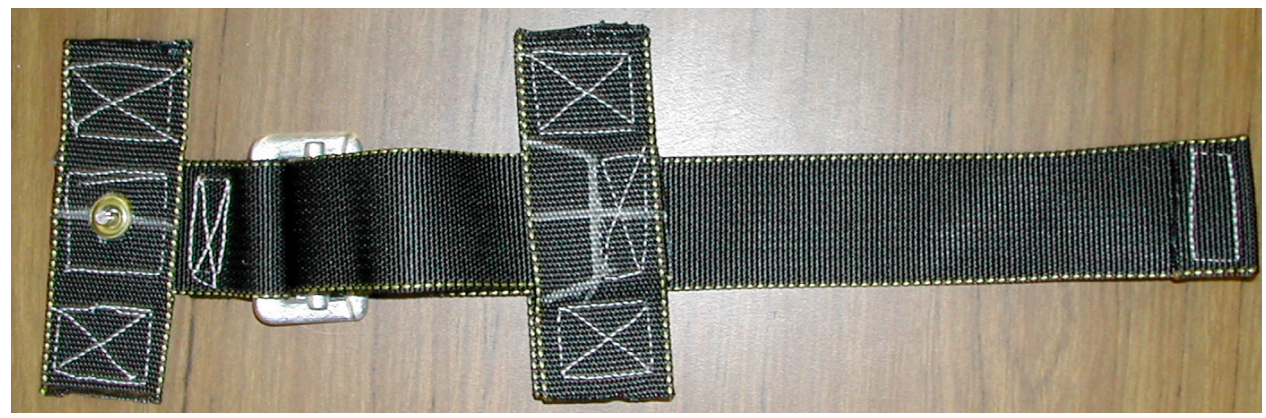

Figure 13 - Hard Plate Retainer with Quick Adjustment Buckle 


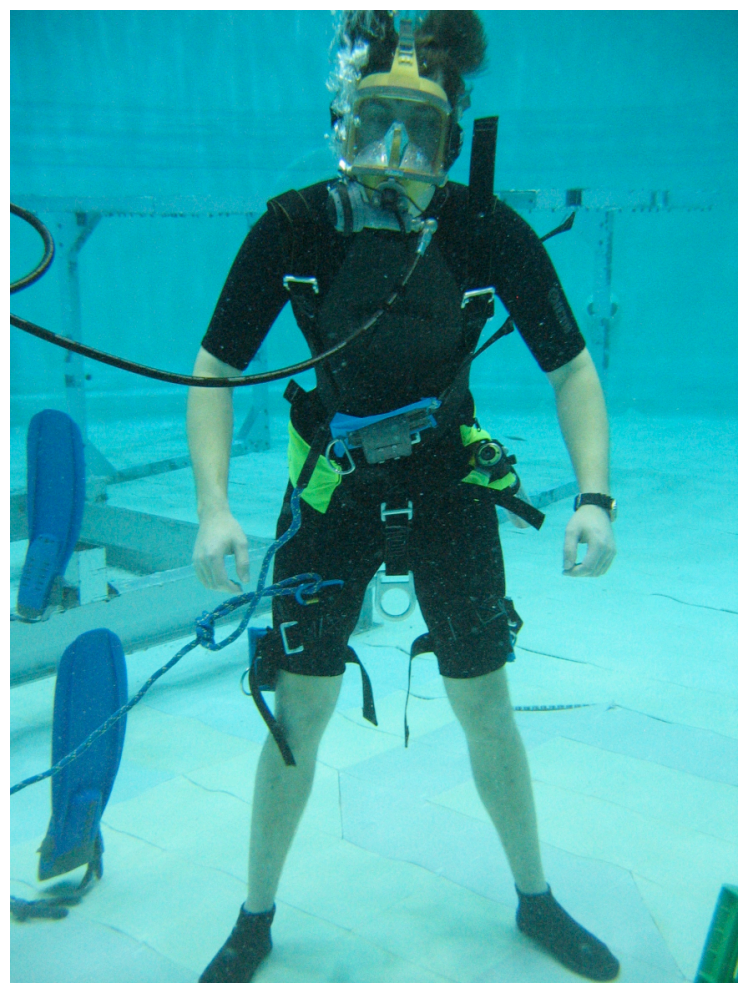

Figure 14 - Partial Gravity Test with Hard Plate System

After the demonstration rig showed that the concept was feasible, the hard plate system was integrated into the harness described earlier. The integrated system is shown in Figure 14. A test dive was conducted to see how the hard plate system functioned on a test subject. The dive was conducted with the subject and the lead diver utilizing Full Face Masks (FFM). The FFMs allowed for constant verbal communication between the subject and lead diver allowing them to work though any problems that were encountered during the test. The test dive did not go as smoothly as the dives with the demonstration rig. Two major problems and one nuisance contributed to the difficulties encountered during the test. The problem was that the plates were not as easy to attach as they were with the demonstration rig. This was most pronounced on the thigh ballast and was due primarily to the curvature of the body. This forced the safety divers to have to bend the plates as they inserted them, which was made difficult by the rigid weight that was bolted 
to the plate. The plates were also prone to slipping out of the slots, which appeared to be a combination of the curve of the plate and the narrowness of the slots. The slots were made to fit the tab tightly so that the plates would be held firmly. Instead the narrow slots prevented the tabs from fully inserting. The nuisance found during the test was the sharp edges on the plates. An attempt to mitigate this was made using plastic tubing around the edges, but this tubing did not remain in place during the test. For these reasons and the fact that a different set of plates would have to be made for each test subject it was decided to discard the hard plate system.

\section{$\underline{\text { Pocket System }}$}

Once it was discovered that the hard plate system was not feasible attention was turned to designing a soft pocket system. This system would use pockets containing lead shot pouches in the same location as the plates. This system would have some advantages over the hard plate system, such as ease of ballast adjustment and the use of soft weights themselves. Through the use of different sized shot pouches the amount of ballast can be quickly varied for subjects of different masses. The soft weights themselves are also safer in that they will not hurt if they land on a subject's foot; they simply conform to the shape. The major concern with the pockets is that the ballast will slide around upsetting the stability of the test subject. This problem is managed by keeping the pockets close to the size of the ballast that will be in them. Two different release concepts were conceived for the pockets: a Velcro release and a ripcord release. The two concepts were the same in all respects except at the bottom of the pocket where the ballast would be released during an emergency. The ballast is loaded into the top of the pocket and this opening is sealed using a Velcro flap. 
The ripcord pocket was conceived as having the bottom front corner form a hinge. Through this hinge would be inserted either a rod or a cable holding the bottom flap in place. When the cable or rod was pulled free, gravity would cause the bottom of the pocket to fall away and the ballast would be released. The rod and cable each have advantages and disadvantages and a final decision would have been based on trial runs. The rod would have likely held the load easily, but the length required for the torso pocket could have prevented the subject from completely extracting it in one motion. The cable on the other hand would not have suffered from this problem, but substitutes the problem of possibly sagging under the load of the ballast. This would create a large pull force. The concept was considered in case the Velcro pocket proved to have either too high of pull force or insufficient holding power to restrain the ballast.

The Velcro pocket was the primary pocket design and was the only one tested. The Velcro release consists of two flaps, one on the front of the pocket and one that includes the bottom side of the pocket. The upper flap covers the bottom flap, so that when the upper flap is pulled up the Velcro disengages and the ballast is released. Figure 15 shows the pocket with the flap closed and the flap open; the D-ring is used as a handle. In the open photo you can see the ballast weight starting to exit the pocket. 

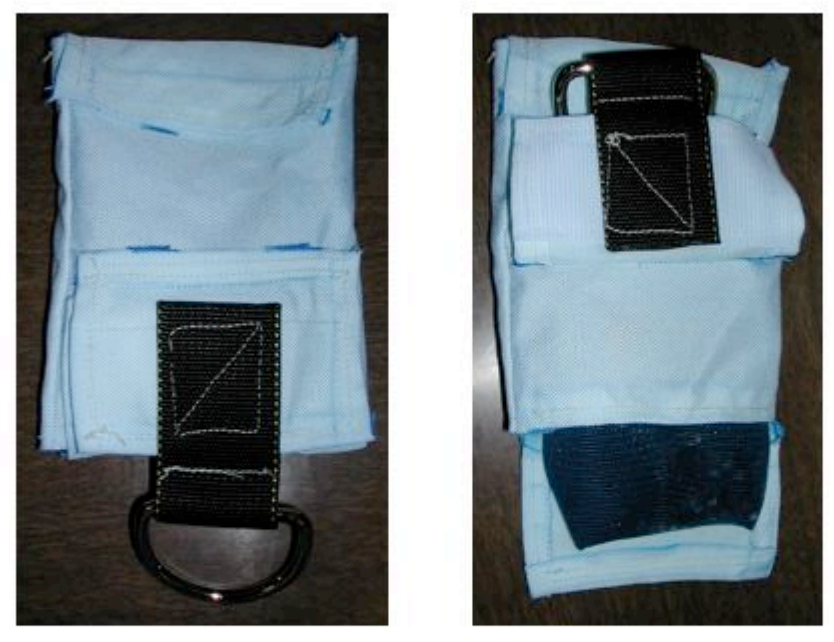

Figure 15 - Pocket Closed (left) and Open 


\section{Chapter 4: Procedures Development}

An important part of a system such as the one discussed in the previous chapter is a complete set of procedures for handling both nominal and off-nominal conditions. The nominal procedures serve to keep all divers on the same page which increases productivity and safety. The emergency procedures are in place so that in the event of an off-nominal condition everyone involved conducts a coordinated response. The development and testing of those procedures will be discussed in this chapter.

\section{Nominal Operations}

This section will discuss the nominal dive operation of the SSL as well as the procedures specific to the research being discussed. All dives at the SSL require three personnel: a lead diver, a deck chief, and a second diver. Anyone who is a diver at the SSL must meet certain basic requirements. Among these requirements are SCUBA certification, first aid \& CPR training, and training as an oxygen provider. A physical is also required. After these requirements are met a checkout dive is conducted testing the diver's basic dive skills. Once this checkout is complete they may work as a diver in the lab. Once a diver is cleared to work in the dive tank they are allowed to participate in the deck chief course. The deck chief is responsible for the safety of everyone involved in a dive. They are the final word on all safety related matters. They monitor the dive from the surface through the use of cameras placed in the dive tank. They also have the ability to communicate with the divers through the use of an intercom and underwater speaker. The deck chief course is designed to teach the divers accident management. During the course accident scenarios are conducted and the student working as the deck chief must respond with the 
appropriate action. The lead diver is a SSL diver with 30 hours of experience diving at the lab in a variety of test conditions. They are responsible for keeping an eye on the divers in the water as well as ensuring that all divers check their pressure gauges.

During test runs of the partial gravity simulation system the subject is added to the team. The subject is required to be a diver cleared to dive at the SSL, so they are already familiar with the rules and procedures of the facility. The two other divers are safety divers ready to respond to any trouble the subject may have. If needed to satisfy the objectives of the dive a utility diver can be added to handle tasks such as logistics (retrieving needed equipment from the surface) and documentation (photographic and videographic). Each dive begins with a briefing of the test objectives. This informs the deck chief of what they should expect to see throughout the dive, so that they can more easily recognize off nominal situations. The briefing also informs each diver of the specific role they will be playing in the dive and outlines their responsibilities. The briefing is the time to answer any questions that any of the personnel may have. If anyone is not completely comfortable with the tasks and procedures outlined the plan is reworked or the task may even be removed from the plan. Once everyone has agreed on the dive plan the divers enter the water and gear up. The subject dons the ballast harness with no ballast installed before entering the water. Once everyone is ready the divers descend to the bottom of the dive tank. The ballast is carried down using a basket and a lift bag. The lift bag contains air that offsets the weight of the ballast, so the diver can descend at a normal pace. Once at the bottom the lead diver ensures that everyone is comfortable, after this the divers prepare to start the test. The subject removes their 
scuba unit and switches to the hookah rig. The hookah rig is a regulator attached to a SCUBA cylinder by a 25-foot long hose shown in Figure 16. The rig supplies the subject with air while not encumbering them during the trial.

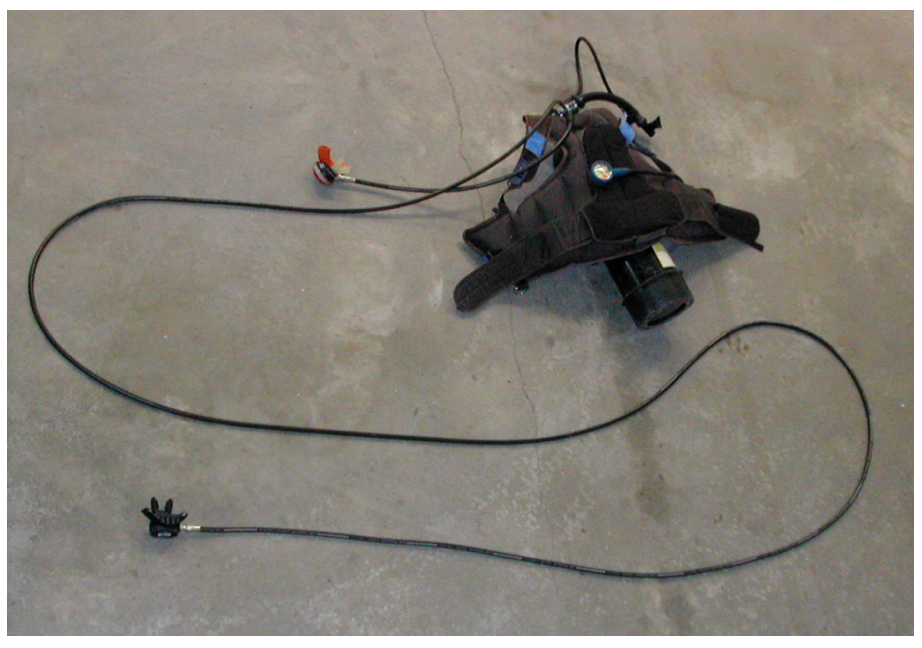

Figure 16 - Hookah Rig

The subject's fins are also removed at this time. At this point the subject is relying on the safety divers, as it would be very difficult for the subject to swim to the surface without fins. With the subject breathing comfortably from the hookah rig the safety divers place the appropriate amount of ballast in the pockets of the harness. The test run may now be conducted. Once the test run is over this process is reversed. The ballast is removed from the pockets using the quick release mechanism. The subject replaces their fins and scuba unit and transfers from the hookah to breathing from the SCUBA cylinder on their back. Once this transition is complete all of the equipment used in the test is gathered and the dive team ascends to the surface. At the surface all of the equipment used is removed from the dive tank and placed on the deck. The divers exit the water and the debriefing is conducted. During the debriefing information is collected on what went well and what can be improved for the next test as well as the subject's impressions and observations during the test. 


\section{Emergency Procedures}

In any emergency it is important to have a pre-defined response, so that all team members involved will know their roles and what response to expect from others. To this end a list of the possible failure modes and responses to these failures has been developed and will be discussed in this section.

There are two major factors that affect the response used for an emergency with the partial gravity system. They are whether or not the subject is able to assist in the response and whether or not the ballast has been released. The combination of these two factors results in four categories each of which has its own method for extracting the subject from the dive tank as seen in Table 2 .

Table 2 - Subject Extraction Breakdown

\begin{tabular}{|c|c|c|}
\cline { 2 - 3 } \multicolumn{1}{c|}{} & Ballast Released & Ballast Attached \\
\hline Subject Assisting & Normal Extraction & Ladder Extraction \\
\hline Subject Unable to Assist & Safety Divers Swim Subject & Crane Extraction \\
\hline
\end{tabular}

\section{$\underline{\text { Normal Extraction }}$}

This extraction covers two main families of emergency: subject discomfort and loss of breathing gas. The first family is very broad, but at anytime if the subject feels uncomfortable the test is ended and the normal end of test extraction procedure is carried out. The second family, loss of breathing gas, requires immediate action. The first step is providing the subject with an alternate source of air. This can occur in one of two ways. Either through a safety divers alternate air source or through a Spare Air bottle. 
Each of the safety divers has a second regulator that can be donated to the subject in an emergency. The subject is also wearing a 3.0 cubic foot tank with integrated regulator on their harness, which will provide enough air until the subject is either given a safety diver's alternate or the tank they descended on. Once breathing gas is restored the ballast can be released, the subject is transferred to the tank they descended on, and a normal extraction is used.

\section{Ladder Extraction}

If during either of the two scenarios in the previous section the ballast cannot be released a ladder extraction is used. Attached to the side of the dive tank is a ladder that reaches from the bottom of the tank to the surface shown in Figure 17. The subject can use this ladder to climb out of the dive tank. If the subject is not wearing their air supply during the extraction the safety diver will be able to carry it while monitoring the subject as they climb.

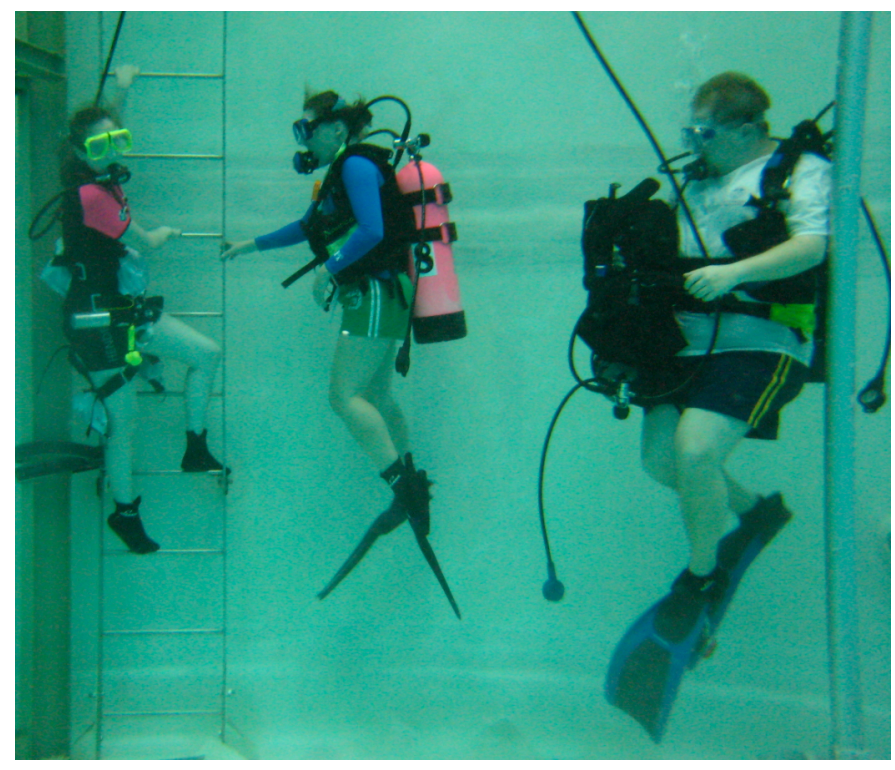

Figure 17 - Ladder Extraction 


\section{$\underline{\text { Safety Diver Extraction }}$}

This extraction would be used in the event that the subjects were unable to assist in their own extraction. This would be most likely due to a medical emergency. During this extraction the safety divers would first remove the ballast from the harness. This lightens the subject so that it is possible to swim them to the surface. Then the two safety divers would swim the subject to the surface as shown in Figure 18. As the hose is 25 feet long, it is possible to reach the surface without carrying the hookah rig up with the subject.

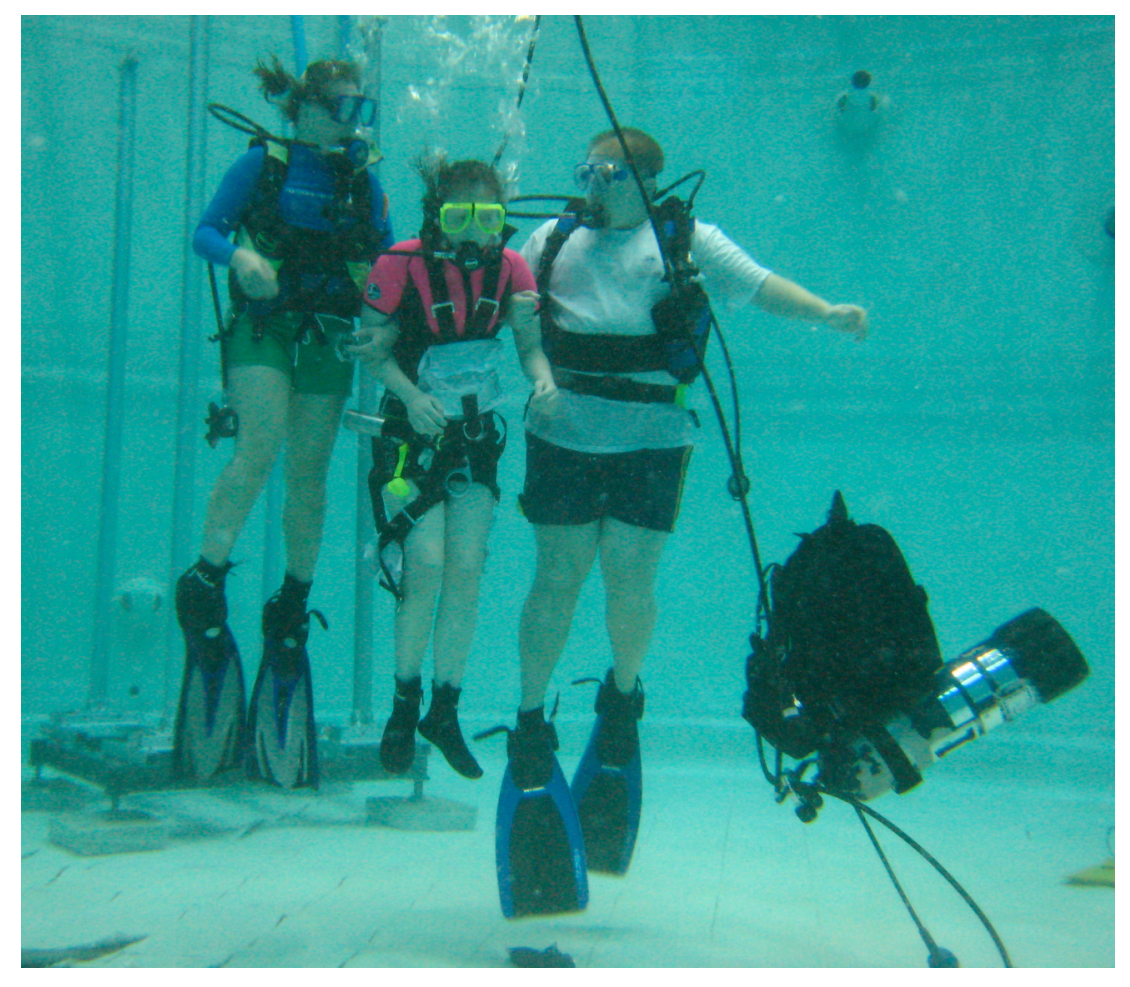

Figure 18 - Safety Diver Extraction

\section{$\underline{\text { Crane Extraction }}$}

If the diver is incapacitated and the ballast is unable to be removed, the subject may be extracted by using the overhead crane. This is required, as it has been shown in testing to be extremely difficult for the safety divers to swim a fully ballasted subject to the surface. Even if the safety divers succeeded the subject would have no means of flotation to 
remain at the surface. The front of the harness has a ring such as those found on fallarrest harnesses. This ring is connected to the crane and the subject is lifted to the surface. The crane and attachment point can be seen in Figure 19.

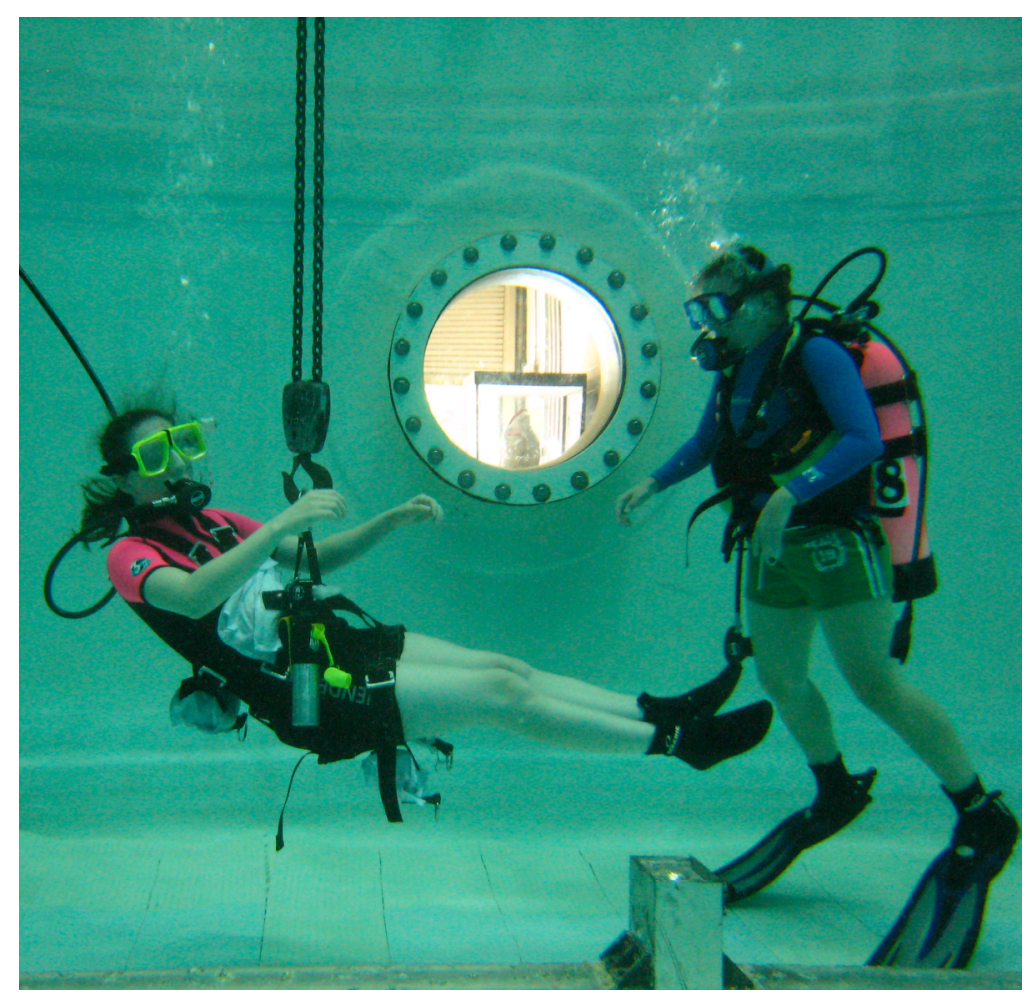

Figure 19 - Crane Extraction 


\section{Chapter 5: Experimental Procedures \& Hardware}

This chapter will describe the procedures and hardware used during data collection. The experiment consisted of two phases: the orientation phase and the data collection phase. The orientation phase consisted of one dive to familiarize the test subject with the hardware and the emergency procedures. The data collection phase took place over two or three dives per subject.

\section{Orientation Dive}

The orientation phase consisted of one dive for each of the subjects. This dive served to familiarize the subject with the hardware and the emergency procedures. The dive was conducted in accordance with the nominal procedure for descent and ascent outlined in the previous chapter. Once the subject had removed their SCUBA unit and was comfortably breathing off of the hookah their neutral buoyancy was tested. For this they stood on the bottom of the dive tank without ballast and breathed normally. If they are approximately neutral they will ascend as they inhale and descend as they exhale. The buoyancy of the test subject changes while they breathe due to their chest expanding and displacing more water when they inhale, with the opposite happening as they exhale. Weights can be removed or added to a belt around the subject's waist until the desired effect is achieved. Once the subject was neutral the proper amount of ballast was added to the pockets of the harness. For all of the orientation dives the proper amount of ballast for lunar gravity was used. The subject was then allowed to walk around and acclimatize to the partial gravity environment. Once the subject felt comfortable the subject and a safety diver jettisoned the ballast, so the subject could get a feel for how the pockets 
operated. Once the releases were reset and the ballast was replaced in the pockets the subject practiced bailing out to their onboard alternate air supply, the Spare Air. With a feel for how the regulator breathes on the Spare Air bottle the subject practiced receiving the octopus regulator of one of the safety divers. With a mastery of the techniques required in a loss of breathing gas emergency the subject was ready to practice the ladder extraction. This test gave the subject a sense of how much traction and balance they had on the exit ladder. One safety diver monitored them while the other diver carried the hookah rig towards the surface. The crane and swimming extractions are not practiced as they assume the subject is incapacitated and therefore require no action on the part of the test subject. With these scenarios completed the subject was given further time air supply and time permitting to become further acquainted with the sensation of partial gravity. After this final familiarization period the dive was terminated and the nominal ascent procedures were completed.

\section{$\underline{\text { Data Collection Dives }}$}

Data was collected on the stability of the subjects standing on various slopes under different loading conditions. Besides the ballast system, four major components were used in the data collection process: a ramp, a pusher, a backpack, and a video camera. The components are used to collect data by disturbing the test subject while they are standing at rest. The results of the disturbance are recorded by the video camera for postdive analysis. 


\section{$\underline{\text { Ramp }}$}

The ramp shown in Figure 20 can be adjusted to approximately ten, fifteen, or twenty degrees. The maximum angle of the ramp was set at twenty degrees due to proposed OSHA regulation 1910.26. This regulation calls for a railing on any ramp with an angle greater than 20 degrees. Since this ramp would not have a railing this was deemed an appropriate maximum slope to test. The ramp's center section is covered with strips of non-skid tape as it was found during early testing that the ramp's surface did not provide enough consistent traction for the experiment. The plate is reinforced with two bars that run the length of the ramp. The reinforcement reduces the amount of flex in the ramp so that the subject does not bounce during the trials.

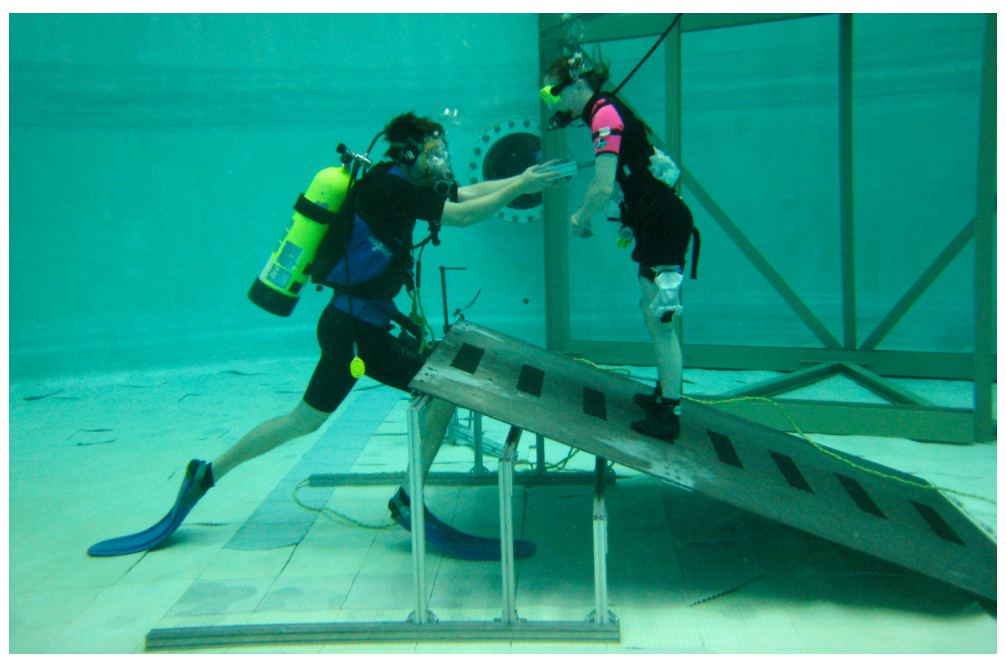

Figure 20 - Subject on ramp set at 20 degrees

\section{$\underline{\text { Pusher }}$}

The purpose of the pusher shown in Figure 21 is to provide a consistent disturbance to the subject. The pusher consists of a three main components: a length of two-inch square rapid prototyping extrusion beam, the pushing assembly and the latch. The extrusion acts as the handle with the latch and pushing assembly attached to it. The pushing assembly 
consists of a plastic rod, a spring, the pushing surface, and a guide bolt. The plastic rod is held in the center of the extrusion using by the guide bolt at the back end and a thin plate attached to the front of the extrusion. The plastic rod slides through the thin plate imparting the disturbance to the test subject. The latch consists of an extrusion joining plate into which a notch has been cut. The head of the bolt on the pushing assembly engages the notch holding the pushing assembly in the ready position. When the test diver releases the latch, the spring forces the pushing assembly forward imparting the disturbance to the test subject.

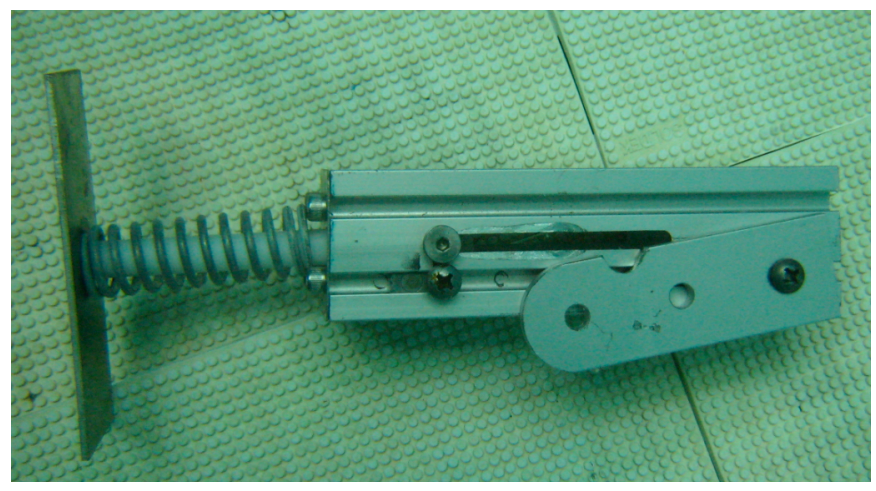

Figure 21 - Pusher

Two different springs were tested for the pusher. The first spring allowed the test diver to easily compress the pusher and latch it without outside assistance. However this spring did not appear to provide enough force. For this reason a stiffer spring was substituted. This second spring provided enough force to the subjects, but proved to be nearly impossible for the test diver alone to compress. To solve this problem the Cclamp shown in Figure 22 was used. This allowed the test diver to compress and latch the pusher at his own pace. 


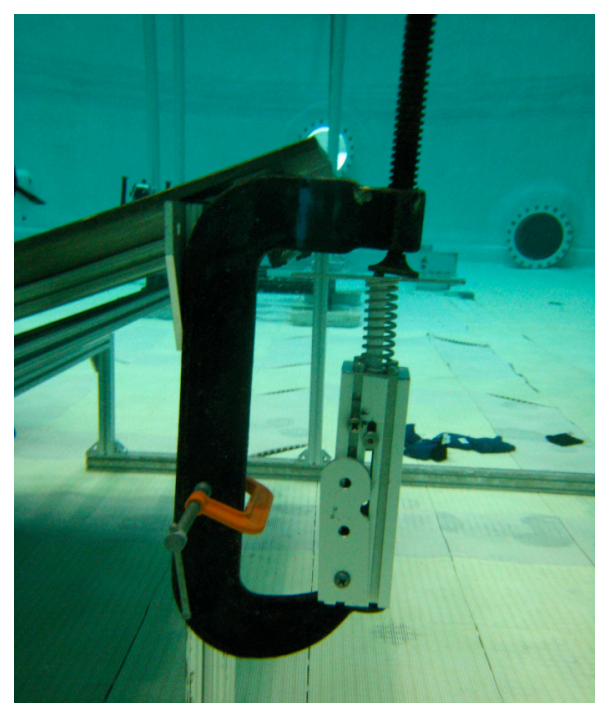

Figure 22 - Pusher in C-clamp

\section{$\underline{\text { Simulation PLSS Backpack }}$}

The backpack seen in Figure 23 was used to simulate a Portable Life Support System (PLSS) such as those used on current spacesuits. The mass and CG of the backpack can be adjusted using the two extrusion beams shown in the left of the photo. The harness and tubular frame of the backpack were originally part of an external frame backpack. The harness consists of two padded adjustable shoulder straps and a padded adjustable waist belt with quick release buckle. The configuration shown weighs seven pounds and was used in the lunar gravity simulation equating to a forty-two pound PLSS. While this is significantly lighter than current PLSS it is within the goal range of next generation designs. [23] The horizontal beam moves up and down to adjust the CG vertically. To adjust the CG in the horizontal direction weights are attached to the horizontal beam and slid towards or away from the test subject. 


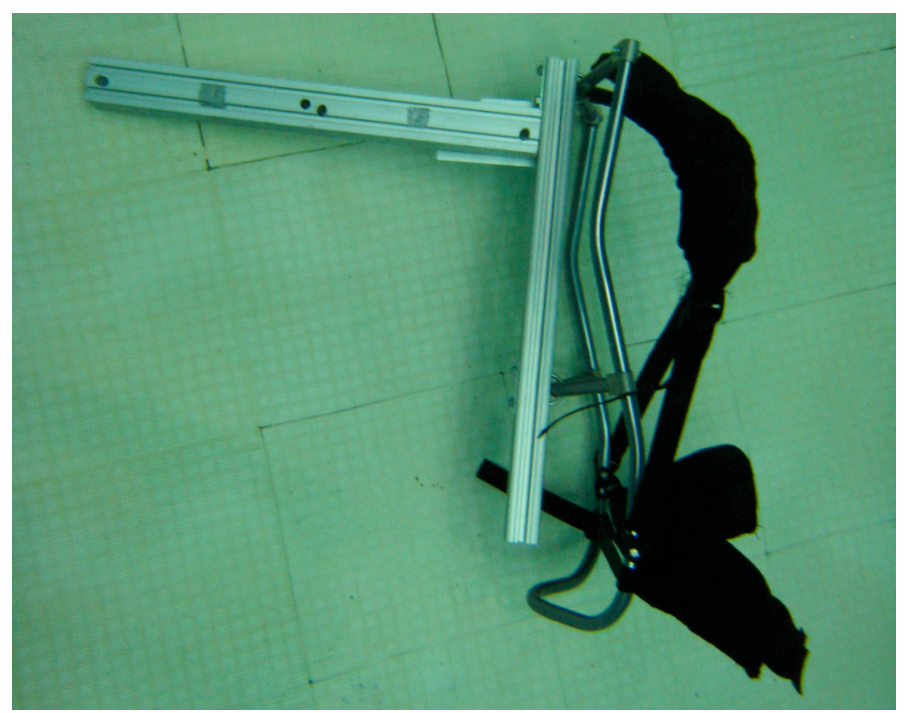

Figure 23 - Simulation PLSS Backpack

The ballast on the subject's torso can still be jettisoned with the backpack in place. The only requirement is that the safety divers ensure that the release D-rings are pulled out from the padded waistband.

\section{$\underline{\text { Video Camera }}$}

A video camera was used to collect data during the experimental runs. The camera used was a Sony DCR-TRV 950 Digital Video Camera Recorder. The data was recorded onto sixty-minute Mini-DV cassettes. The camera was housed in an Ikelite Digital housing to protect it during the underwater trials. A mount was built and attached to the housing allowing it to be clamped around a mockup that was in the dive tank. This provided a stable base and ensured the camera was the same distance from the ramp during all trials. The camera, housing, and mount are shown in Figure 24. 


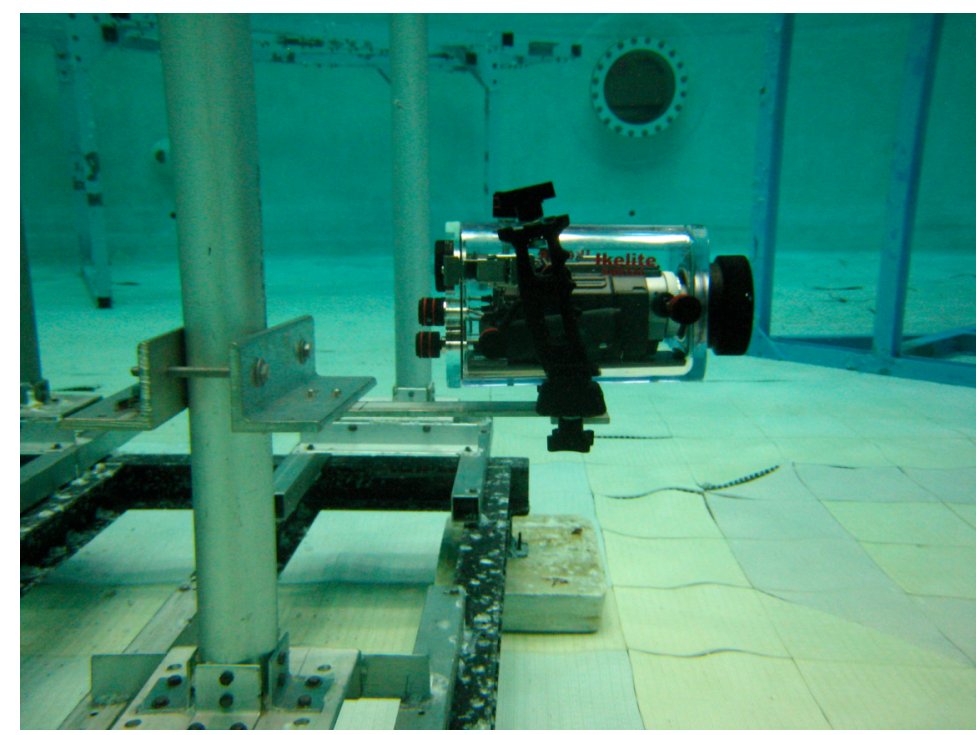

Figure 24 - Camera in Housing

\section{$\underline{\text { Experimental Procedures }}$}

Three different weighting configurations were completed with each subject over the course of two dives per subject. All three configurations were carried out in lunar gravity, so that the pockets were able to hold the appropriate ballast for the full range of subjects. The two lightest subjects were put through three weight configurations in Mars gravity for comparison. To accommodate simulating heavier subjects in Martian gravity larger pockets need to be constructed. The current pocket size was chosen to hold lunar ballast for the heaviest subject while limiting how much the ballast would be able to shift during tests of the lightest subject. The three weighting configurations for the Lunar tests were as follows: no backpack, seven pound backpack with high CG, and seven pound backpack with low CG. The backpack CG was located 4.3 inches from the subject's back in both trials. For the high CG configuration the CG was 13.3 inches above the middle of the waistband of the backpack. The low CG location placed the CG 7.7 inches above the middle of the backpack waistband. For the Mars gravity trials the three 
weighting configurations were no backpack, seventeen-pound backpack with high CG, and seventeen-pound backpack with low CG. The backpack trials had approximately the same CG in both the Lunar and Mars cases and the Mars backpack weight was chosen to simulate backpack of equivalent mass to the Lunar trials. These weighting conditions represent only a very small fraction of the data that can be collected once the system and data collection procedures are perfected. The no backpack trial was conducted first with all subjects while the order of the backpack trials was not set. Each trial contained six different orientations that the subjects were placed in while data was collected. Two of these were on a zero degree slope in which the subjects were pushed from the front and from the back. The remaining four orientations were on a twenty-degree slope where the subjects were pushed from the front and the back while facing up the slope of the ramp as well as down the slope. In each orientation the subjects were pushed at least three times so that an average response could be found. The orientations are labeled by the push direction and the orientation of the subject. The two zero slope orientations are labeled as Front and Back. During the Front trials the subjects were pushed from the front and the Back trials pushed the subjects from behind. The twenty-degree slope trials are labeled with two terms. The first describes the direction the subject was facing either Up the ramp or Down the ramp. The second term is the direction they were pushed either Up or Down. For example a Up Up trial would have the subject facing uphill and the push would be from the back pushing them farther uphill.

During each push the subjects were videotaped. To provide a reference point to measure displacements the subjects wore four small white targets. These targets were placed on 
the upper arm, the waist, and one on each ankle as can be seen on the subject in Figure 25.

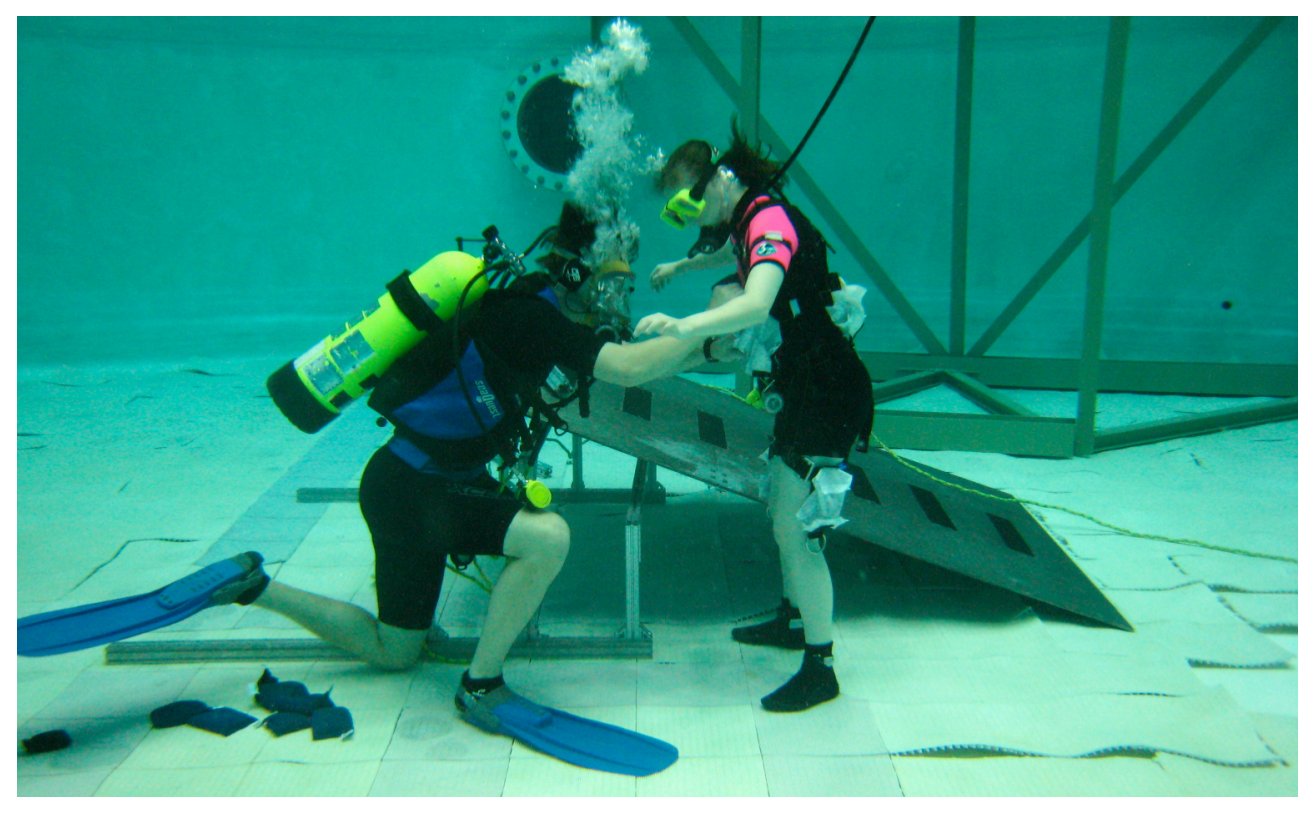

Figure 25 - Diver Adjusting Ballast

The videos were viewed in iMovie, a video editing program that allowed the start and end of each push to be found. The start of the push was defined as the point when the pusher was seen to release. The end was marked as the time at which the subject's maximum displacement was reached. Still images were extracted at the start and end of every push for the first round of analysis. The second round of analysis involved selecting several images between the start of the trial and the moment the subject's foot left the ground. The images were analyzed using MATLAB, which allowed for several parameters of each push to be measured. These parameters include displacement of the targets and angle of the subject's torso in each photo. The targets were located using the ginput command, which allowed the author to click on the targets and receive an $\mathrm{x}-\mathrm{y}$ coordinate for each. 
The video camera was run continuously throughout each testing sequence. This allowed data to be collected about the operation of each test in addition to the stability data. This was done to study the efficiency of the current testing procedures. And if the procedures are not efficient, look for ways to improve them. The data collected for this analysis included the number of misfires of the pusher, the length of time to reset the pusher and the length of time to swap the targets. 


\section{Chapter 6: Results \& Data Analysis}

\section{$\underline{\text { Subjects }}$}

Four subjects completed the lunar trials that were discussed in the previous chapter. Their weight ranged from 114 pounds to 176 pounds. Subjects 1 and 2 also completed trials at Mars gravity. The subjects consisted of two females, the lightest two subjects, and two males, the heaviest two subjects.

Table 3 - Subject Information

\begin{tabular}{|c|c|c|c|}
\hline Subject & Gender & Earth Weight (lb) & Height (in) \\
\hline 1 & Female & 130 & 61 \\
\hline 2 & Female & 114 & 64 \\
\hline 3 & Male & 176 & 74 \\
\hline 4 & Male & 171 & 67 \\
\hline
\end{tabular}

\section{Quantitative Results}

Two rounds of analysis were conducted utilizing the video data collected during the experiments. The first round utilized two photos. One was taken at the start of the trial and the second came at the point the subject ceased to move away from the pusher. The data generated by analyzing these photos in MATLAB was tabulated and viewed to see if any patterns could be discerned. The first thing that was investigated was how closely the data from each push was to the others completed with the same orientation and weighting. This was accomplished by finding the range in each parameter measured for one of the subjects. The results of this analysis are shown in Table 4. The third column shows the average amount of variation in the parameter across all configurations. The last column shows what percentage the average variation is of the average value. 
Table 4 - Data Variation for Subject 2

\begin{tabular}{|c|c|c|c|c|}
\hline Parameter & $\begin{array}{c}\text { Minimum } \\
\text { Variation }\end{array}$ & $\begin{array}{c}\text { Average } \\
\text { Variation }\end{array}$ & $\begin{array}{c}\text { Maximum } \\
\text { Variation }\end{array}$ & $\begin{array}{c}\text { Variation, as } \\
\text { Percent of Avg }\end{array}$ \\
\hline Time (sec) & 0.07 & 0.87 & 1.80 & $26.54 \%$ \\
\hline $\begin{array}{c}\text { Shoulder } \\
\text { Displacement }\end{array}$ & 0.30 & 23.87 & 65.21 & $39.64 \%$ \\
\hline $\begin{array}{c}\text { Waist } \\
\text { Displacement }\end{array}$ & 3.78 & 21.85 & 86.05 & $43.90 \%$ \\
\hline $\begin{array}{c}\text { Near Leg } \\
\text { Displacement }\end{array}$ & 3.46 & 30.06 & 69.12 & $59.29 \%$ \\
\hline $\begin{array}{c}\text { Far Leg } \\
\text { Displacement }\end{array}$ & 8.55 & 30.00 & 76.34 & $52.04 \%$ \\
\hline $\begin{array}{c}\text { Starting Torso } \\
\text { Angle (deg) }\end{array}$ & 1.18 & 8.87 & 20.02 & $15.21 \%$ \\
\hline $\begin{array}{c}\text { Ending Torso } \\
\text { Angle (deg) }\end{array}$ & 1.58 & 12.31 & 27.31 & $22.31 \%$ \\
\hline
\end{tabular}

As can be seen from the last column there is a large amount of variation in the displacement and angular data. This implies that either the tests that were conducted are not repeatable and do not give consistent data, or this is not the proper way to analyze the data. This large variation would make any conclusion distilled from this analysis suspect. Consistent with the large variations no clear patterns emerge from any of the measured parameters.

The large variation and lack of consistent trends led to a second round of data analysis. In this round six photos of each trial were used. This was done to better understand the time history of each subjects' response. The six photos were chosen at even intervals from the start of the trial to the point at which one of the subjects' feet left the ground. This spacing placed the photos closer together for the quicker trials in order to capture the subject's faster response. This analysis only utilized two out of the four targets: the waist and the ankle closest to the camera. This was done, as the shoulder target did not always 
track the movement of the body well. If the subject moved their arms during a trial this would cause movement of the upper arm target that was not indicative of the motion of the rest of the body. With all six photos selected the subject's angular change was graphed in a variety of combinations to look for trends. Each orientation was graphed for each subject with all backpack configurations to analyze backpack effects. All subjects were graphed together in each orientation to see how the mass and height of the subjects affected the response. And finally the Mars gravity results were graphed against that subject's Lunar trials to isolate any variation due to gravity level. Early in the analysis, while viewing the data of one subject, interesting trends appeared to emerge. The Lunar and Mars trials appeared to follow the same trend of angular change, but in the Mars trials the subject lifted their foot sooner and after less angular change. Another trend was that the angular change in each trial appeared to be linear. It would be expected that the slope would continually increase as the subject leaned farther due to the increasing moment arm. However after analyzing all trials of all subjects none of these trends held for all subjects. In addition to graphing the time history, the lift time and maximum angular rotation were also compared as was the slope of each trial. The slope was found by taking the point of maximum angular rotation in each trial and dividing by the time to reach that point. After this was done for each trial, the trials with the same experimental conditions were averaged. No definitive conclusion was possible from these graphs either due to the wide spread in some of the data sets. It is difficult to pin down the cause of the variations because there are numerous sources of error that are apparent upon qualitative assessment of the videos. 


\section{Experimental Problems \& Solutions}

Although a quantitative analysis yielded no clear conclusions, an analysis of the experimental errors will serve to improve the next generation of research into this field. Several of the experimental problems were created due to the unforeseen reactions of the human test subjects. The next largest contributor of experimental problems came through the use of a portable disturbing force operated by a human test diver. After completing the trials and viewing the video the reactions that disrupt the data can be identified. Once identified, countermeasures can be developed to combat the disruptions. Although most are instinctive reactions the test subjects can overcome them through conscious effort.

One of the most obvious problems seen in some of the trials was the subject utilizing their hands for propulsion and stability as shown in Figure 26. This is a natural human reaction to use every means at their disposal to regain balance. It is however a detriment to the accuracy of the simulation due to the high density of water as compared to a planetary atmosphere.

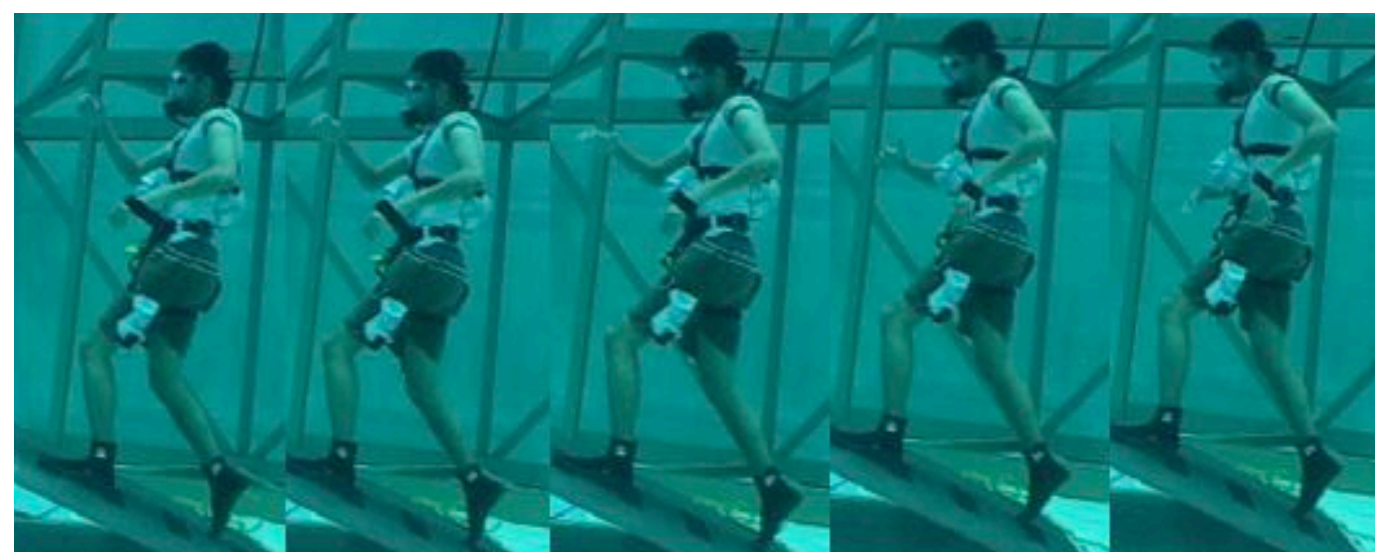

Figure 26 - Hand Propulsion 
This problem is not likely to be eliminated completely as balance is hardwired into the human brain. However the effects can be mitigated by having the subjects clasp their hands in front of them as seen in Figure 27. This occurred on some of the trials and seemed to be quite effective in reducing arm motion.

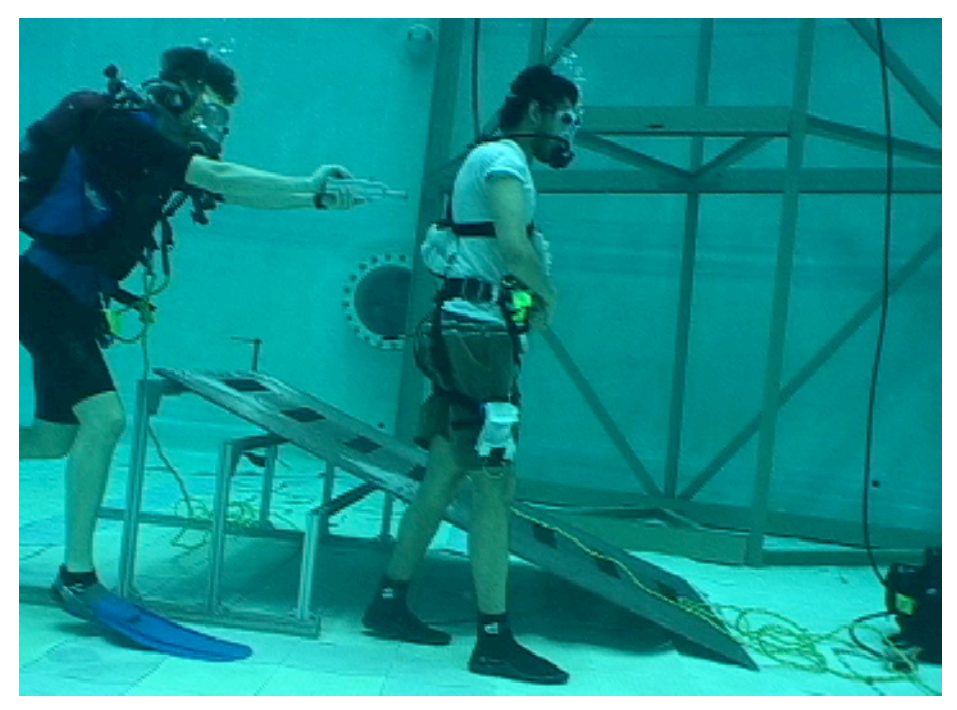

Figure 27 - Hand Clasped

The next problem encountered was caused by the subjects' reaction to return to the start point for the next trial as quickly as possible. This caused the subject to lose traction in some cases while trying to run back to the start position. The main problem is that the subject's maximum displacement appears to be reduced as they try to fight their way back to the start. This skews the results related to angle and displacement. For this reason foot lift was used as the finish for the second round of analysis. This would not be that large of a problem if the subjects slowed their movement the same way every time, but this is impossible. One of two problems is usually responsible for the inconsistent nature of the movement. The subjects tended to either slip in between the grip tape causing them to fall back towards the start point or were inconsistent with the amount of 
force applied to return to the start. This tendency also prevents the subject from achieving a stable posture at the end of the trial. This makes it difficult for the data analyst to pin down the end of the trial on the video, disrupting the time measurement. To solve this problem the subjects should be instructed to maintain the ending posture until instructed otherwise by the test diver. Future experiments should also cover the entire ramp with grip tape to provide a uniform amount of traction.

The last problem created by the subjects was the inconsistent manner in which they moved after being pushed. During some trials the subject hopped backwards almost immediately after being pushed causing little rotational motion. In other cases the subject would pivot as far as they could and then took a large step to catch themselves. And still other times the subject would pivot a little and then take several steps. Any or all of these reactions could be applied to the same weighting and directional conditions. This is a very tough problem to solve. It is likely that this problem is impossible to solve and can only be mitigated by discussing the problem with the subjects and reminding them to try and use the same movement technique every time. It may also be possible to attack this problem by using a disturbance that does not require the subject to move their feet, such as a weaker spring on the pusher.

The test diver operating the pusher generated several anomalies as well that need to be addressed. Since the pusher was a handheld device it had to be aligned by the operator and relied on sight and feel to attempt to repeat its placement in each trial. This caused numerous errors due to poor contact and misalignment of the pusher with the direction of 
travel. The largest problem in this category was placing the pusher as close to the subject as possible without imparting a separate disturbing force with the operator's arms. If the pusher was too far from the subject, some energy was lost as the push plate traveled across the gap. If the pusher was too close to the subject extra energy was imparted to the subject before the latch was released. The operator is also not placing the pusher in the same orientation every time. This causes some of the energy of the spring to be expended in directions other than the one intended. The mobile pusher is also a problem as it moves in the opposite direction of the subject reducing the force. Since the same diver was used to impart each push their mass was constant, but it is impossible to ensure that the he was standing in the exact same manner every time. This causes a variation in the amount of energy imparted to the test diver, which affects the amount imparted to the subject. A solution to these problems is to replace the pusher operator with a test stand that places the pusher in the same position every time. This solution does however add its own set of problems. Now the subject must be maneuvered to place them in the same relative position to the pusher. As inaccurate as it may have been the pusher operator performs this compensation automatically. Another problem is that a reset mechanism must be fitted to the test stand. Currently the pusher is placed in a c-clamp, reset, and then removed before the trial. The test stand would have to allow for the spring to be compressed and the mechanism moved out of the say so it does not interfere with the release of the pusher. This mechanism will trade inaccuracy for complexity.

The targets themselves are also a source of error. The shoulder target in particular had a habit of shifting down the subjects arm. This was caused by gravity and the narrowing of 
the arm from the shoulder to the elbow. The shoulder target also moves if the subject waves their arms. This causes a false impression of the movement of the subject's body and was the reason for excluding this target from the second analysis. The other targets were not always placed in the exact same location, but their position did not shift much from trial to trial. Their error was created by human divers installing them. These errors could be reduced by rigidly attaching the targets to the harness system. The divers would still have to ensure that the harness was worn in the same way every time, but this appeared to be the case during the experiment already.

\section{Data Analysis Problems \& Solutions}

Once the data was collected including all of the associated problems mentioned in the previous section, it had to be analyzed. This process used two different programs, iMovie and MATLAB, and added its own series of errors to the data. The first step in the data analysis was to pick out each individual push from the video. This was done by playing the video until the pusher was placed next to the subject's torso. Once the pusher was in place the video was advanced frame by frame until the pusher was seen to release. This point on the video was almost always obvious and thus the selection was accurate. With the beginning of the push identified the point at which the push ended was the next priority. This was difficult to find due to the lack of a definitive end pose. A subjective cut off was often made between what was reaction to the push and what was the subject attempting to return to position. Solutions for this problem were discussed in the previous section. The next step in the analysis required still photos to be selected from the video clip for analysis in MATLAB. Selection of these photos depends on the parameters that are most important to what information is desired. For the first analysis 
photos were chosen at the beginning and end of push. These two photos were chosen because they would show the subject's maximum displacement and it was a time efficient way of selecting photos. Neither of these two photos typically depicts the point of maximum rotation. A MATLAB script was written that read in the two photos and asked the user to select the four targets worn by the subject. As imprecise as this method seems, it generates results that are repeatable. Table 5 is the raw MATLAB data from ten attempts to pick out the targets in Figure 28. As can be seen the data shows that on many occasions the same numbers are generated in different trials. Trial 5 does show one anomaly in the Leg 2 data. This error is believed to be caused by a delay in MATLAB. After the point was clicked the mouse was moved while MATLAB was processing which may have skewed the value.

Table 5 - Repeatability Test Data

X Coordinate
\begin{tabular}{|c|c|c|c|c|}
\hline Trial & Shoulder & Middle & Leg 1 & Leg 2 \\
\hline 1 & 383 & 385 & 375 & 375 \\
\hline 2 & 383 & 385 & 375 & 375 \\
\hline 3 & 383 & 385 & 375 & 375 \\
\hline 4 & 383 & 385 & 375 & 375 \\
\hline 5 & 383 & 385 & 377 & 381 \\
\hline 6 & 381 & 385 & 374 & 375 \\
\hline 7 & 383 & 385 & 375 & 375 \\
\hline 8 & 381 & 385 & 375 & 375 \\
\hline 9 & 381 & 385 & 375 & 375 \\
\hline 10 & 383 & 385 & 375 & 375 \\
\hline
\end{tabular}

Y Coordinate
\begin{tabular}{|c|c|c|c|c|}
\hline Trial & Shoulder & Middle & Leg 1 & Leg 2 \\
\hline 1 & 127 & 215 & 451 & 451 \\
\hline 2 & 129 & 217 & 451 & 451 \\
\hline 3 & 127 & 217 & 451 & 451 \\
\hline 4 & 129 & 215 & 451 & 451 \\
\hline 5 & 129 & 217 & 451 & 127 \\
\hline 6 & 127 & 217 & 451 & 450 \\
\hline 7 & 127 & 215 & 450 & 451 \\
\hline 8 & 127 & 215 & 451 & 451 \\
\hline
\end{tabular}




\begin{tabular}{|c|c|c|c|c|}
\hline 9 & 129 & 215 & 450 & 451 \\
\hline 10 & 129 & 215 & 451 & 451 \\
\hline
\end{tabular}

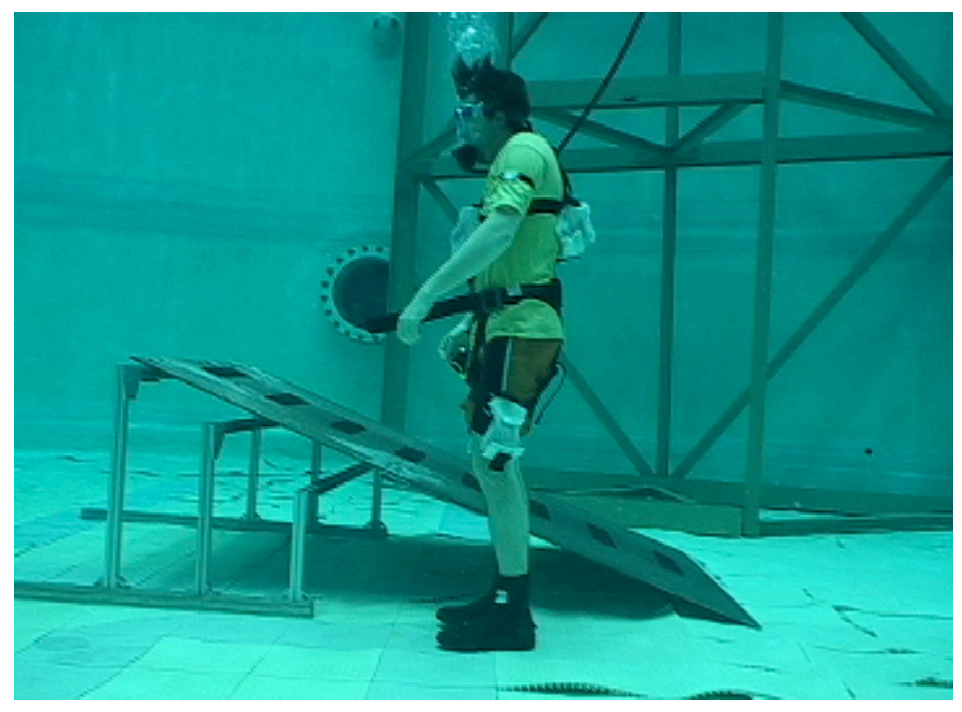

Figure 28 - Photo Used in Repeatability Test

The second round of analysis utilized a series of photos to capture the time history of the subjects' motion. The point picked for the end of he trial in this analysis was the lifting of the subjects' foot. This was chosen in an attempt to reduce the uncertainties due to the subject either not holding in an end pose or rushing back to the start point. The foot lift as an end point for the trial into a problem due to the fact that sometimes the subjects stepped to catch themselves and in some cases they hopped to catch themselves. When the subject steps the data shows a consistent increase in the angle of the subject, however if the subject hops they roll onto the ball of their foot moving their ankle in relation to their hip. This creates an artificial drop in the angular change that is graphed. A possible solution to this problem is to define the end of the trial as the moment the subjects begin a large rapid motion to catch themselves, either stepping or preparing to jump. This introduces the problem of deciding when a large motion has begun which would add errors to the analysis. 


\section{Chapter 7: Conclusions}

The current method of collecting data clearly needs to be improved before the next round of data collection is attempted. These improvements cover a wide range of topics from the equipment used in the tests, to the analysis tools, and even the instructions given to the subjects.

\section{Equipment Improvements}

There is always room for improvement when building the next generation of any system. The major improvements for this system include the adjustments on the harness and the pusher latch. One area that should be looked at, as a possible avenue is a fixed pushing device. The adjustments on the harness are currently a quick adjustment buckle. These buckles are great for quickly sizing the harness, but do tend to creep over time. Replacing them with buckles where the webbing doubles back on itself should eliminate this problem. The latch on the pusher needs to be improved so that the strength of the operator has no bearing whether the pusher misfires or not. Lastly in an attempt to reduce the uncertainty due to the operator, a fixed mount should be considered.

\section{Procedural Improvements}

The main improvement to the procedure should be in the form of instructions to the subjects to reduce the errors inherent to a human experiment. These instructions should include that the subjects hands should be clasped in front of them during all trials to reduce hand waving. Clasping the subject's hand in front may affect their neutral body

posture, but this may be necessary to reduce the amount the subject uses the water drag to assist in the recovery of their undisturbed posture. Next, the subjects should be instructed 
to remain in an end pose until the test diver clears them to move. This will improve the ease with which a trial can be identified in the post tape analysis.

\section{Analysis Improvements}

The analysis of the data can be improved through a different selection of trial end point. If consistent criteria can be developed and applied to define the start of gross motion this will likely be the best condition. Further experimentation will be required to develop the criteria necessary to identify the proper time.

\section{Alternate Experimental Method}

Up to this point the suggestions have focused on improving the current experiment. However this may not be the best approach. As Akin's Law \#11 states: "Sometimes, the fastest way to get to the end is to throw everything out and start over." [24] The current method of disturbing the subjects' posture is force based. The pusher utilizes the same force for every subject at every gravity level. This means that the smaller subjects receive a larger acceleration and the lower the gravity level the larger the acceleration. This can cause problems comparing trials between subjects and gravity levels. A possible solution to this problem is to replace a constant force disturbance with a constant displacement disturbance. This could be implemented in the form of floor that moves horizontally a specified distance. This type of experiment would be analogous to pulling a rug out from under someone. The constant displacement would be consistent for every permutation of the experiment. 
Another way to achieve a constant disturbance would be to utilize a plate that drops slightly under the subject. The plate could either drop and maintain its orientation or be designed to pivot such that the orientation of the plate changes. This plate could be instrumented with a force-torque sensor. The sensor would show how the subject reacts to the disturbance and would quantify changes in the subject's stance that may not be discernable on the video. 


\section{Chapter 8: Future Work}

The research presented represents only a fraction of the possible avenues that can be explored. Ballasted partial gravity systems allow for research into many areas of planetary EVA. Numerous experiments can be completed in the shirtsleeve environment as was done in this study. These include rover/habitat ingress/egress studies, suitport design, and load handling. This research can also be combined with other work being done at the SSL including the MX-2 space suit analogue and surface robotics.

\section{Shirtsleeve Experiments}

In addition, to filling in more PLSS CG data points in experiments similar to the one conducted here, there are several other avenues that can be explored. Studies can be conducted utilizing simulated habitats and rovers. These studies will help to identify the optimum size for hatches. The goal is to design a hatch that is easy to climb through while designing it as small as possible to reduce mass. Suitports as an entry point for rear-entry suits can be studied in a manner similar to the rover and habitat studies. Lastly different methods for lifting loads in partial gravity environments can be investigated. To validate any results gained through further shirtsleeve testing the same studies should be carried out at full Earth gravity both underwater and on land. This will help to isolate the effects that are due to the change in gravity level and those that are due to the drag of water. Earth gravity studies will be difficult to implement. Implementation in the underwater environment will require placing a large amount of ballast on the test subject. This will greatly increase the mass of the test subject adding to the inertial effects on the data. It will also be difficult to place the mass on the subject such that it is both secure 
and comfortable for the test subject. Lastly an extremely reliable ballast release will be necessary in order to ensure the subject's safe extraction in the event of an emergency. Earth gravity testing out of the water environment will be difficult as well. Padding or other safety precautions will be required in order to make the subject feel comfortable with being place off balance. If the subject does not feel comfortable there could be a considerable difference in the subject's reaction as compared to the underwater trials.

\section{$\underline{M X-2 \text { Space Suit Analogue }}$}

The SSL is testing a neutral buoyancy space suit analog known as the MX-2 shown in Figure 29. This second generation design is a low cost platform that is being used to demonstrate technologies that can be incorporated into next generation space suits. Currently the MX-2 has only been used to simulate microgravity EVA, but future upgrades could allow the MX-2 to simulate partial gravity as well. This will allow for data to be compared with the shirtsleeve tests to understand which effects are due to the pressure suit and which are inherent to the partial gravity environment. 


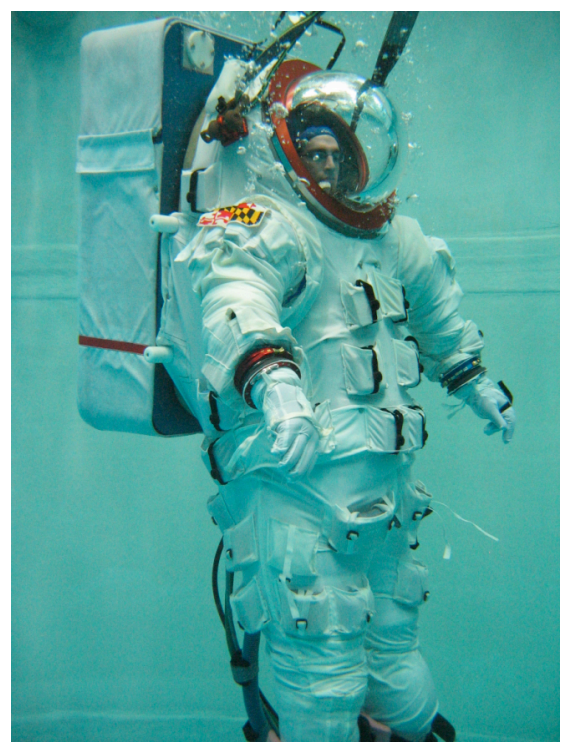

Figure 29 - MX-2 Space Suit Analog

The main obstacle that must be overcome when integrating partial gravity capabilities into the MX-2 will be the attachment of the large amount of ballast required. Due to the fact that the suit is full of air it has a large amount of inherent buoyancy. During current trials this buoyancy is overcome by the addition of lead weights to achieve neutral buoyancy. Approximately $250 \mathrm{lbs}$ of lead is required in addition to the weight of the suit subject. To this more ballast must be added to simulate a properly weighted suit in the chosen gravity field. Current generation planetary prototype suits such as the Mk III and the I-Suit have Earth weights of $120 \mathrm{lb}$. and $84 \mathrm{lb}$. respectively. This translates into $20 \mathrm{lb}$. and $14 \mathrm{lb}$. for a lunar gravity simulation. [19] This ballast is in addition to the amount needed to simulate the weight of the suit subject. For a $175 \mathrm{lb}$ subject on the Moon the total ballast required to simulate an I-Suit would be approximately $293 \mathrm{lb}$. 


\section{$\underline{\text { Human-Robot Interaction }}$}

The SSL has a long history of human-robot interaction going back to the Beam Assembly Teleoperator (BAT). This research has continued with the latest SSL dexterous robot Ranger shown in Figure 30 working with the MX-2. The SSL is also conducting research in planetary robotics including astronaut assistants. With the design and construction of a rover that could be used in the underwater environment, studies could be conducted into planetary human-robot interaction. Studies could be conducted to investigate the best roles for the rovers as well as optimal methods for their implementation.

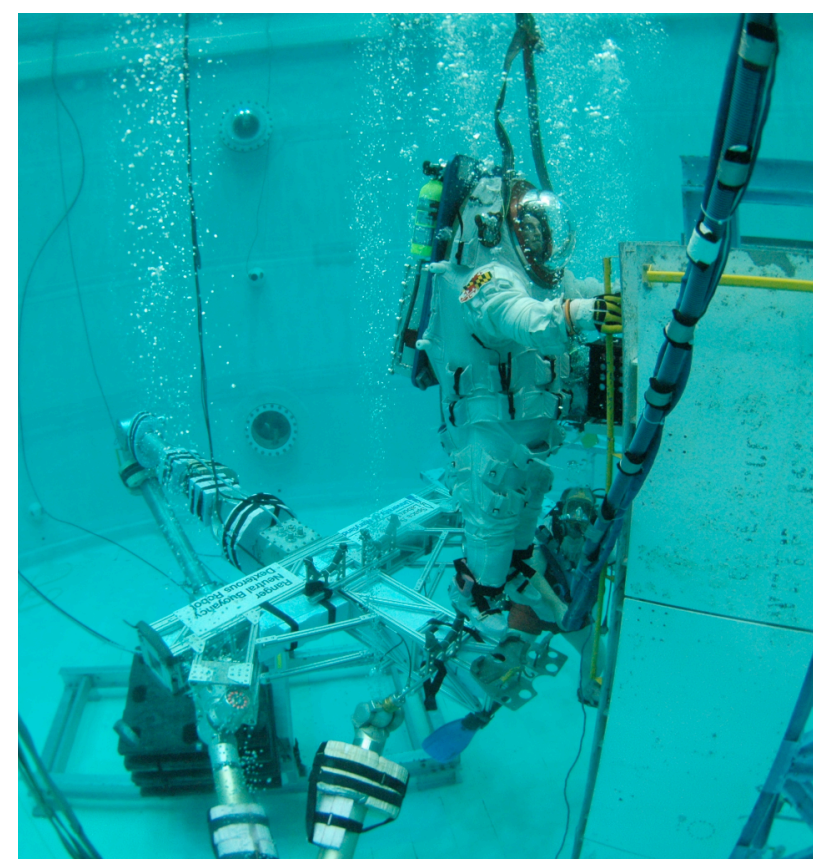

Figure 30 - Ranger \& MX-2 Working Together 


\section{Appendix A: Pusher Experiment Data}

Individual test run data for all subjects at both Lunar and Martian gravity is displayed below. Graphs show the angular change at each point in the trial. Graphs are separated by backpack loading and subject orientation.
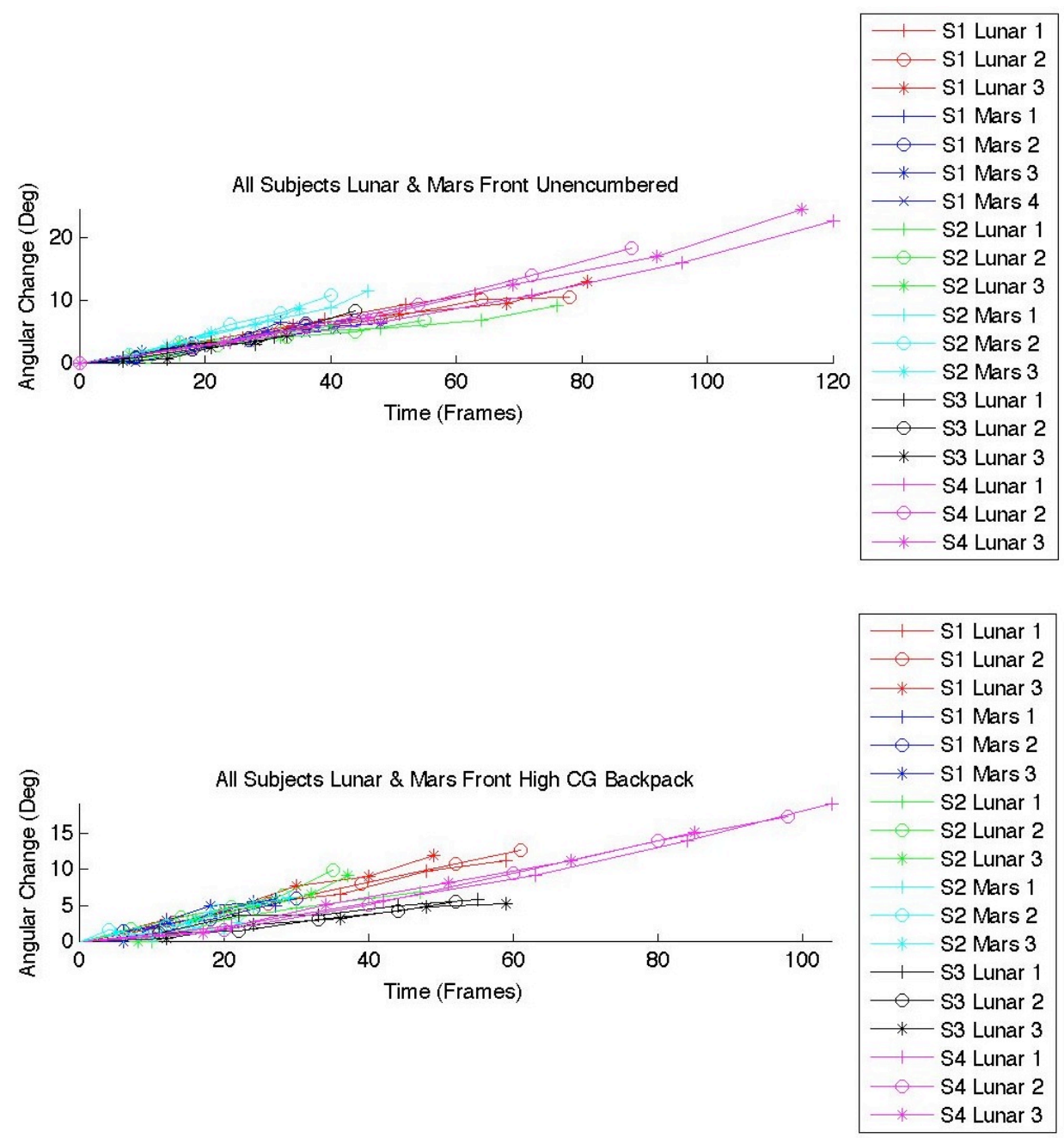

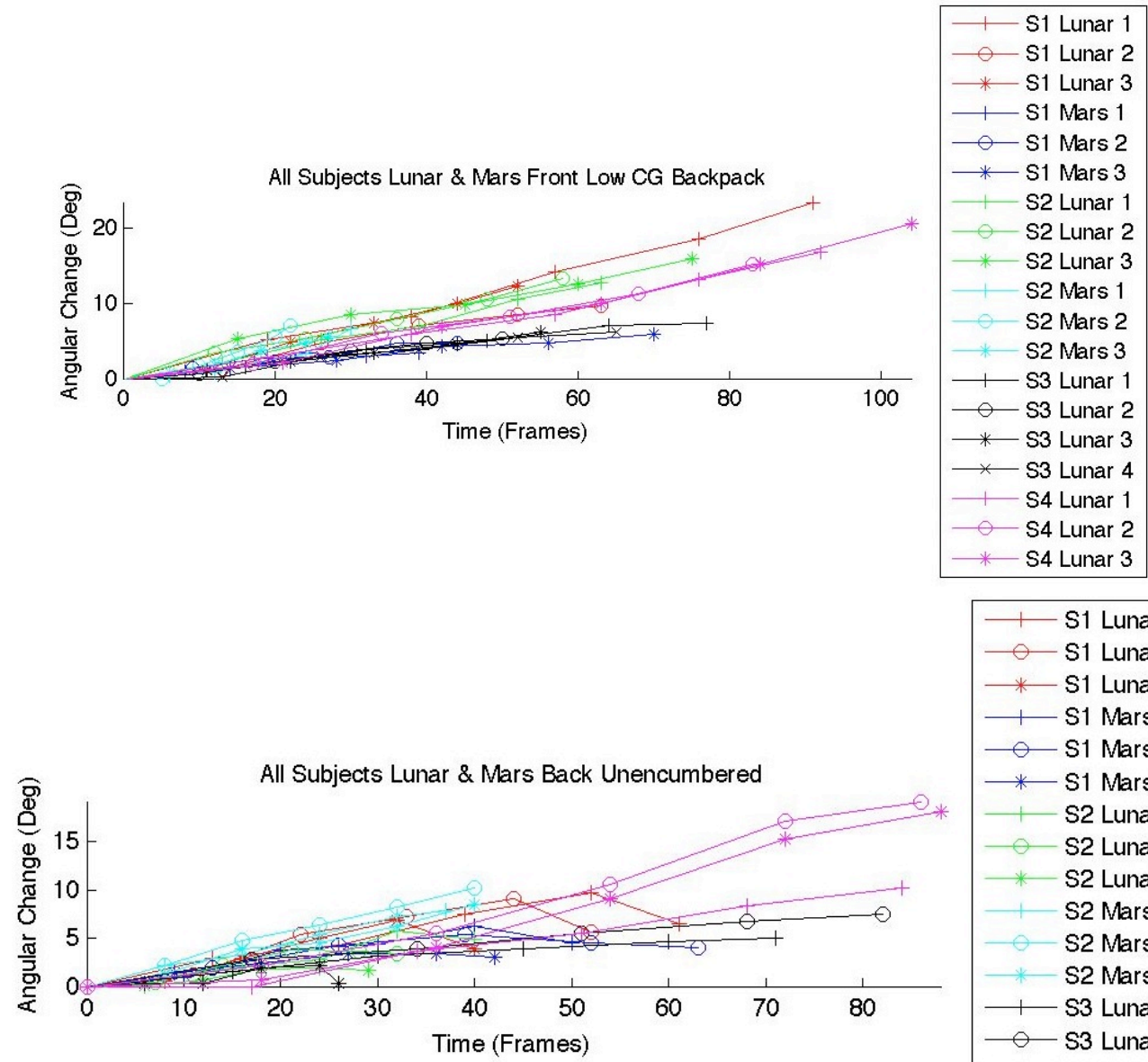

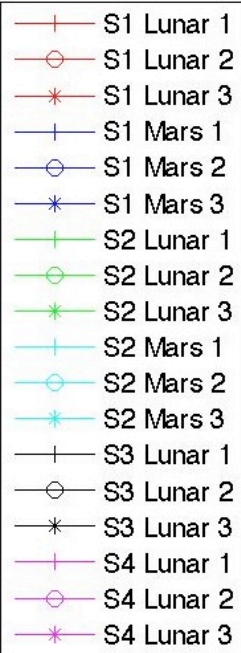

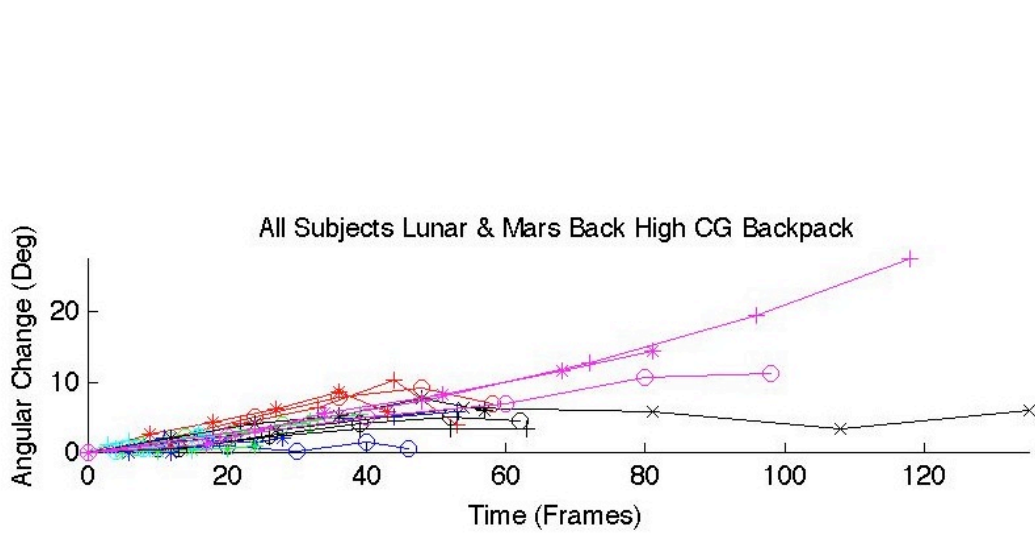

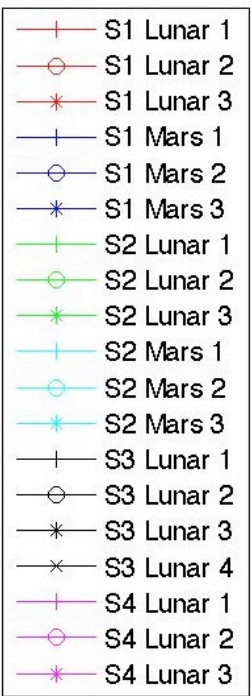



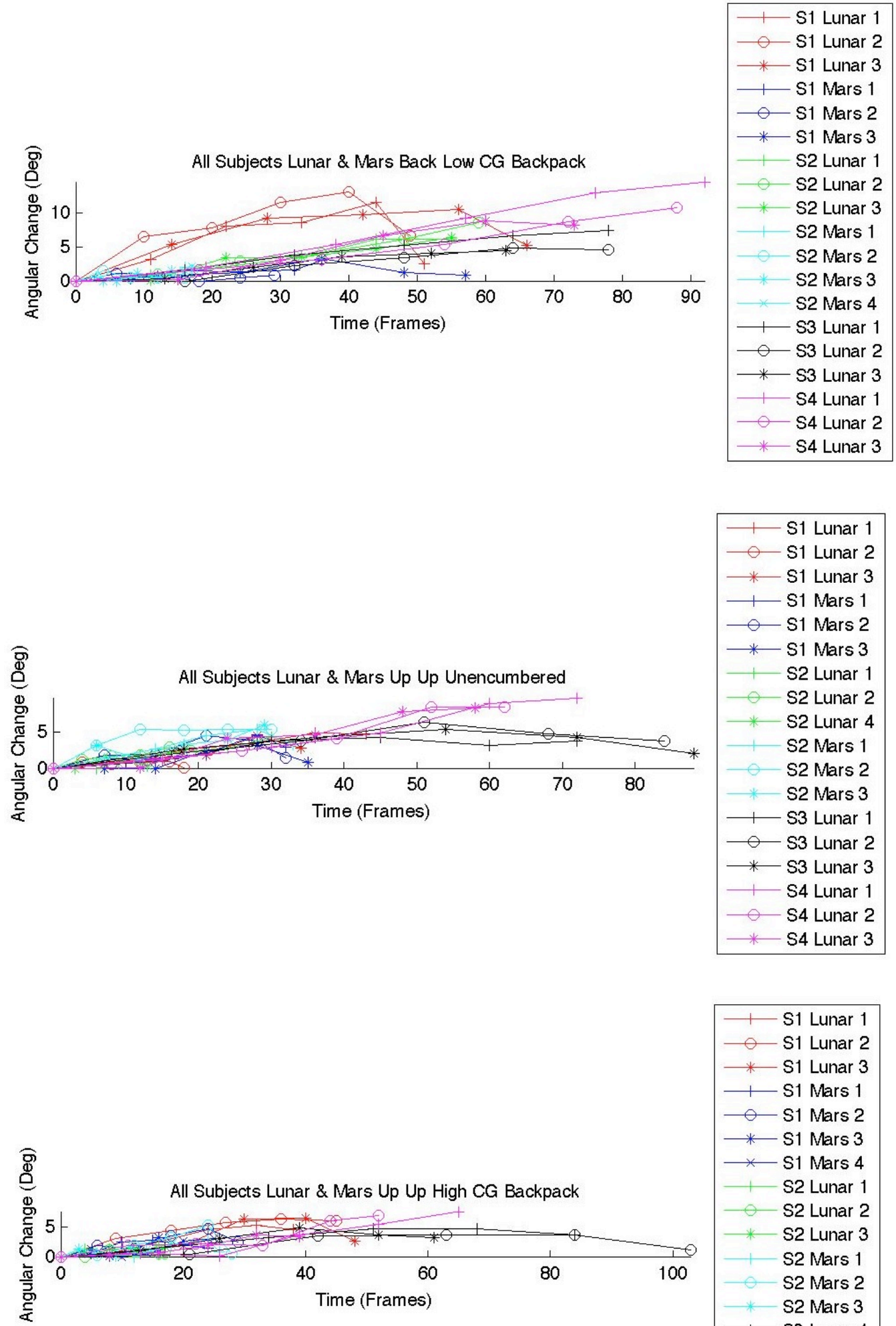

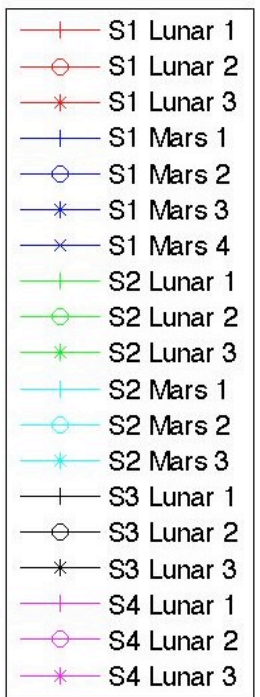



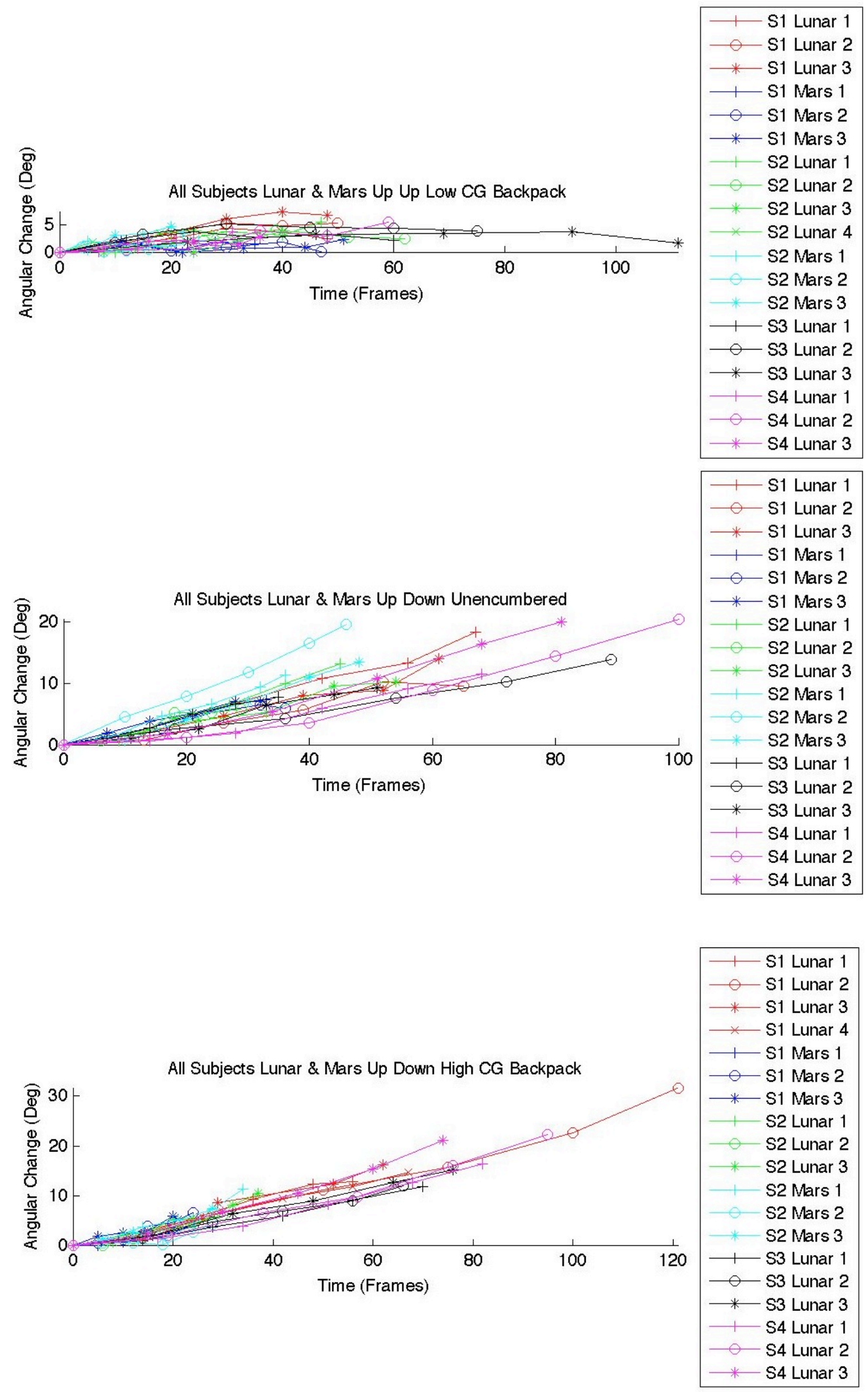

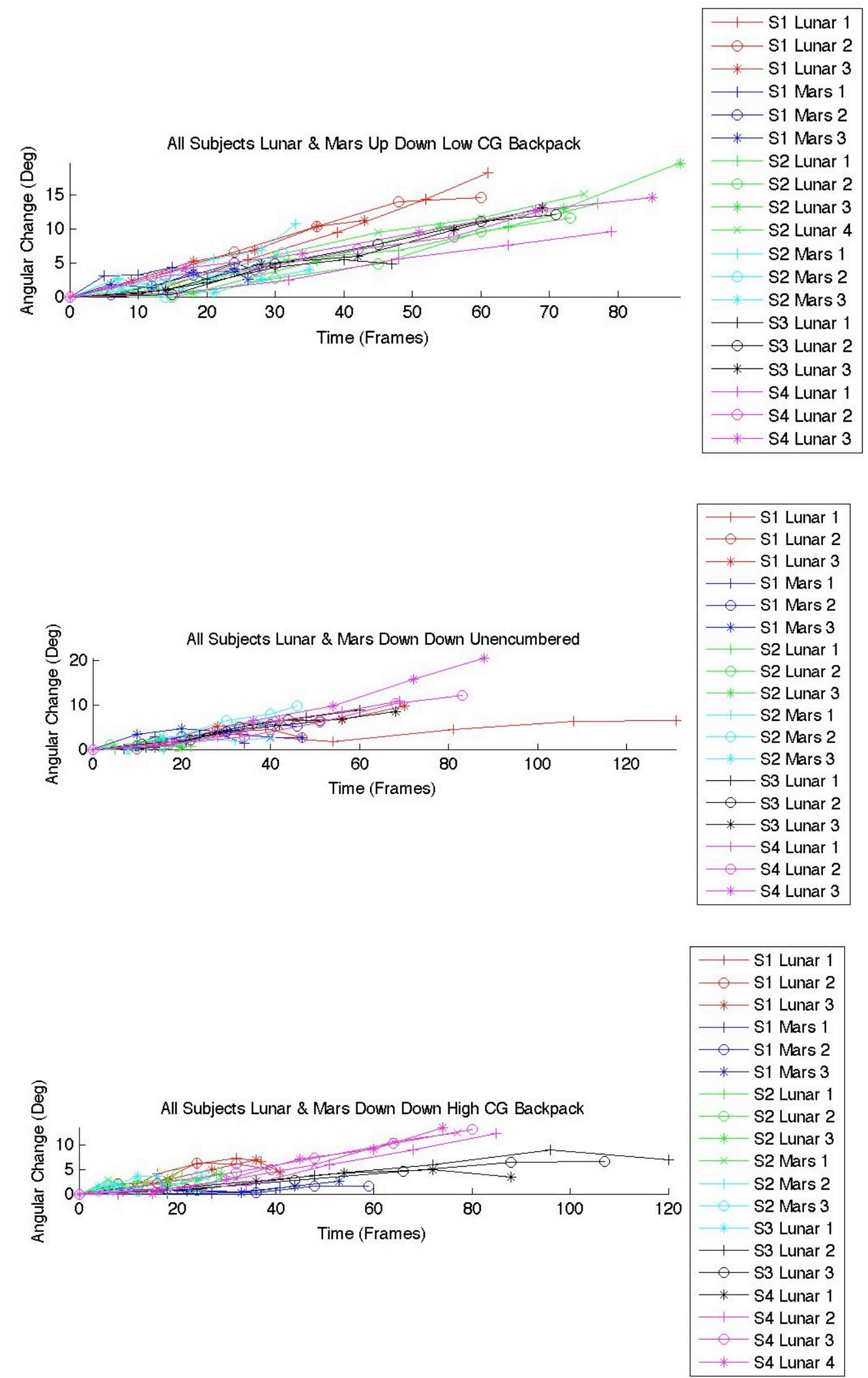

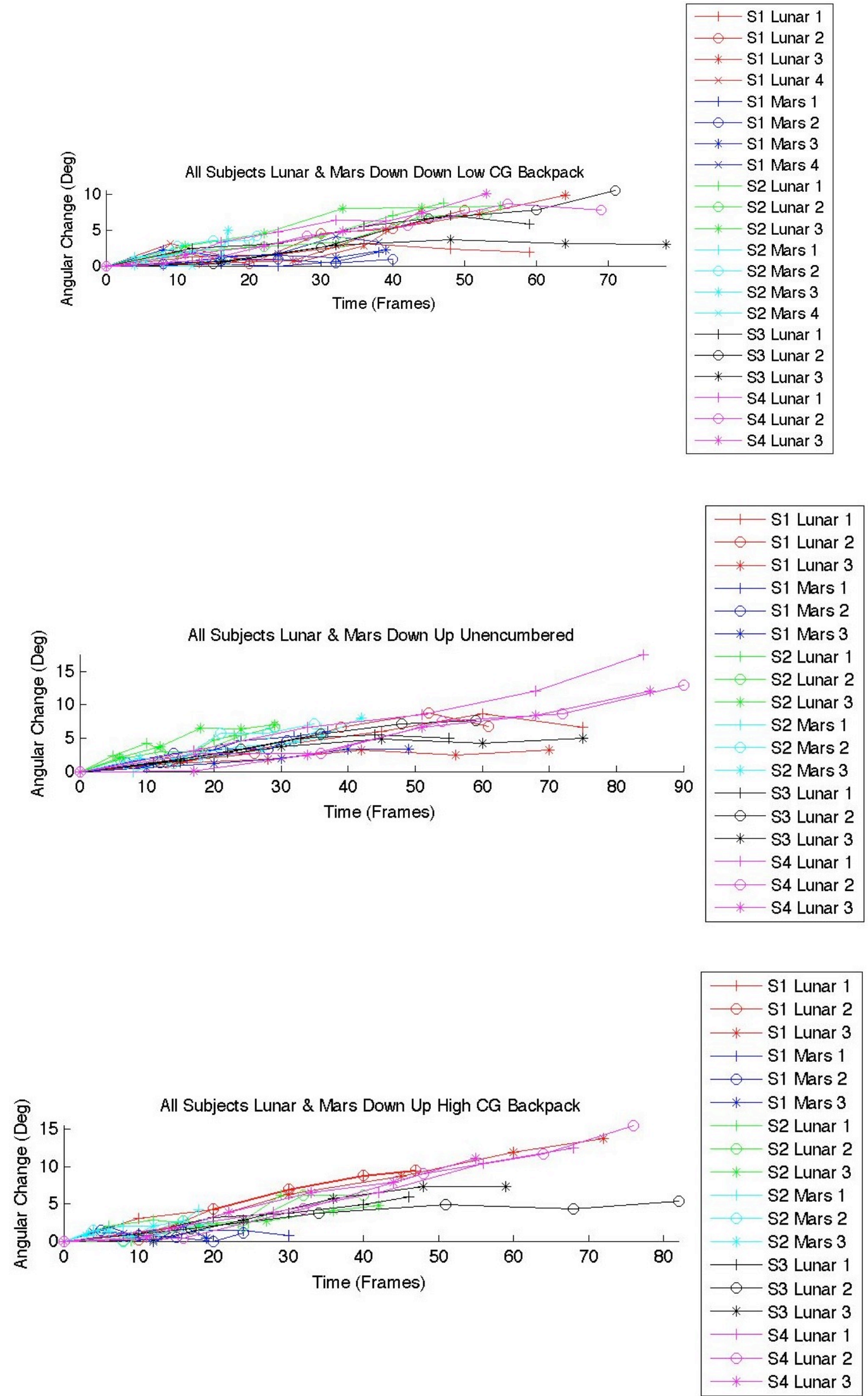


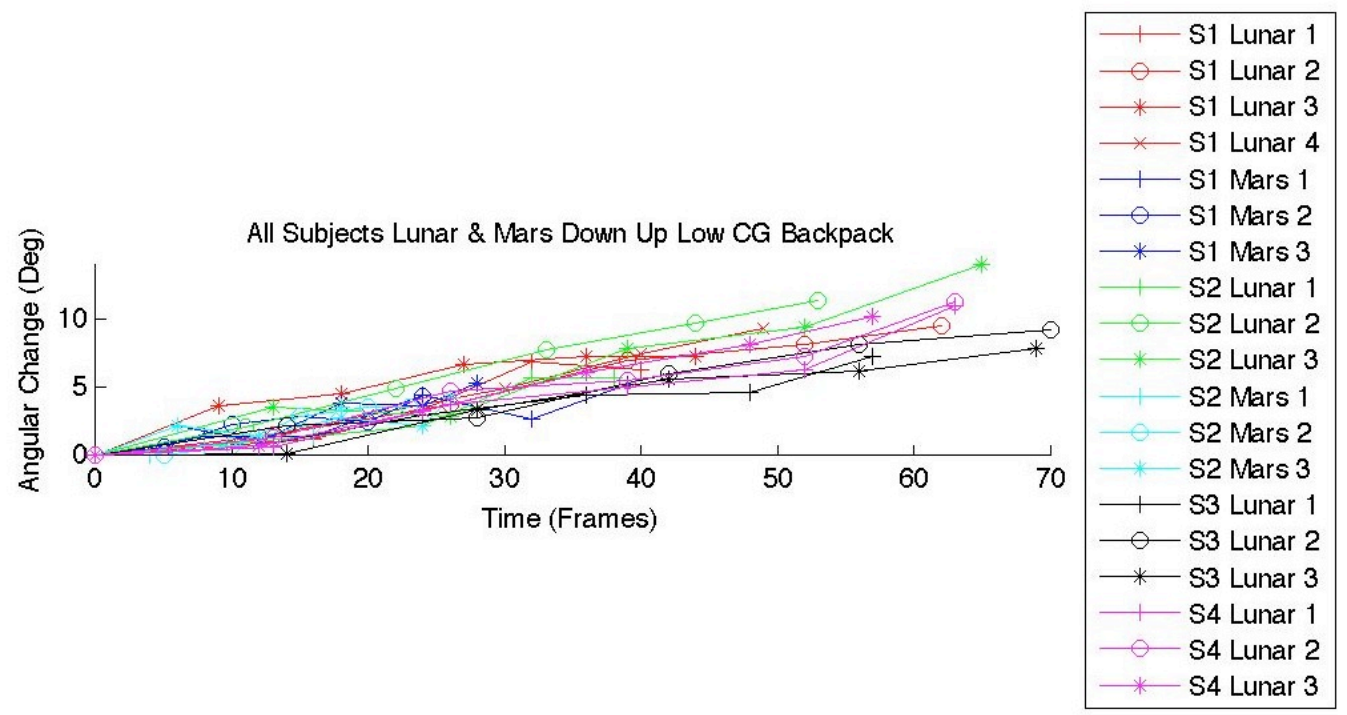

All backpack loading conditions are shown on each graph for Subject 1. Graphs show the angular change at each point in the trial. Graphs are separated by subject orientation and gravity level.
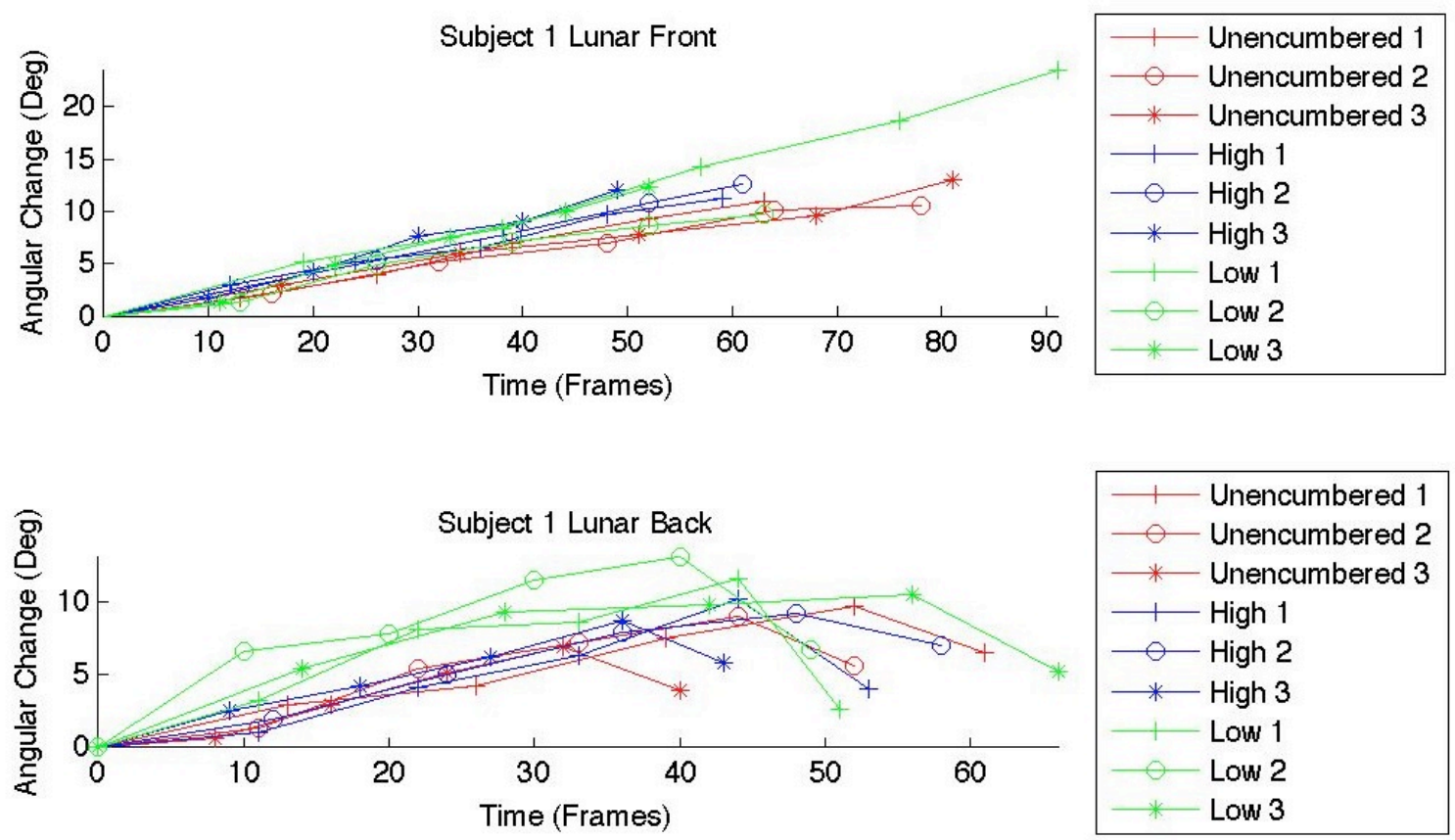


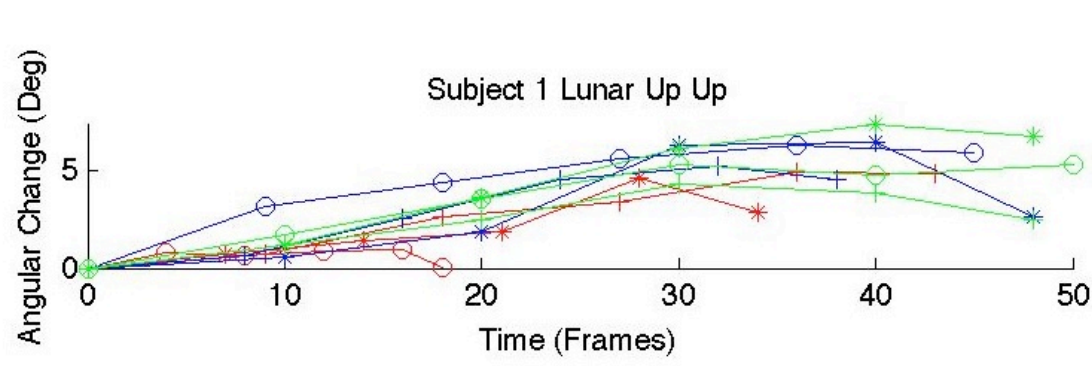

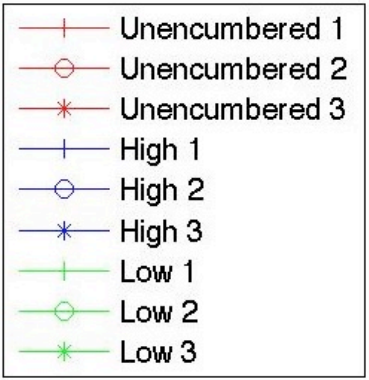

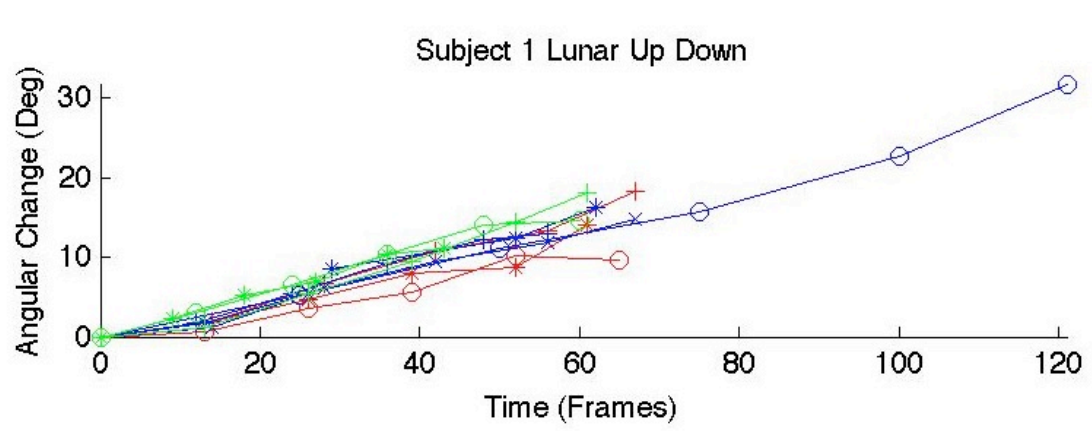

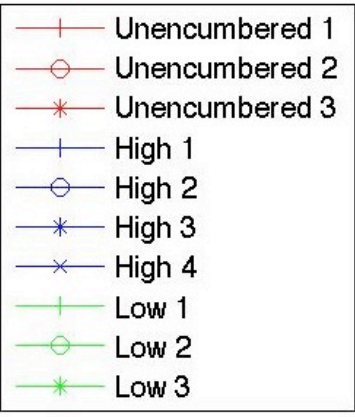
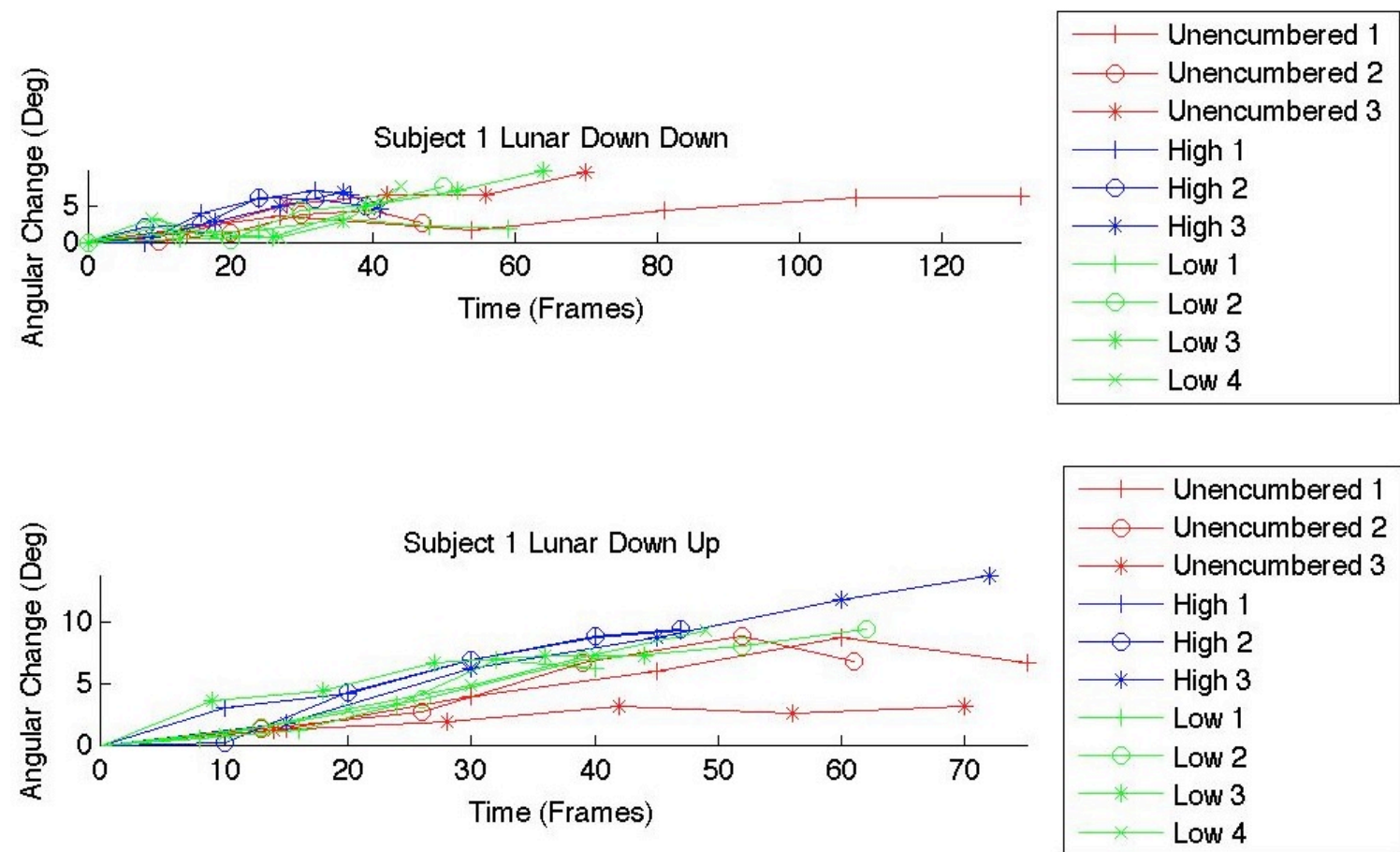

\begin{tabular}{|c|c|}
\hline 1 & Unencumbered 1 \\
\hline+ & Unencumbered 2 \\
\hline+ & Unencumbered 3 \\
\hline & High 1 \\
- & High 2 \\
$*$ & High 3 \\
Low 1 \\
Low 2 \\
Low 3 \\
Low 4
\end{tabular}




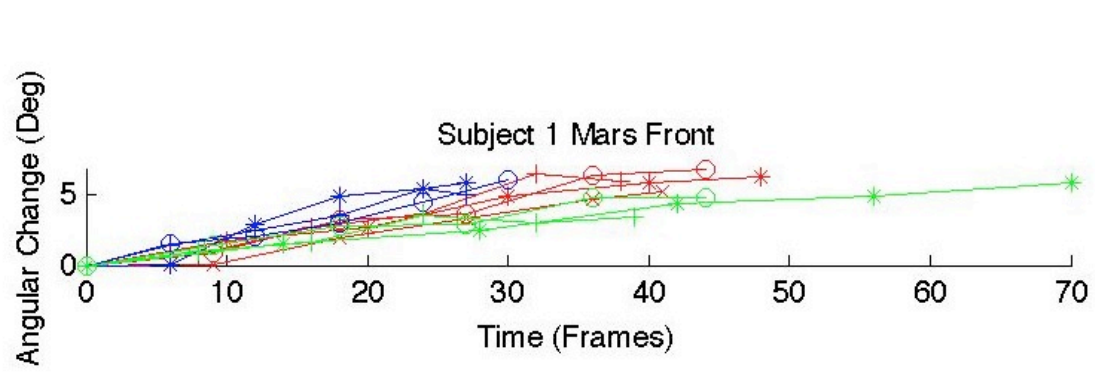

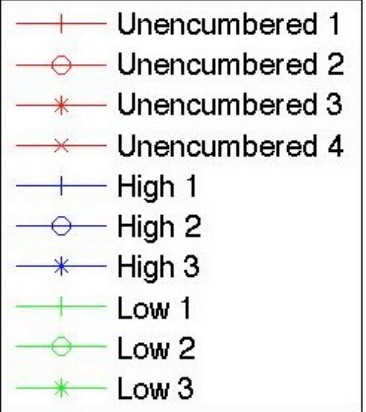

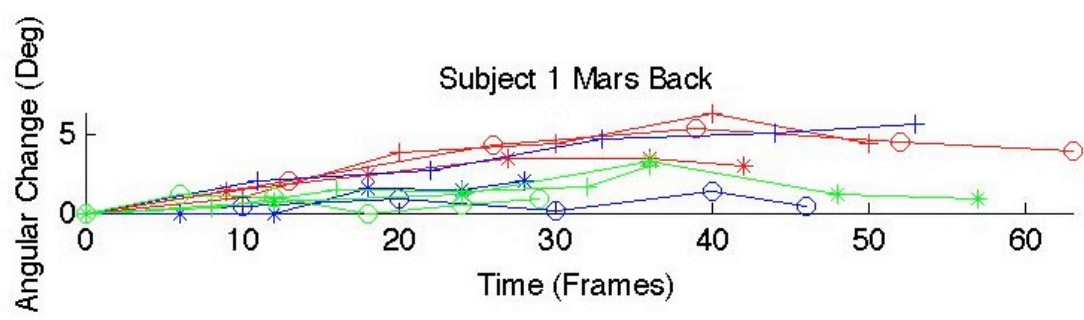

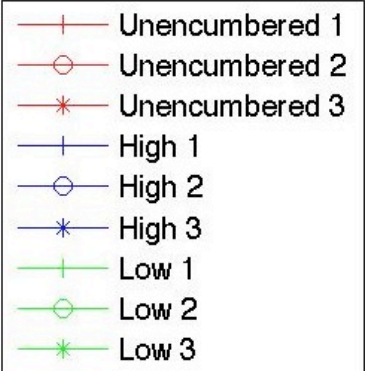

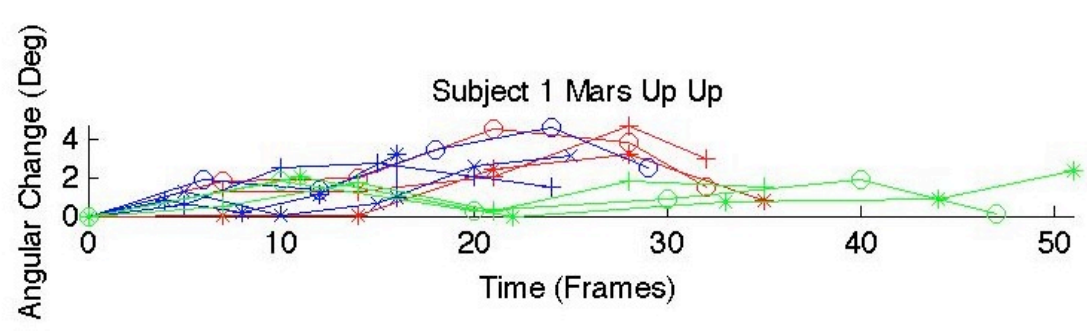

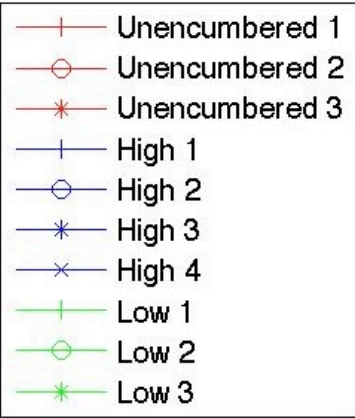

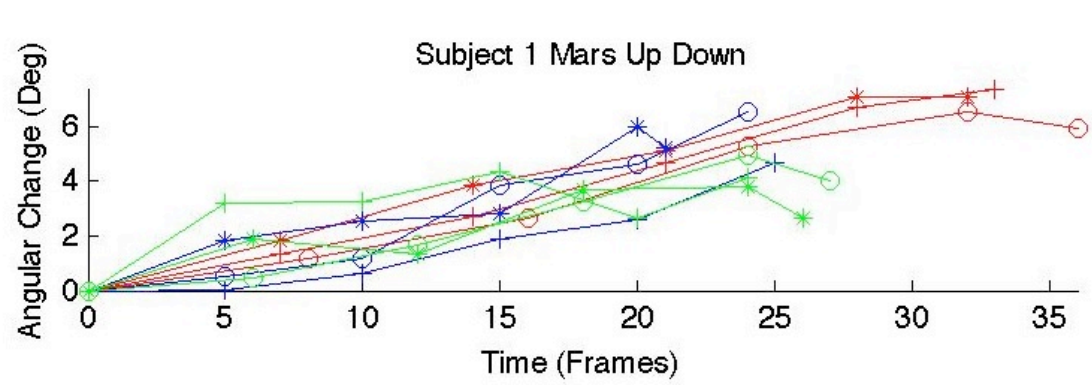

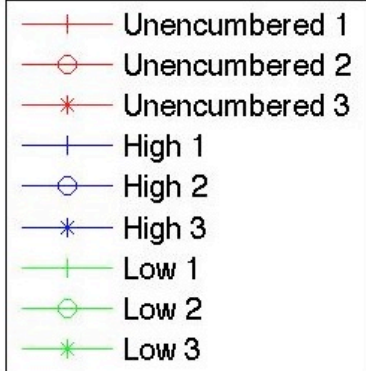



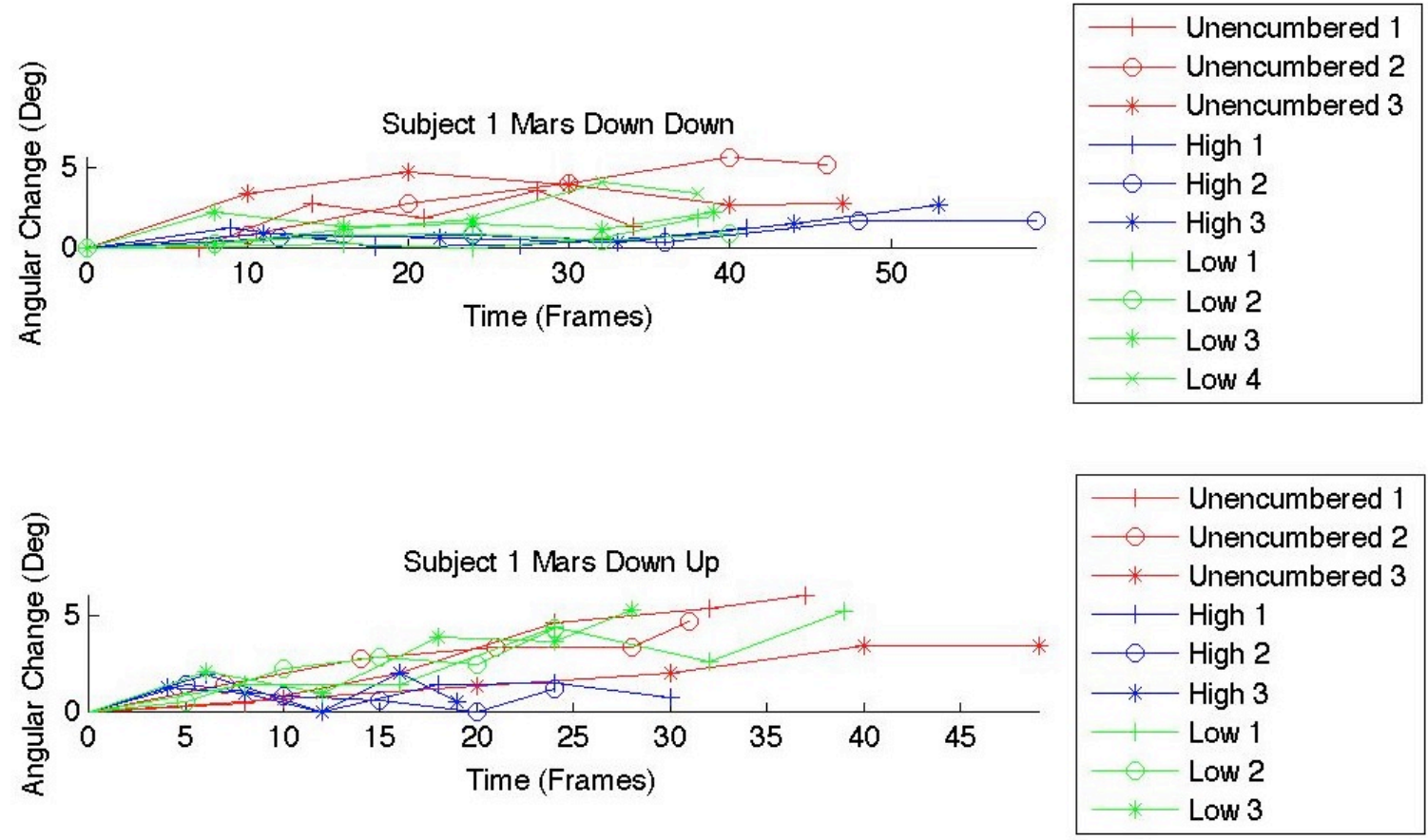

Both Lunar and Martian gravity levels are shown on each graph for Subject 1. Graphs show the angular change at each point in the trial. Graphs are separated by subject orientation and backpack loading.
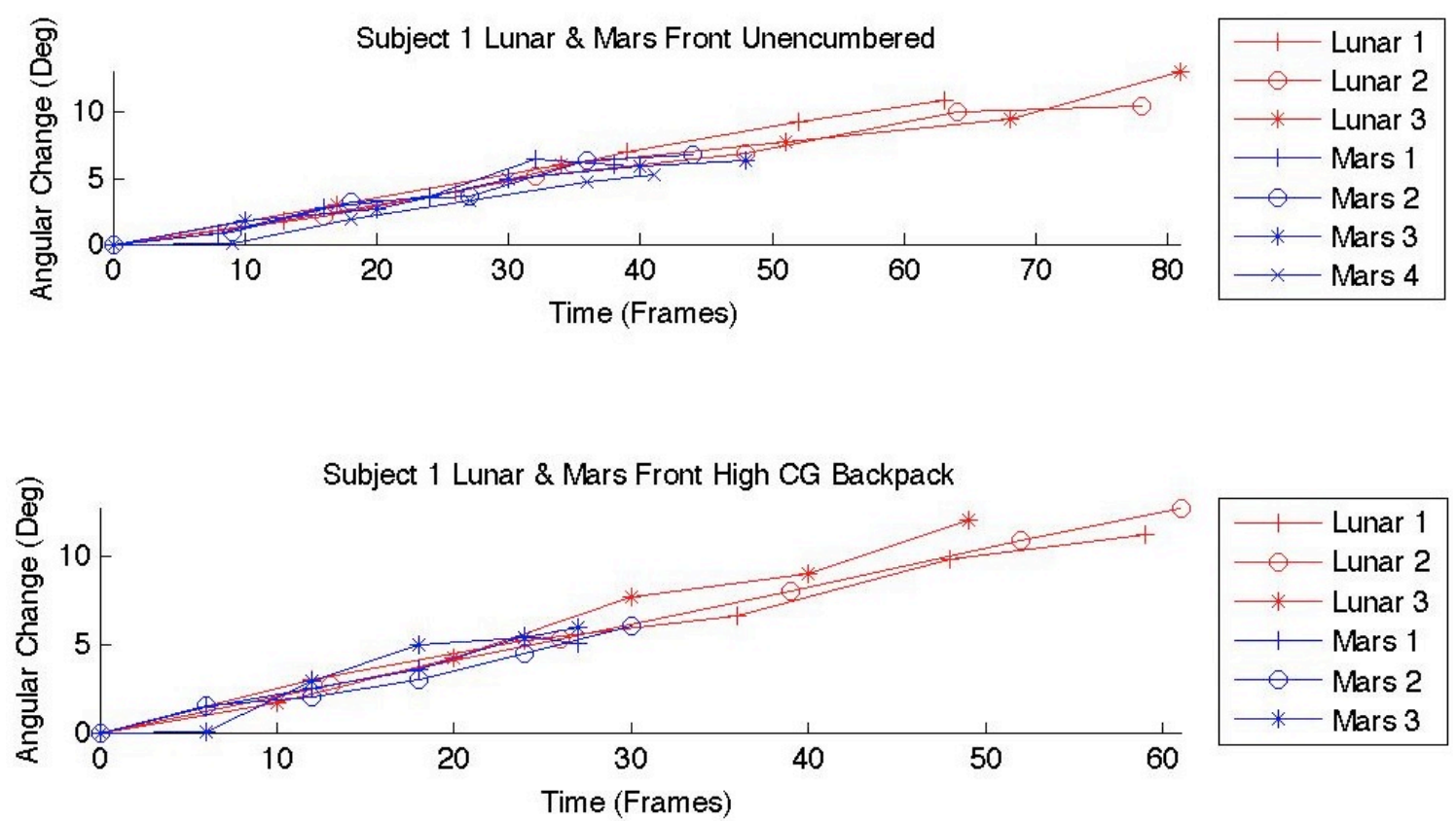
Subject 1 Lunar \& Mars Front Low CG Backpack
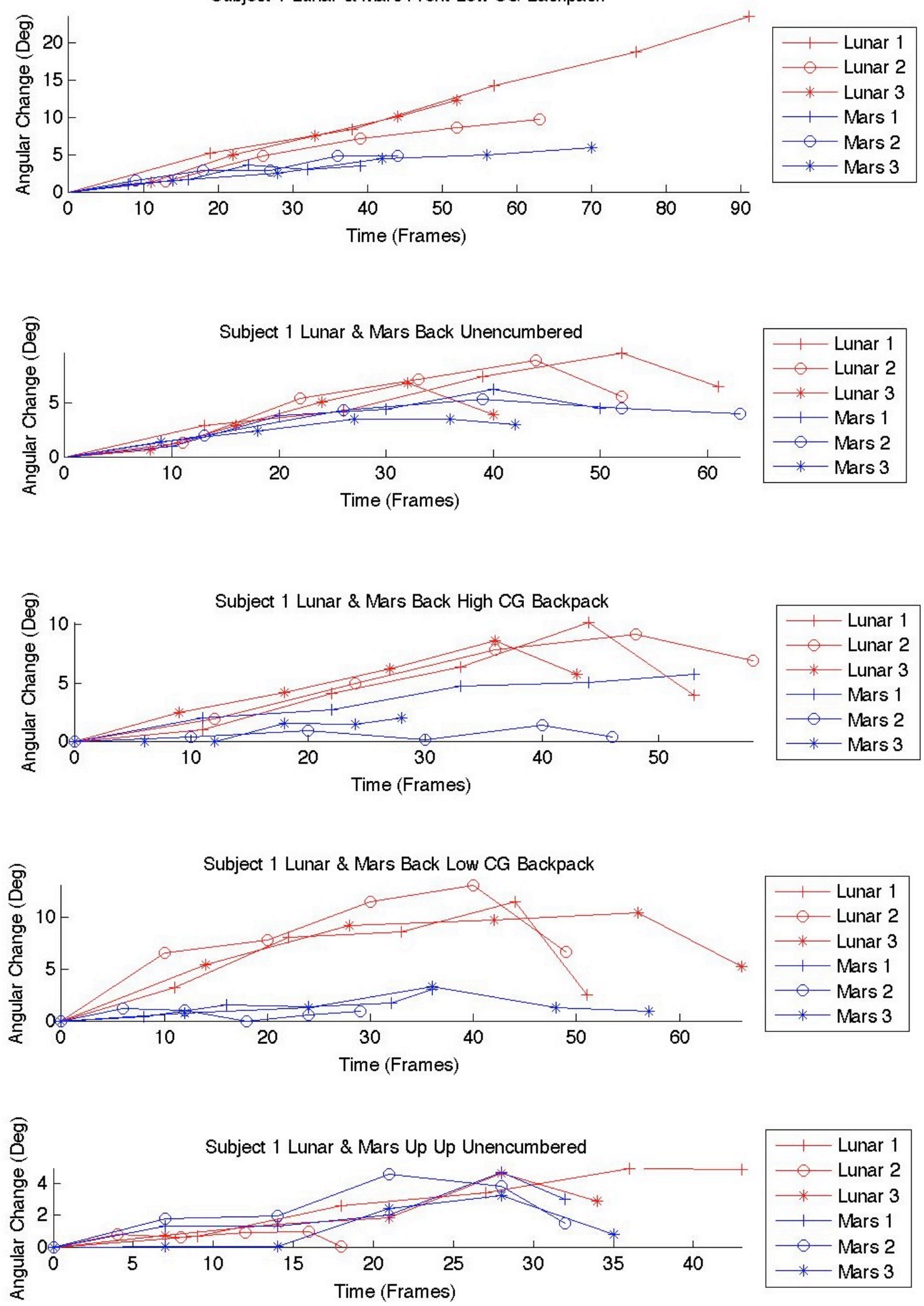

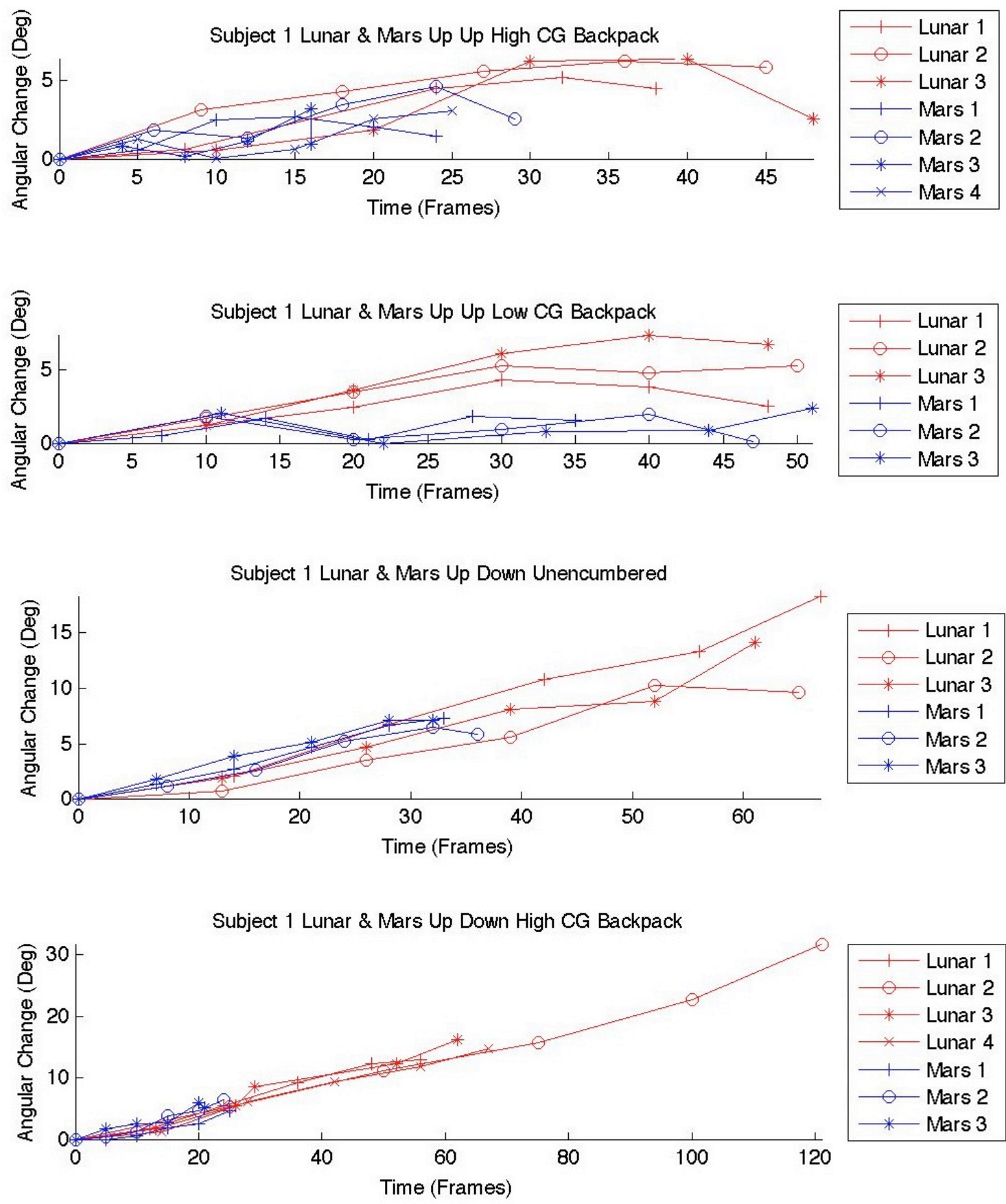

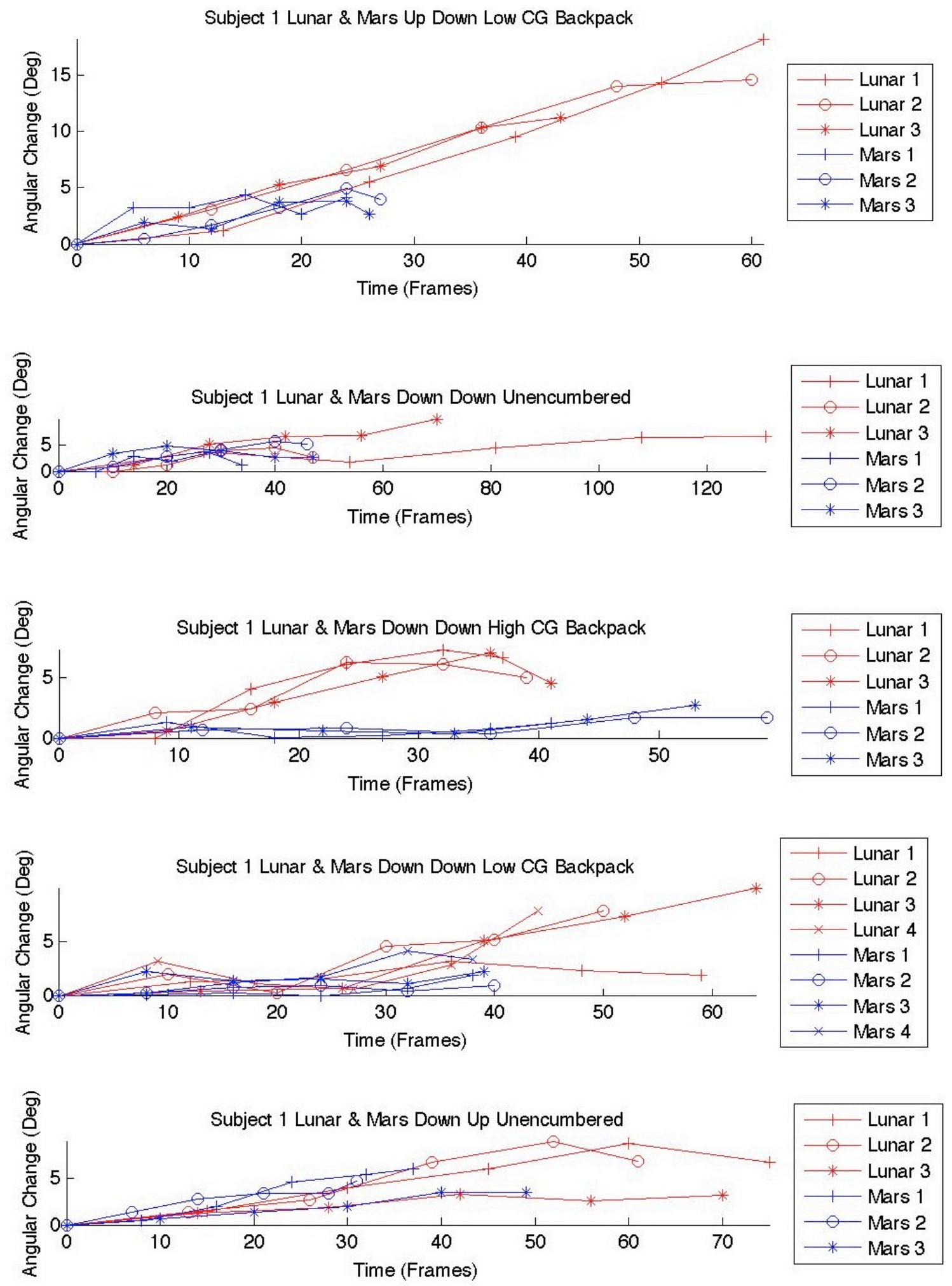

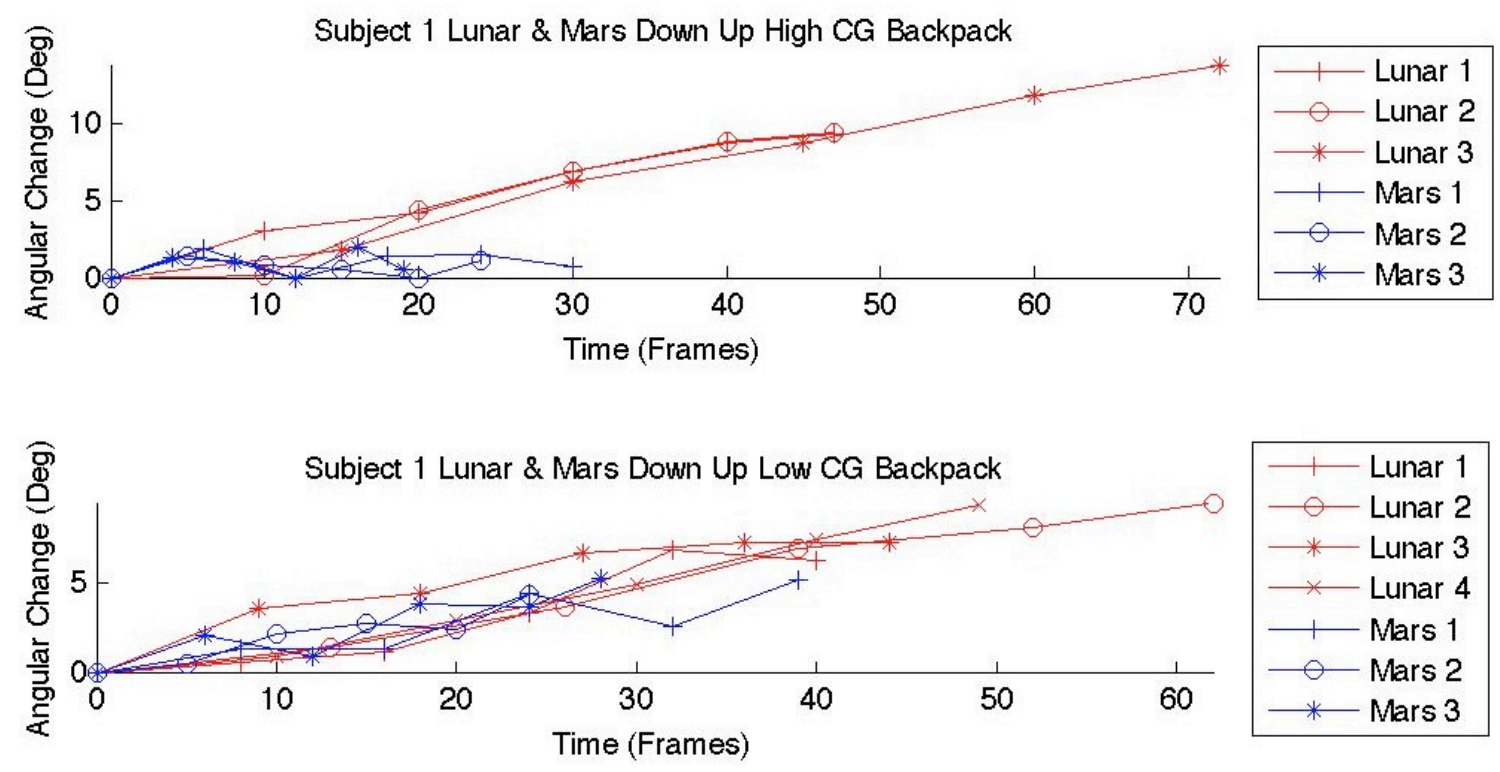

All backpack loading conditions are shown on each graph for Subject 2. Graphs show the angular change at each point in the trial. Graphs are separated by subject orientation and gravity level.
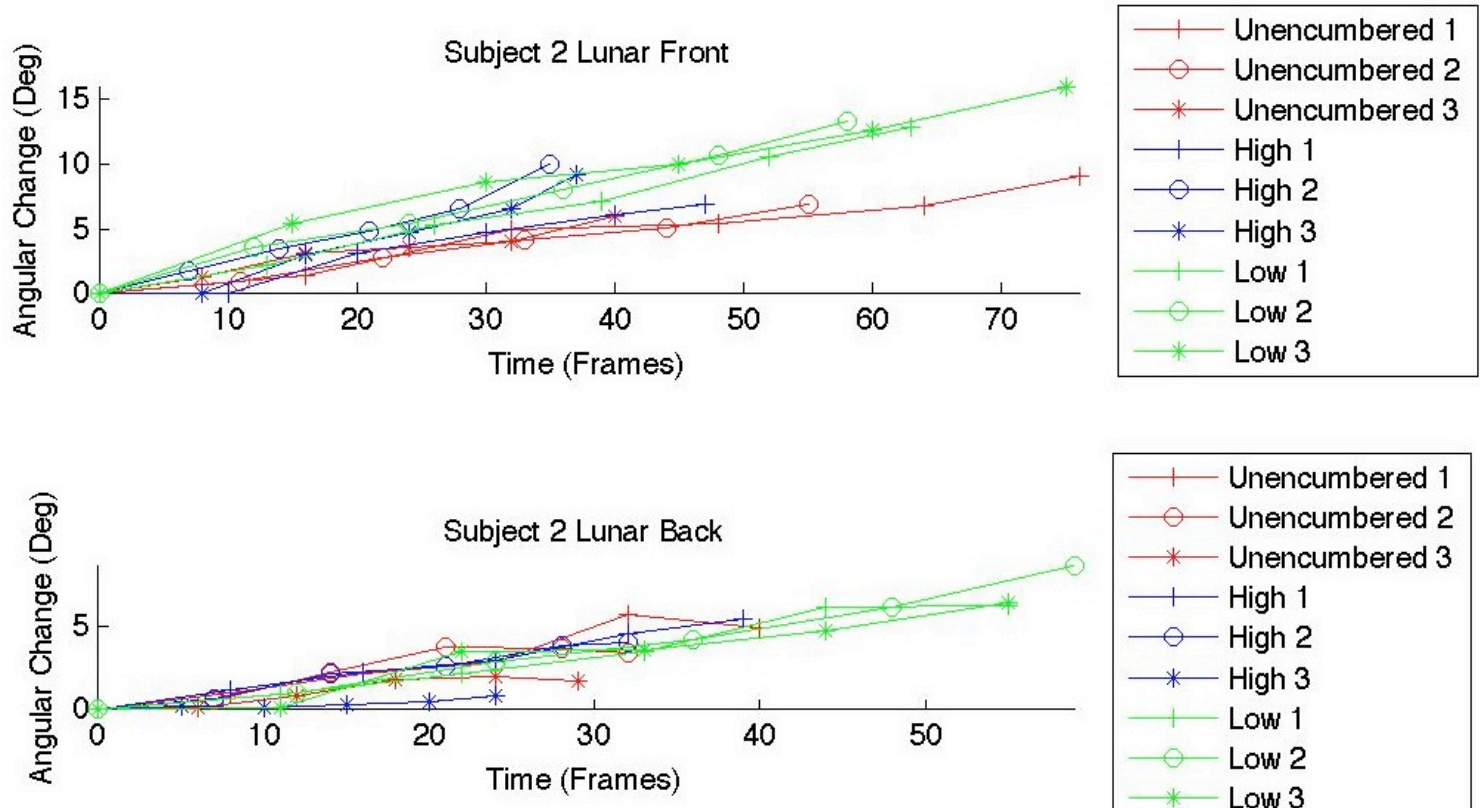

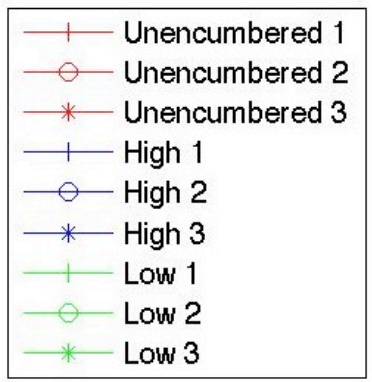




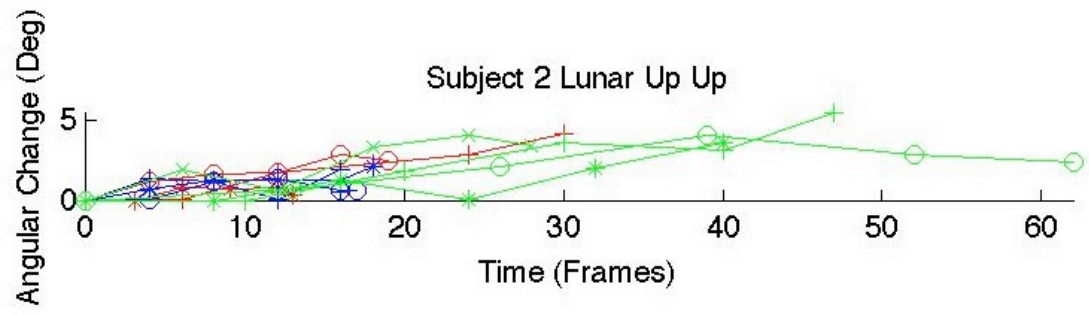

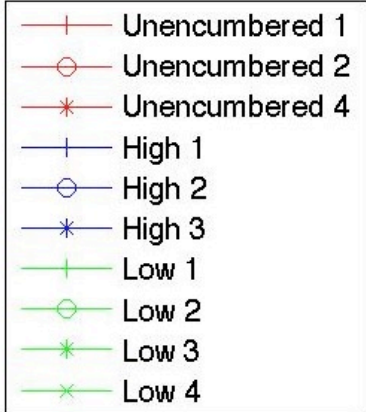
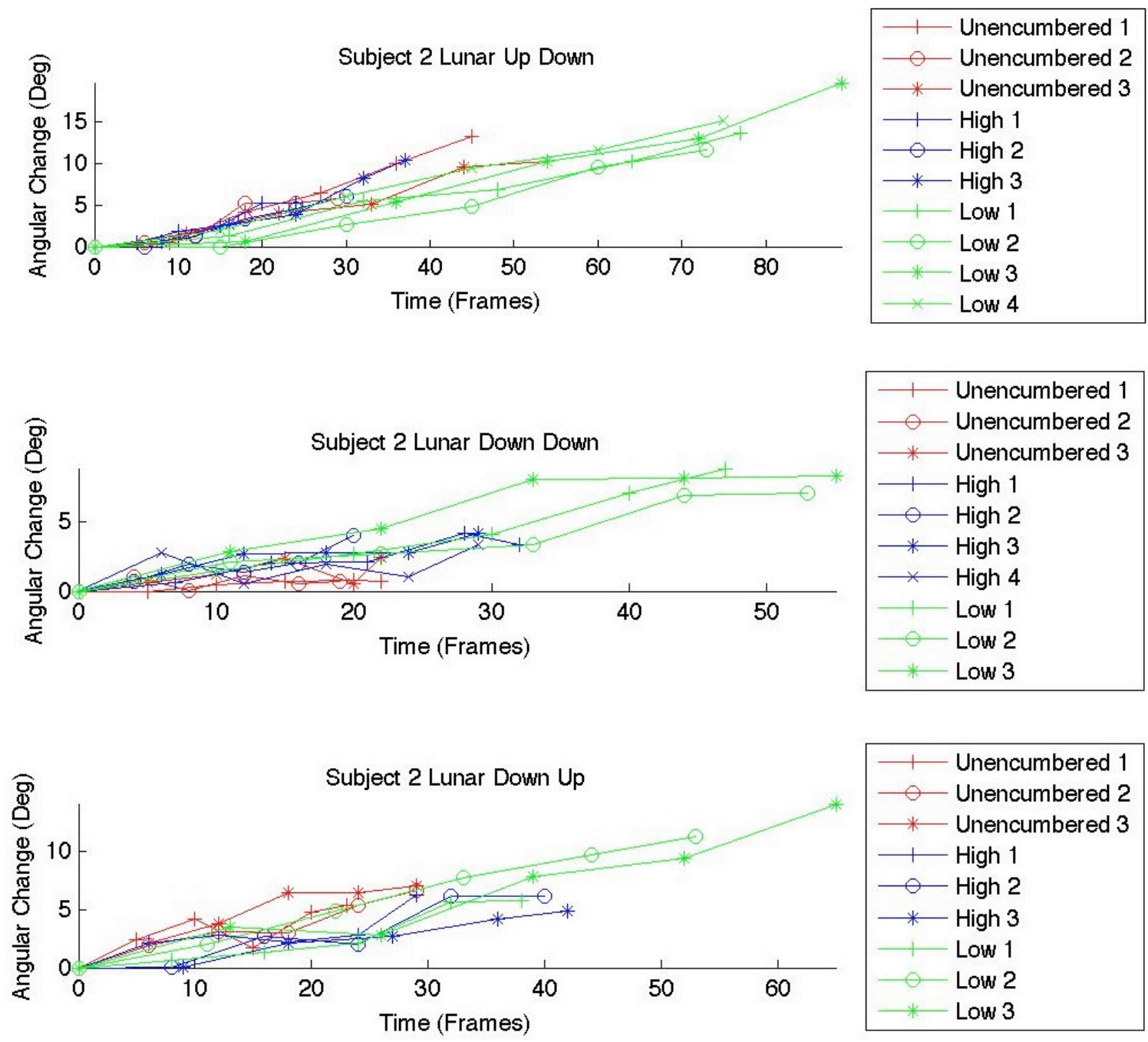

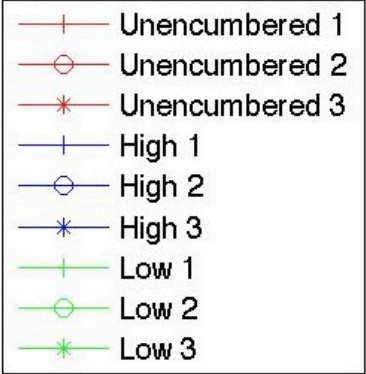



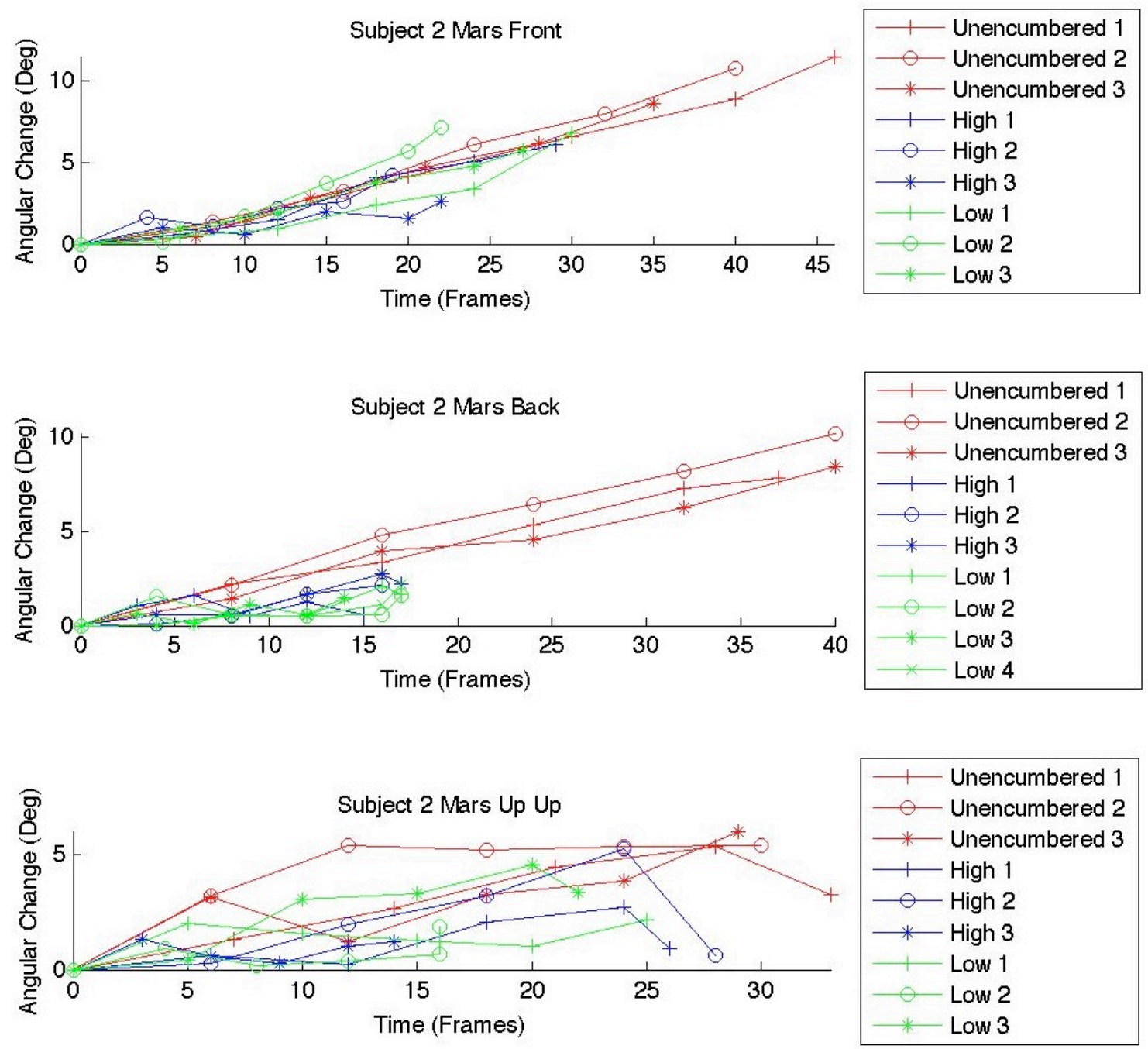

Subject 2 Mars Up Down

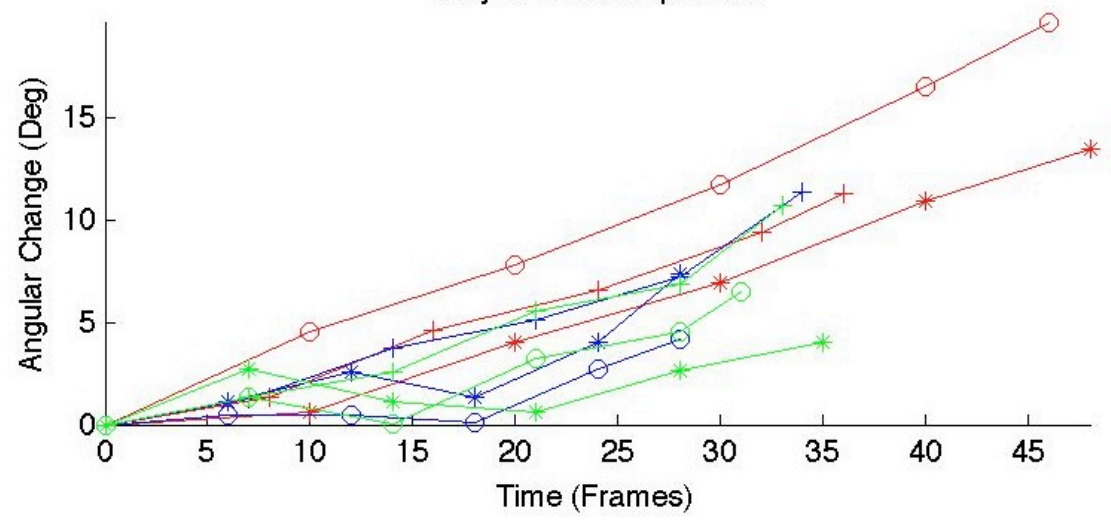

\begin{tabular}{|c|}
\hline 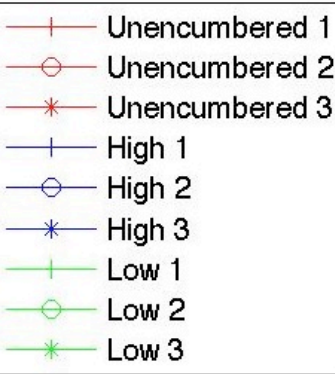 \\
\hline
\end{tabular}



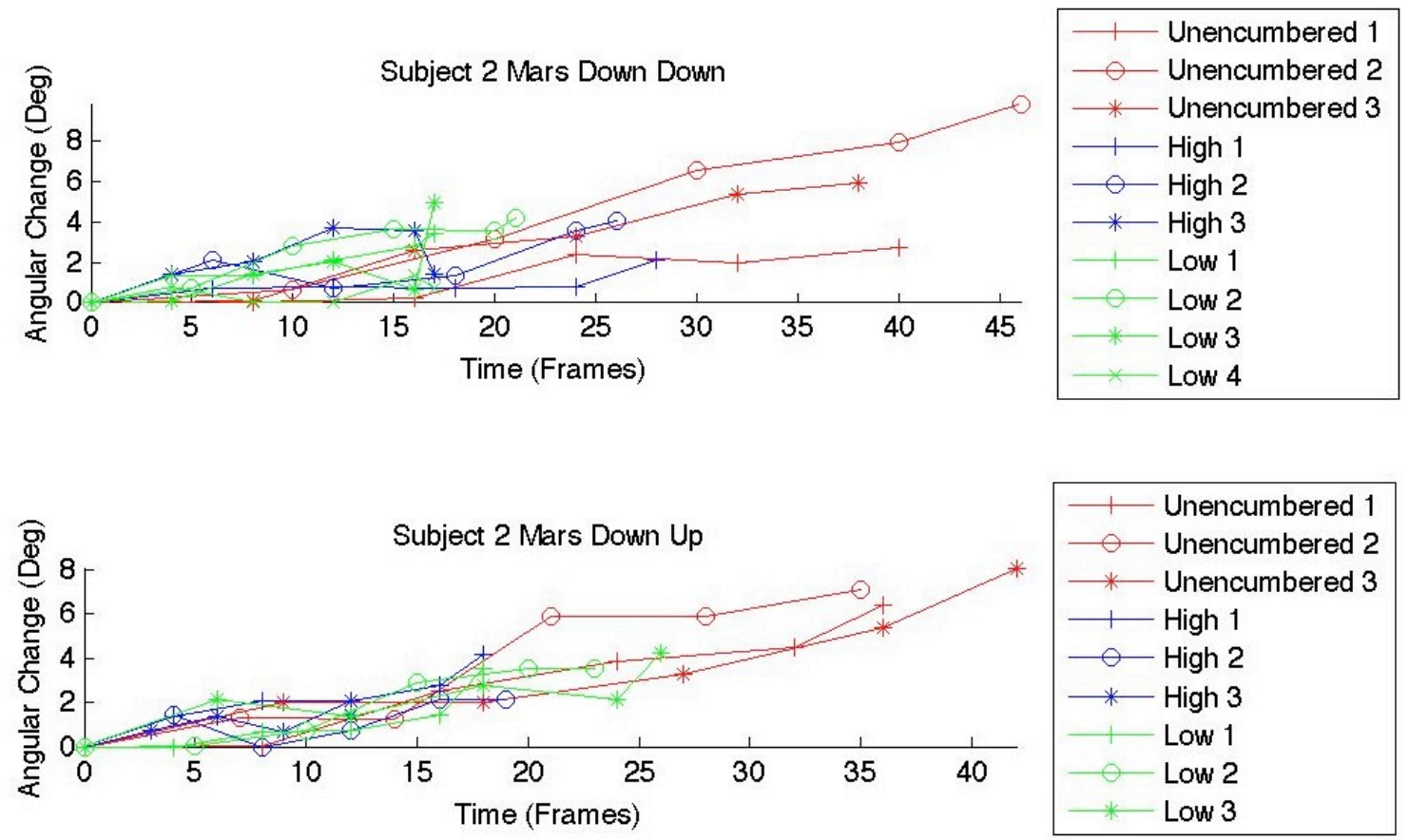

Both Lunar and Martian gravity levels are shown on each graph for Subject 2. Graphs show the angular change at each point in the trial. Graphs are separated by subject orientation and backpack loading.
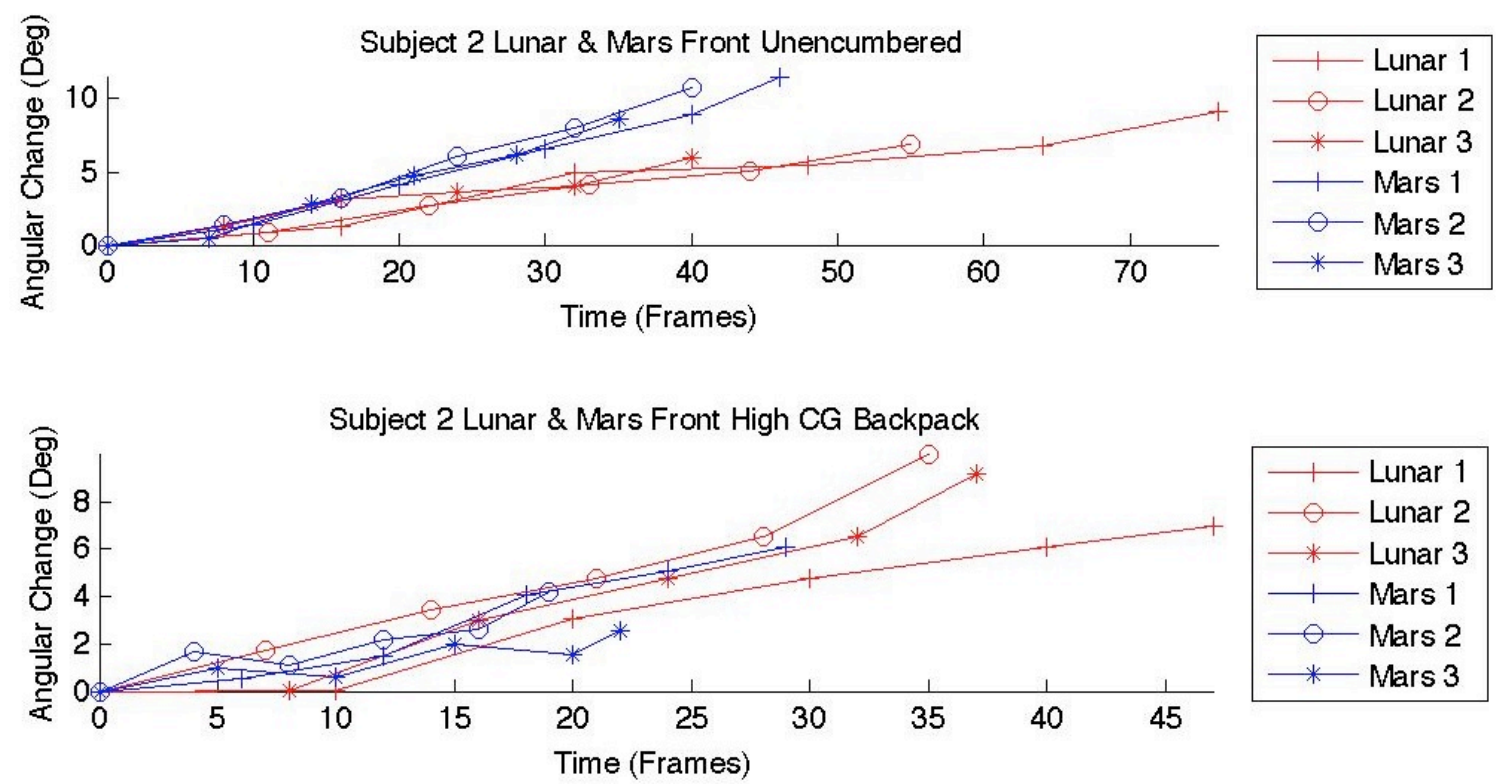

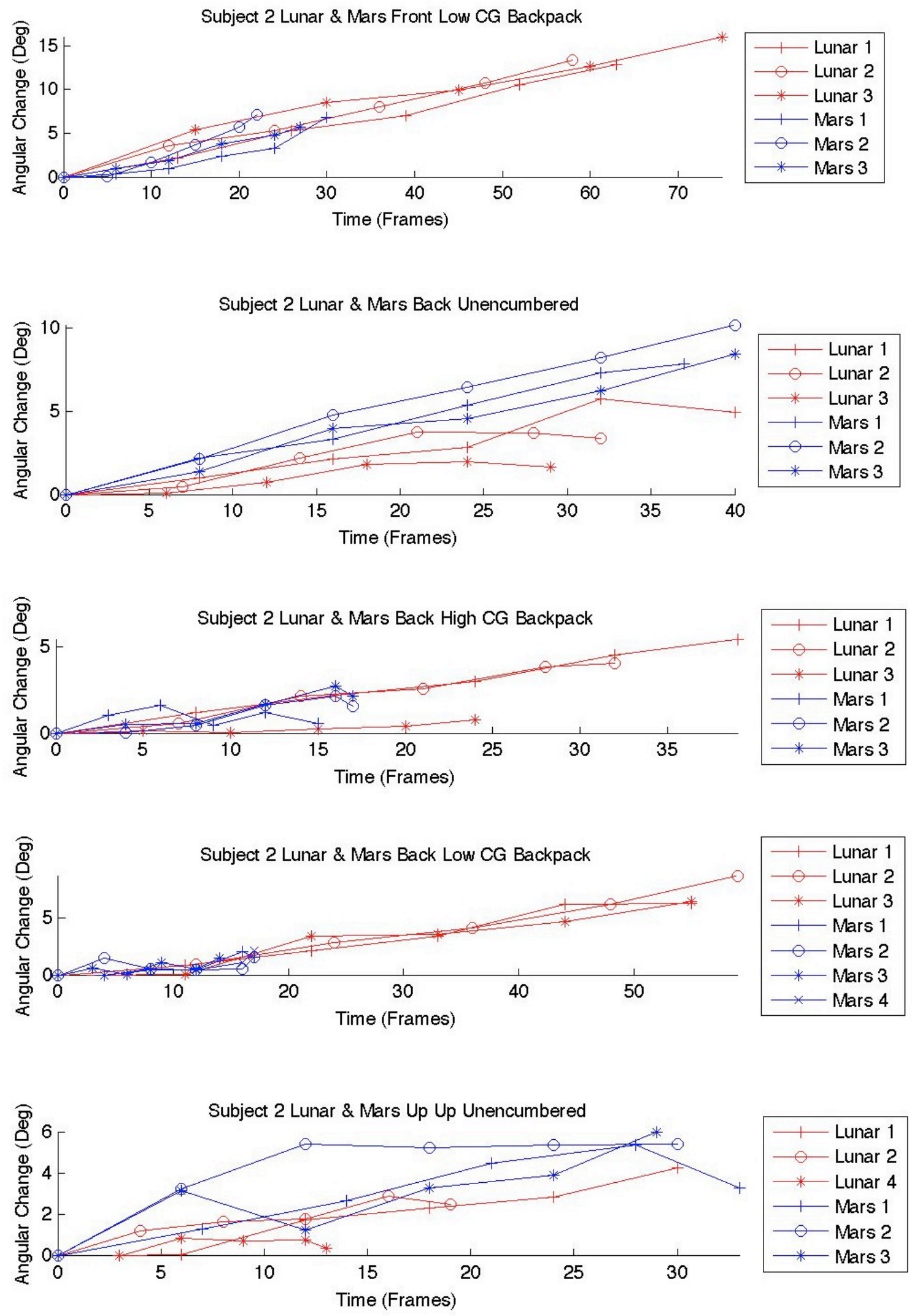

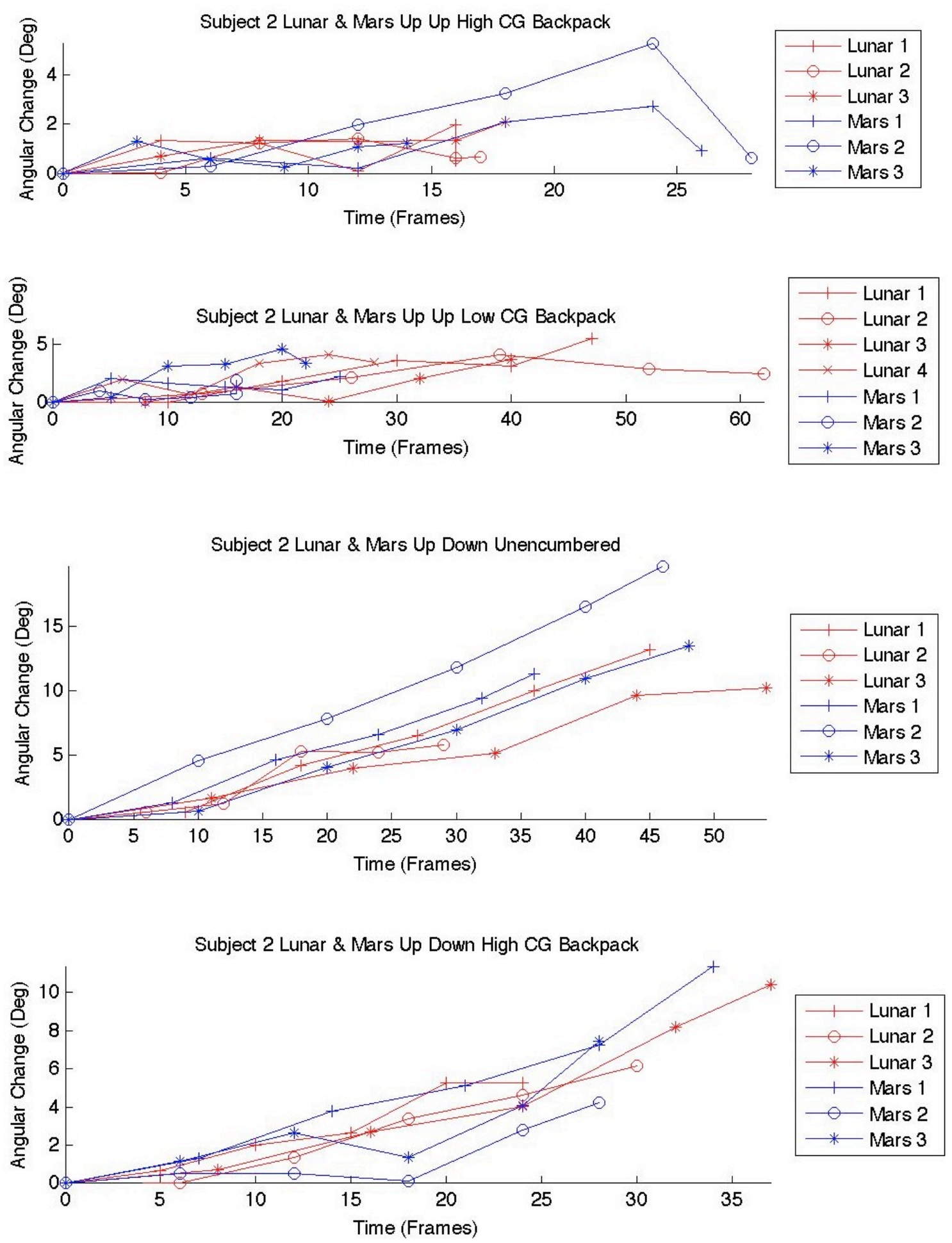

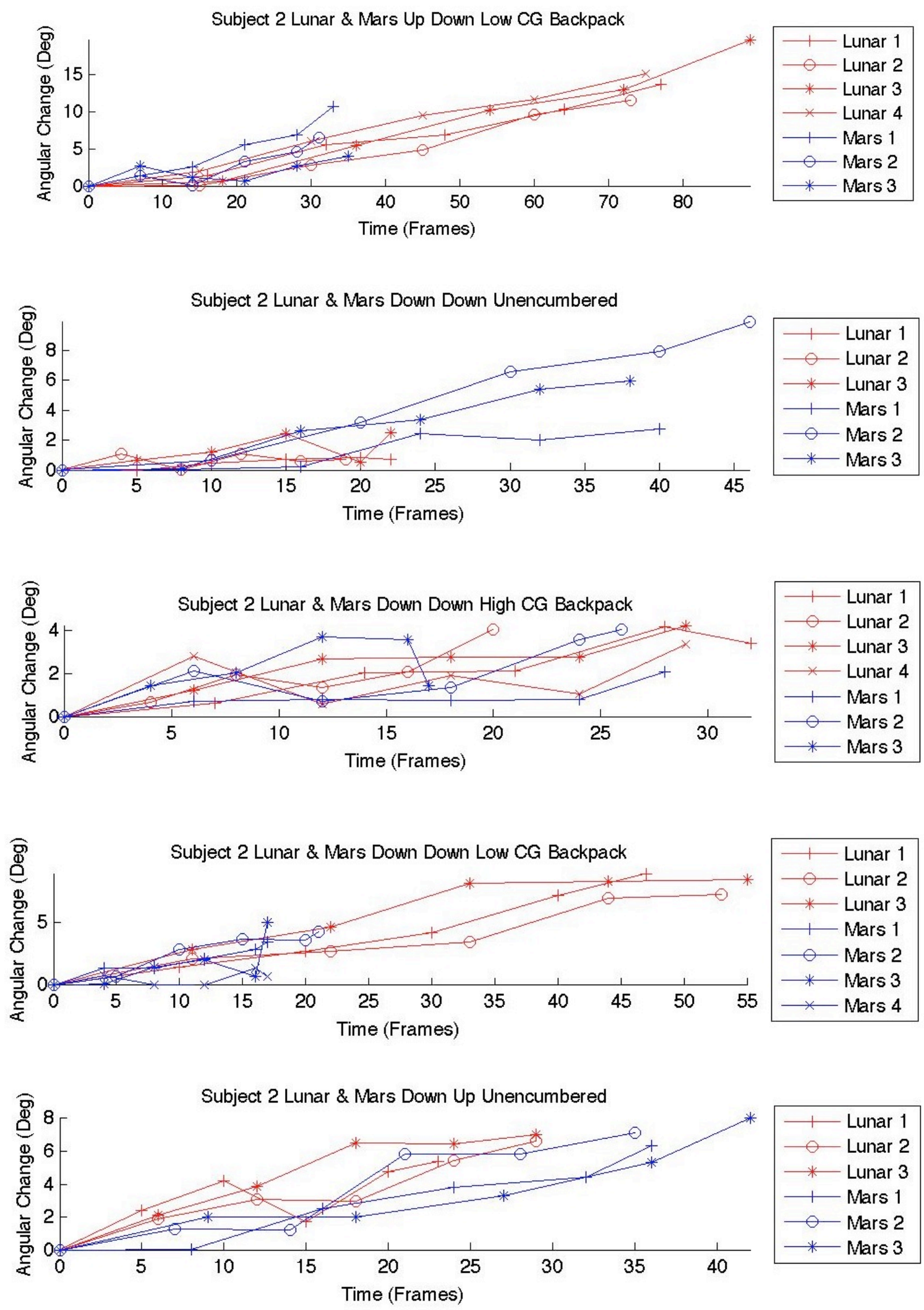

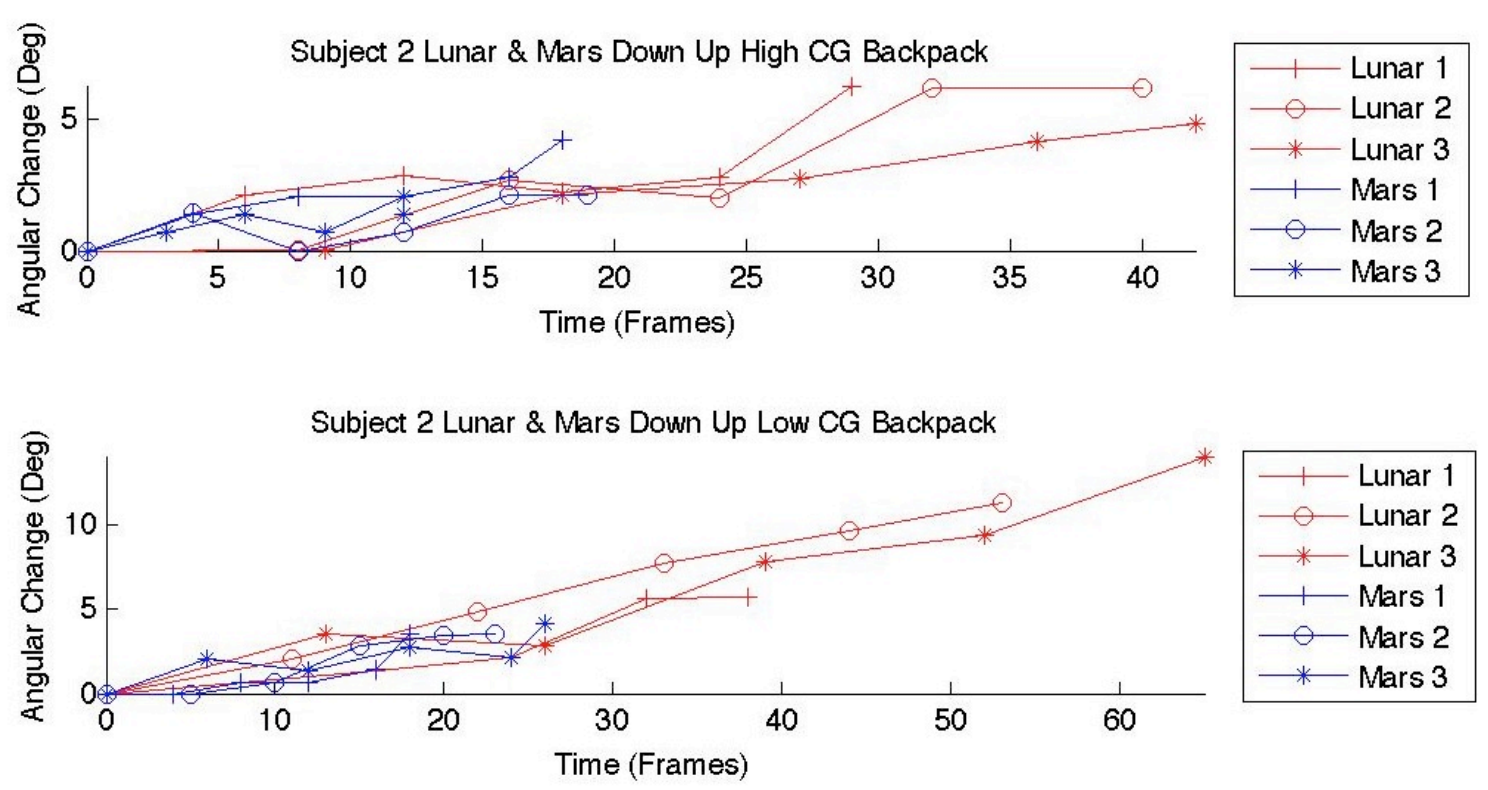

All backpack loading conditions are shown on each graph for Subject 3. Graphs show the angular change at each point in the trial. Graphs are separated by subject orientation.
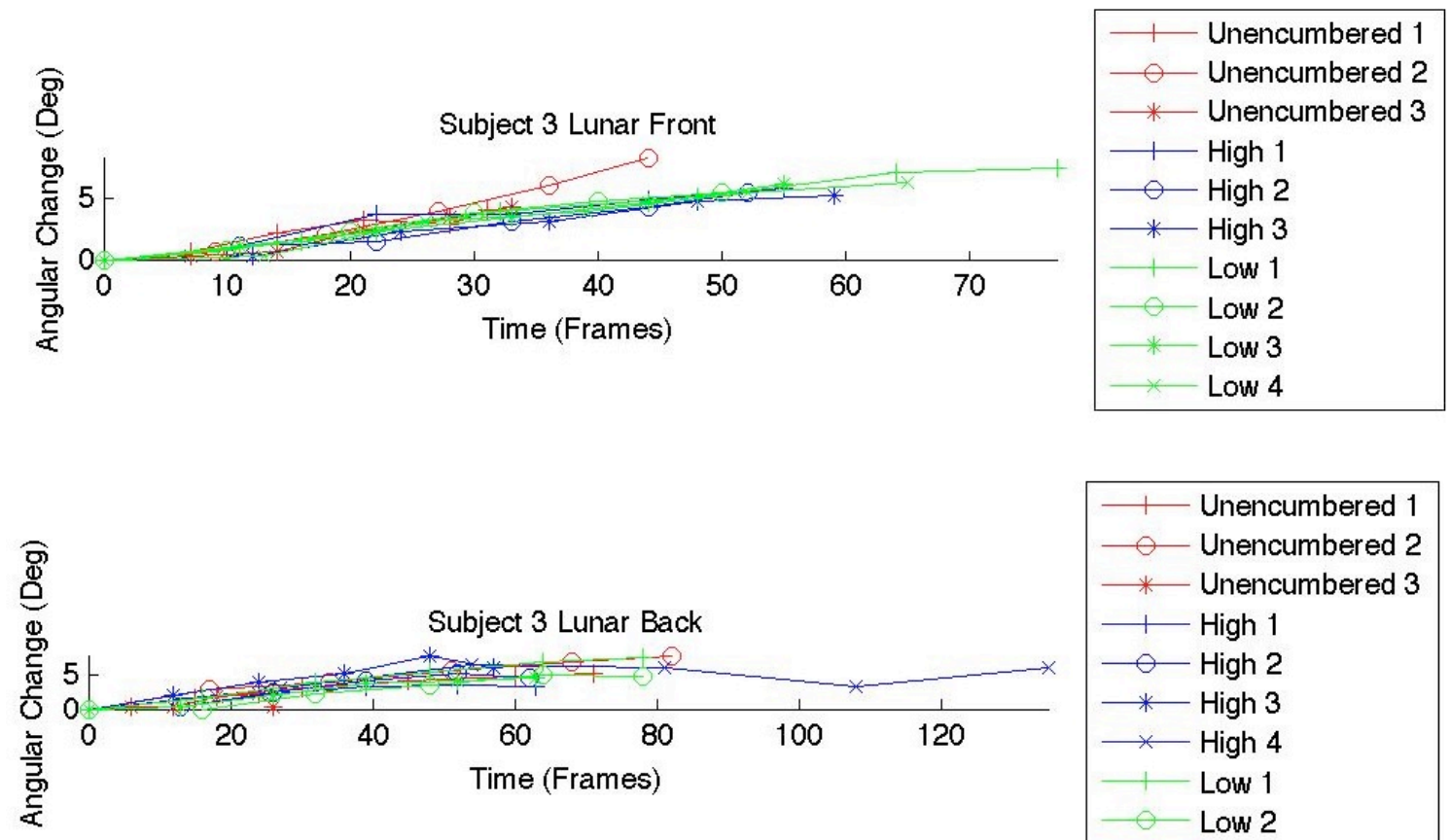

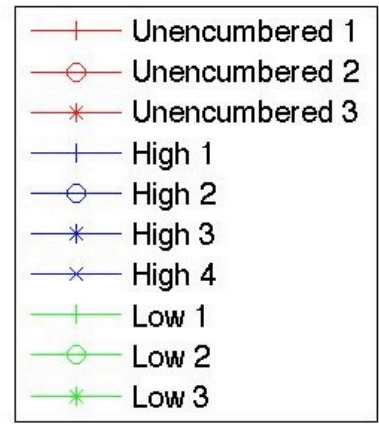



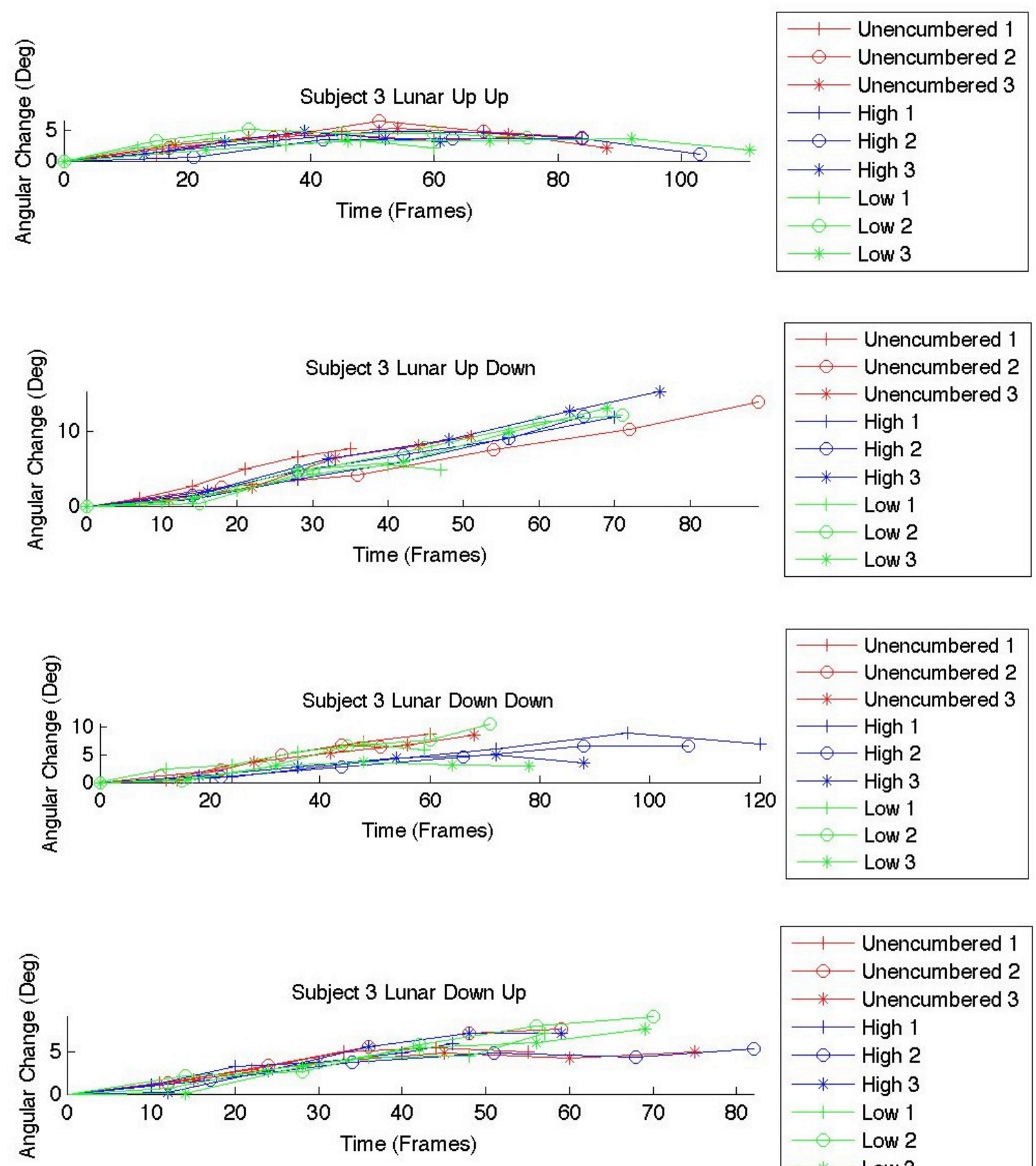

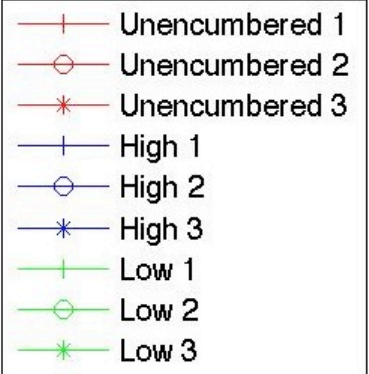


All backpack loading conditions are shown on each graph for Subject 4. Graphs show the angular change at each point in the trial. Graphs are separated by subject orientation.
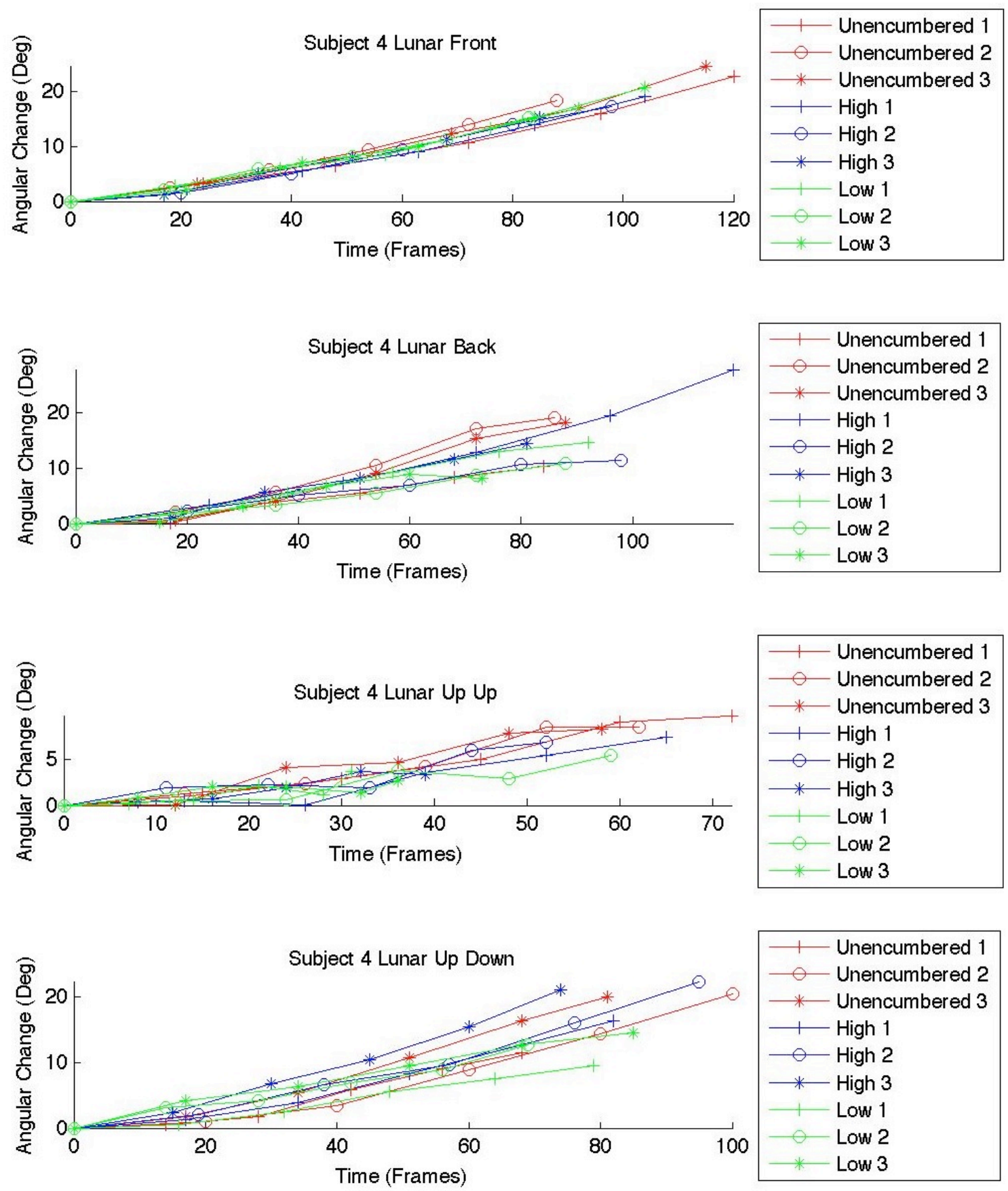

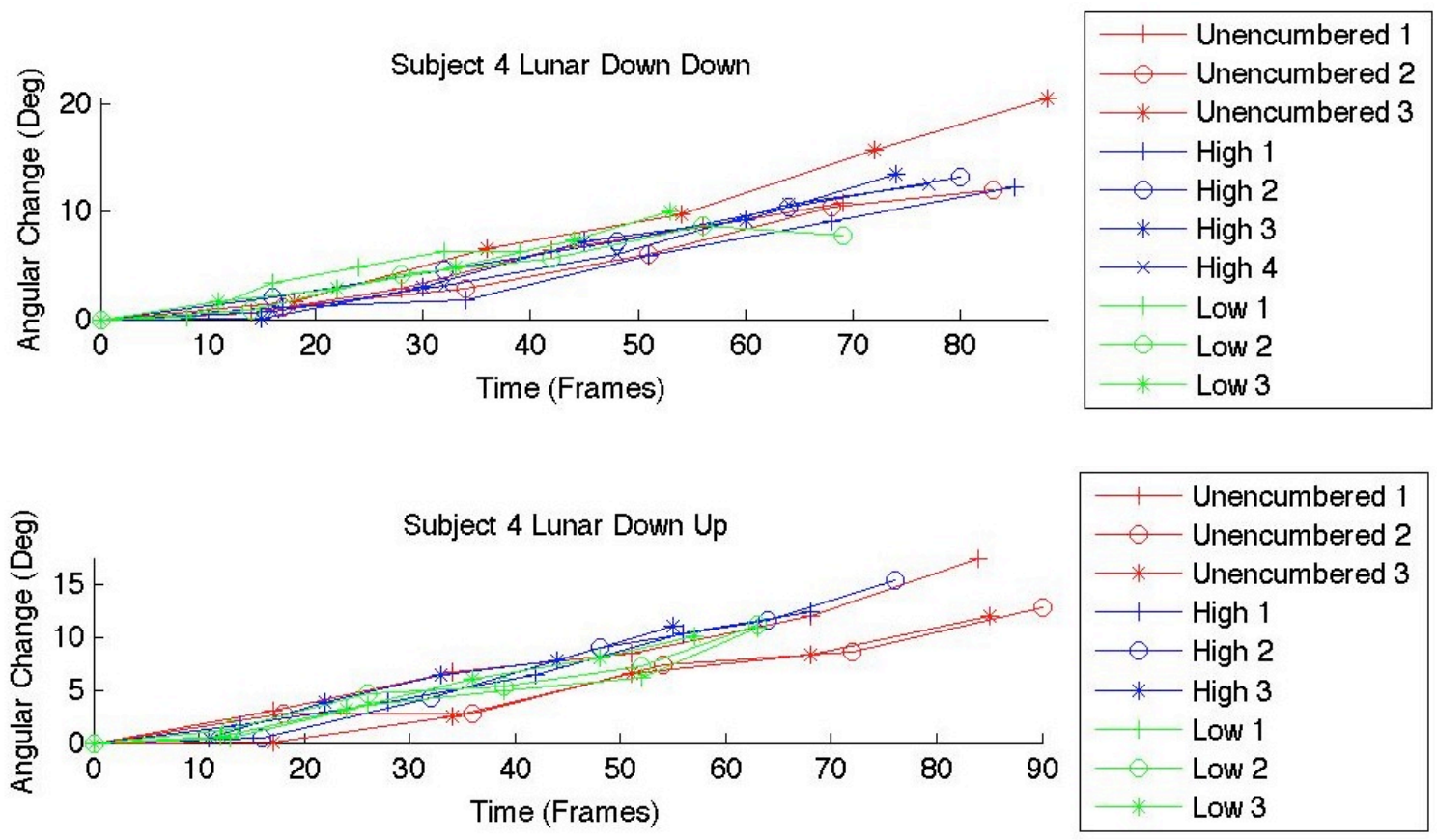


\section{$\underline{\text { Trial Legend }}$}

Trial 1 to 6 - No Backpack

Trial 7 to 12 - High CG Backpack

Trial 13 to 18 - Low CG Backpack

In each range the orientations are in the following order:

Front

Back

Up Up

Up Down

Down Down

Down Up

The following graphs show the average lift time for each configuration. The error bars represent the maximum and minimum lift times. Error bars were not included on graphs when they obscured the data points.

Subject 1 Lunar vs. Mars

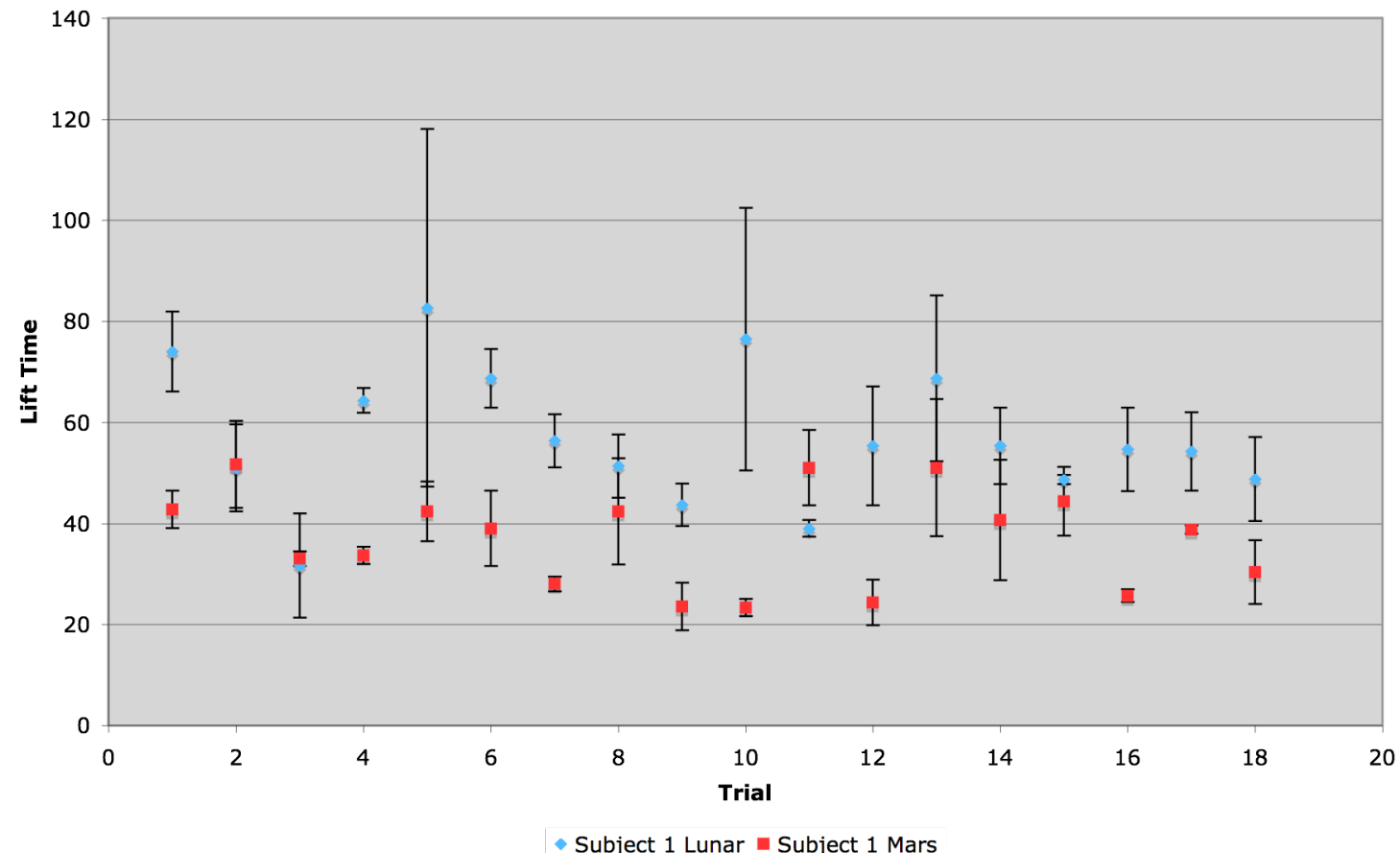


Subject 2 Lunar vs. Mars

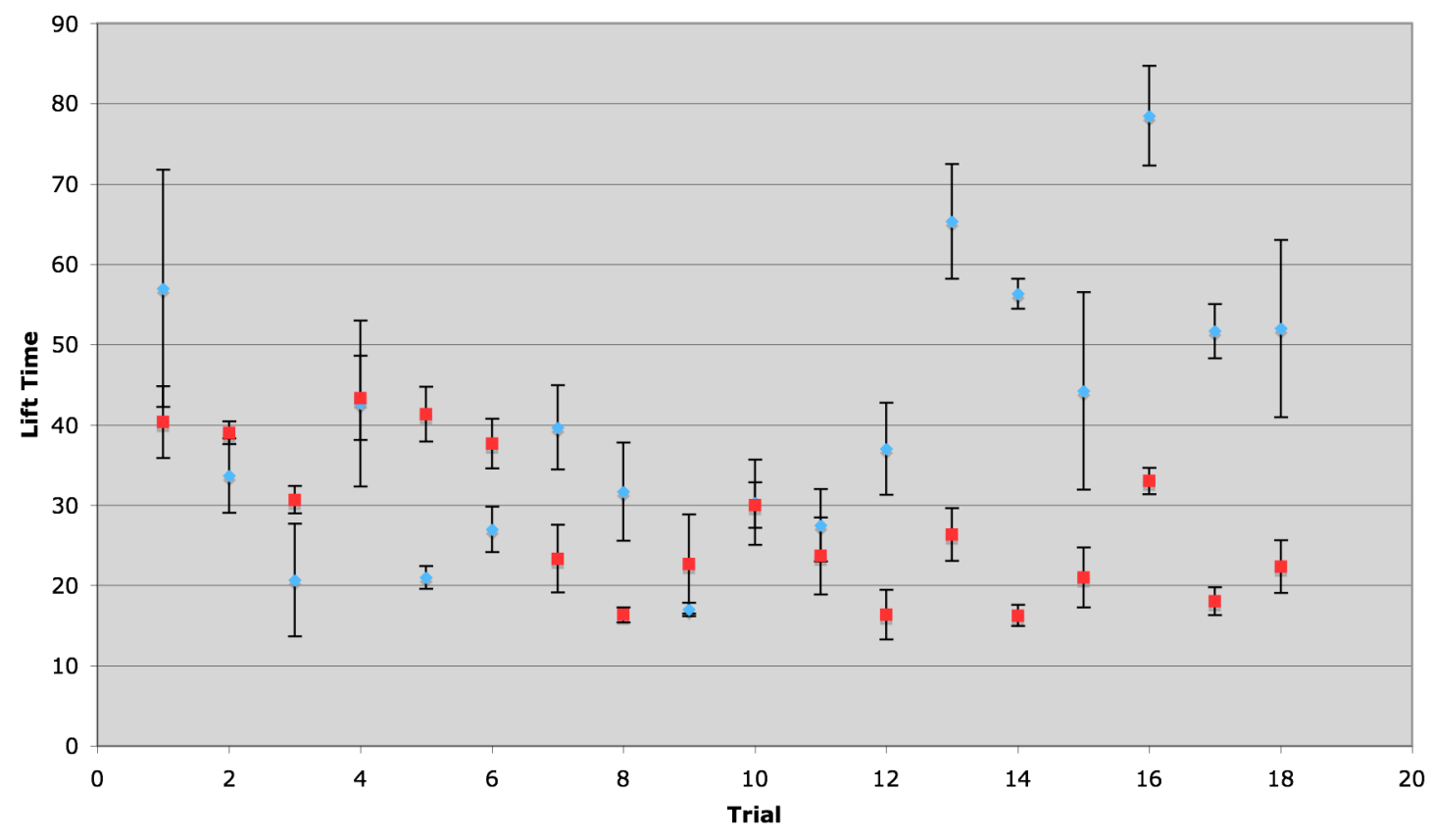

- Subject 2 Lunar - Subject 2 Mars

Lunar Lift Times

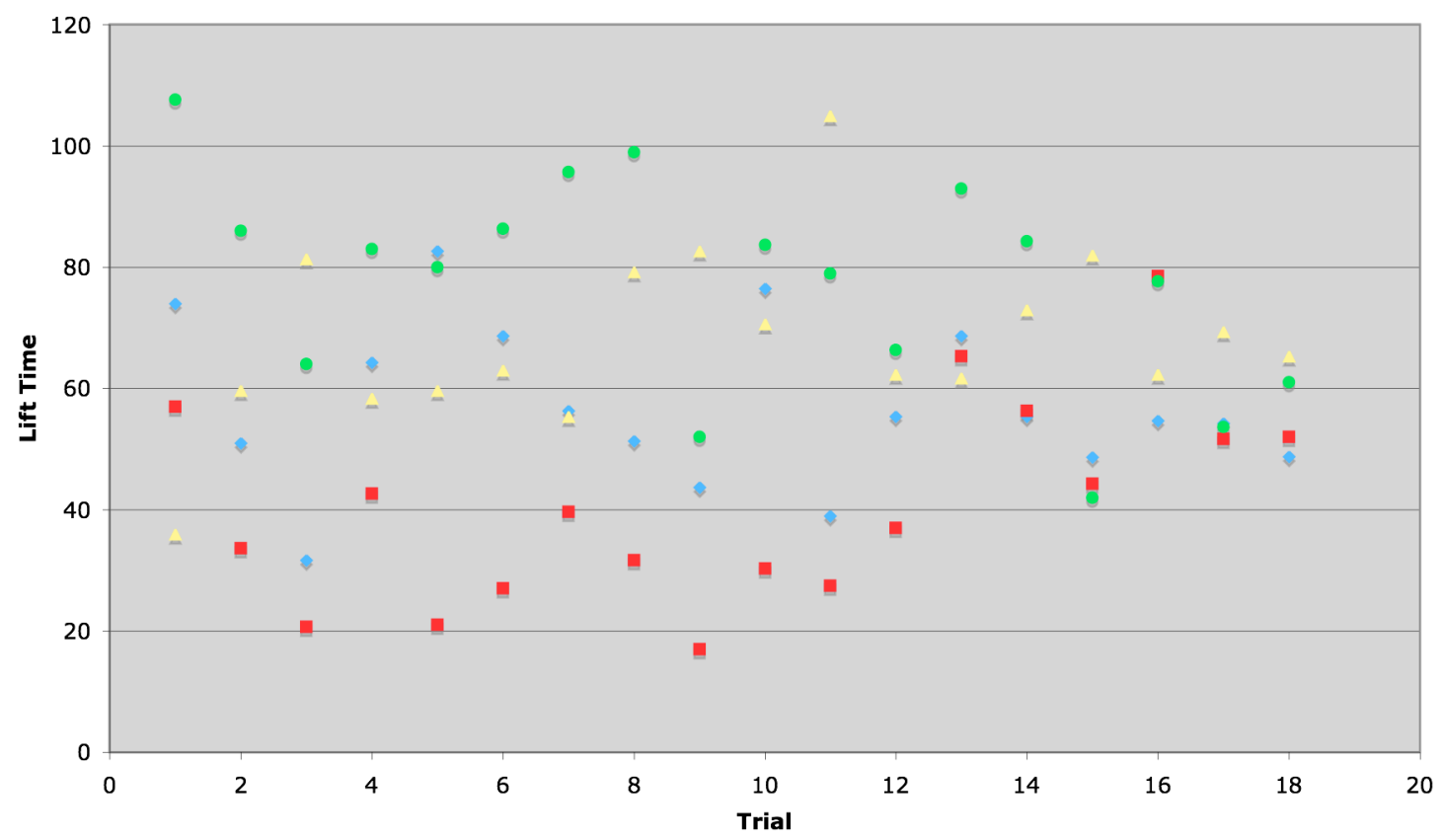

- Subject 1 - Subject 2 Subject 3 - Subject 4 
Mars Lift Times

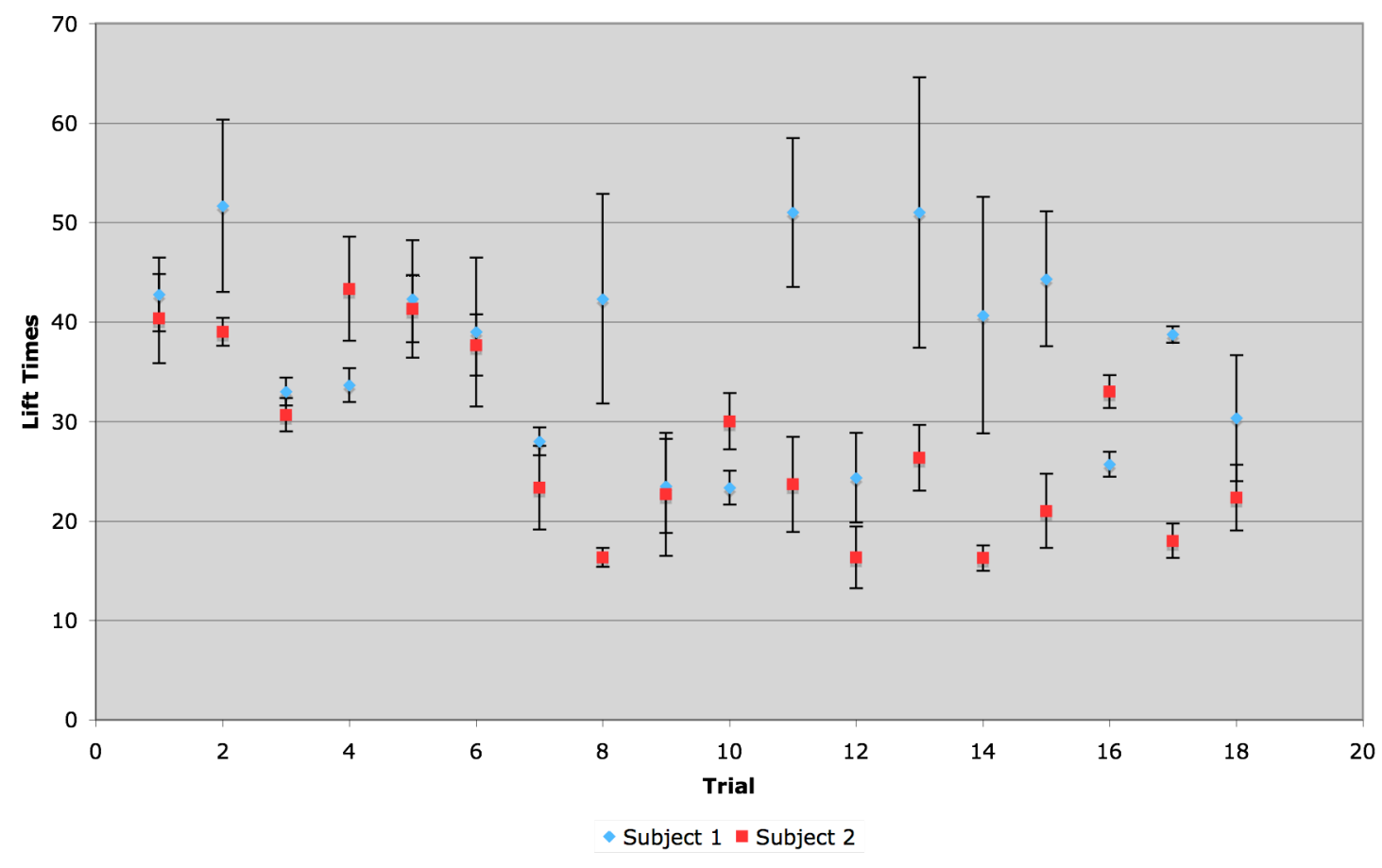


The following graphs show the average angular change for each configuration. The error bars represent the maximum and minimum angular change. Error bars were not included on graphs when they obscured the data points.

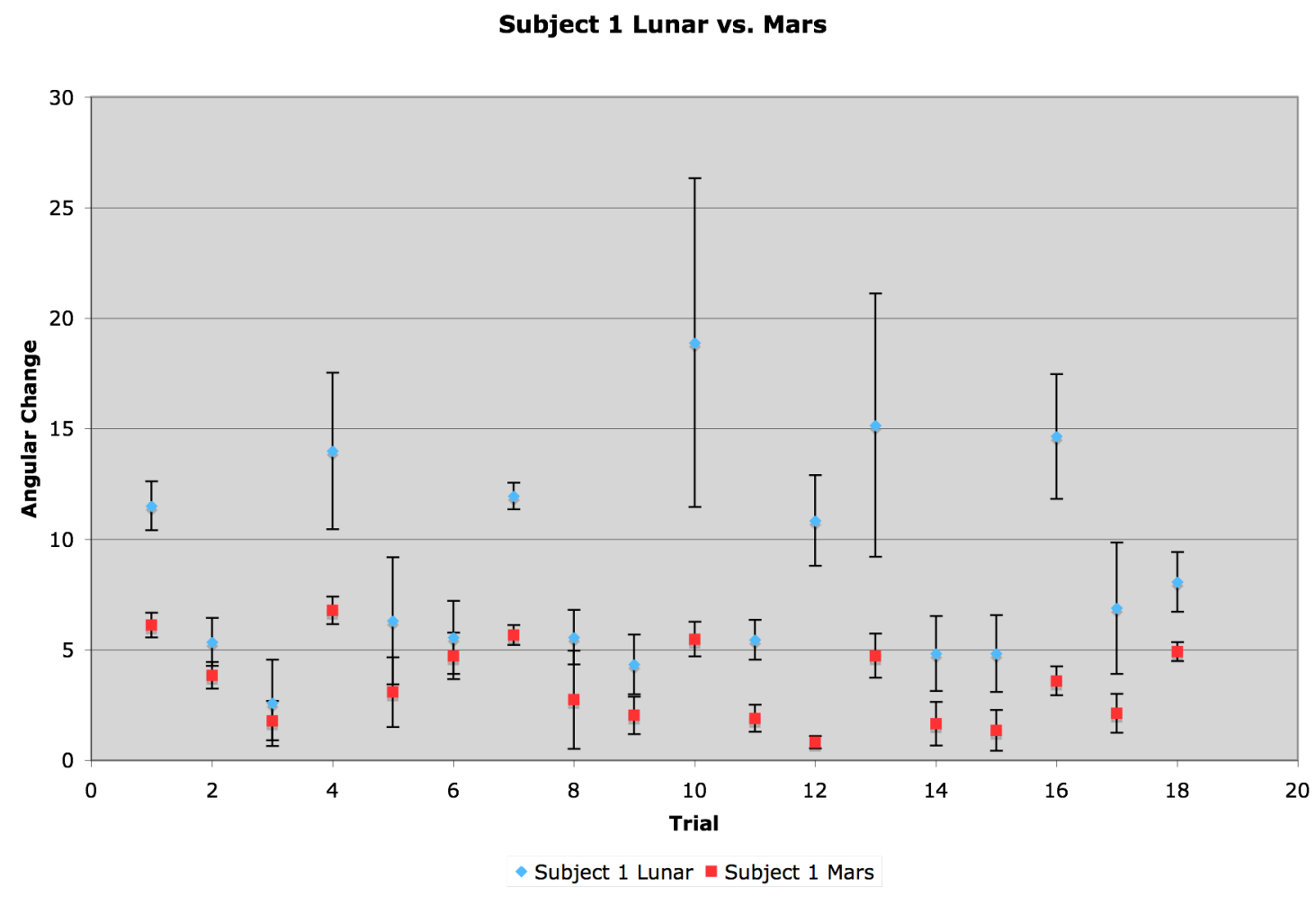


Subject 2 Lunar vs. Mars

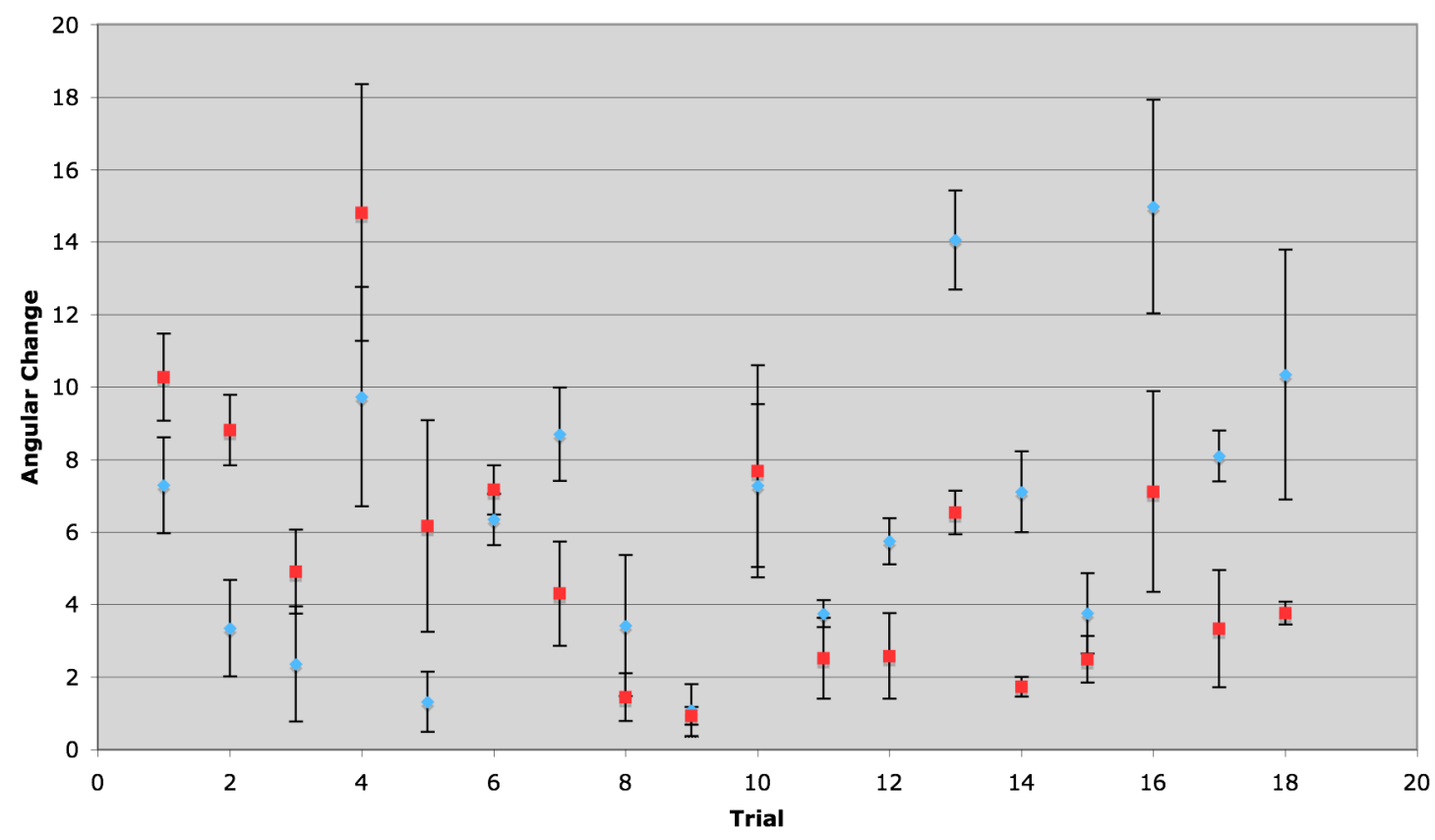

- Subject 2 Lunar - Subject 2 Mars

\section{Lunar Angular Change}

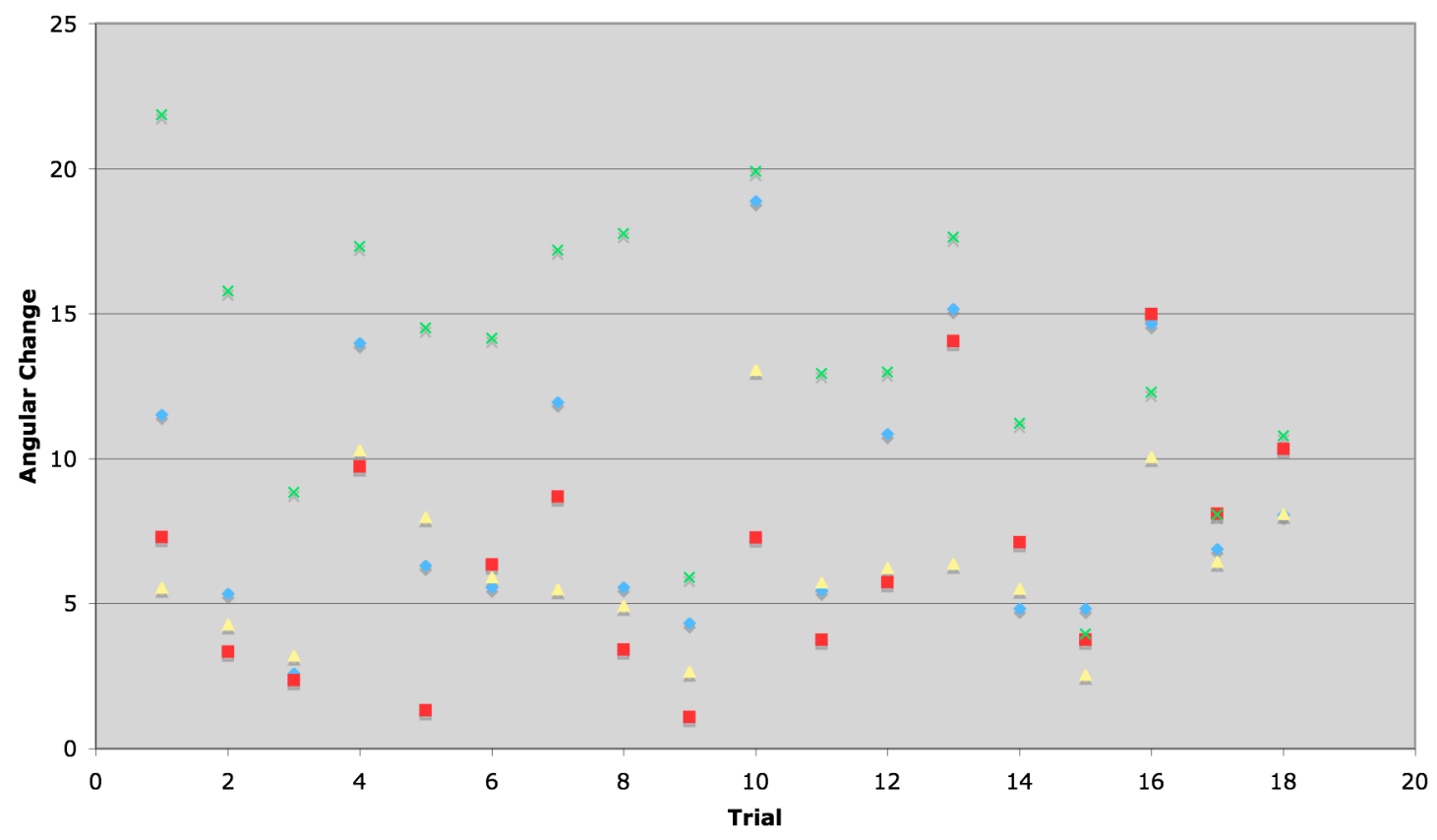

- Subject 1 - Subject 2 Subject $3 \times$ Subject 4 
Mars Angular Change

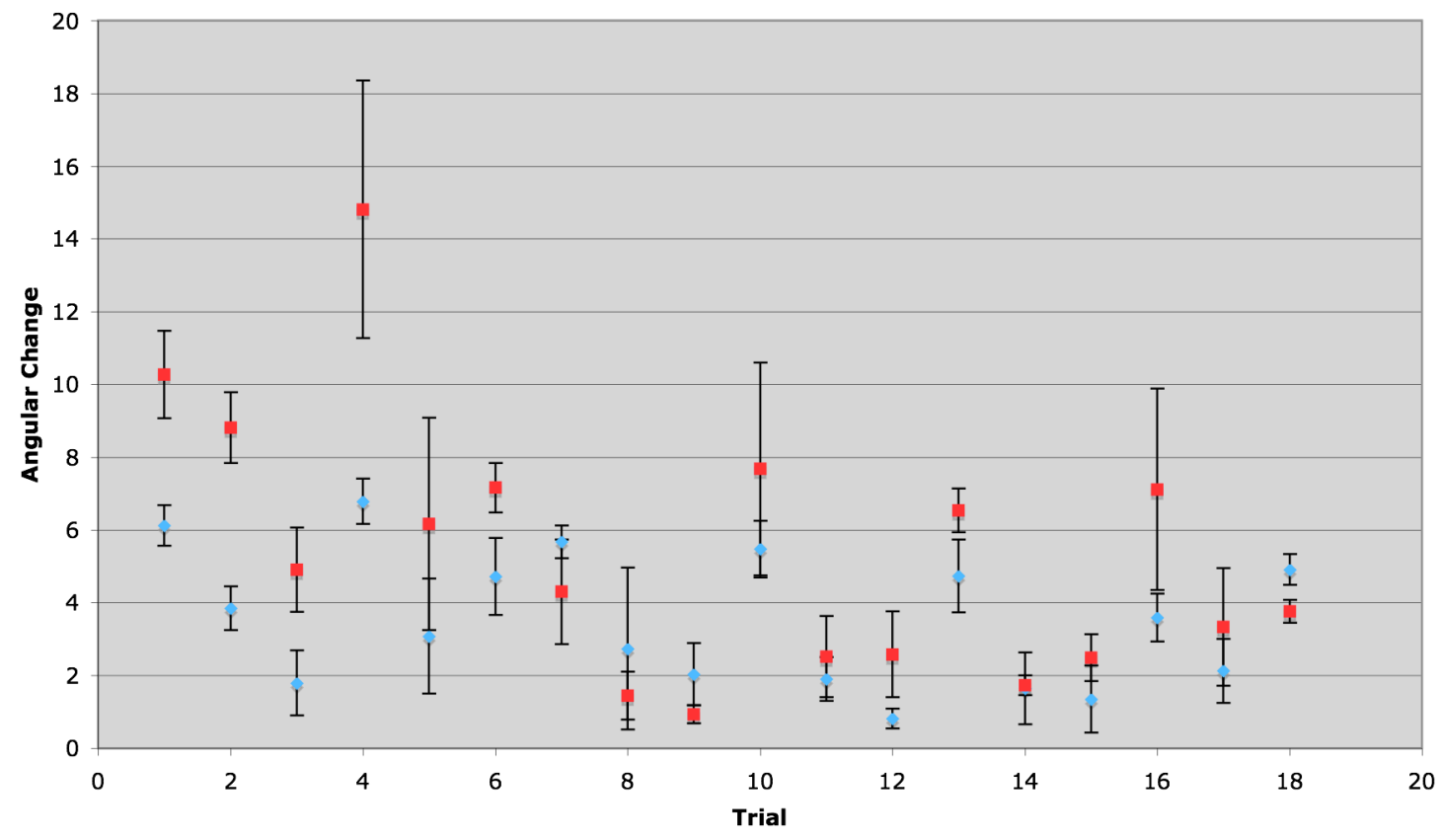

- Subject 1 - Subject 2 
The following graphs compare the average lift time to the average angular change for the two subjects, which conducted trials and Lunar and Mars gravity.

Subject 1 Time vs. Angular Change

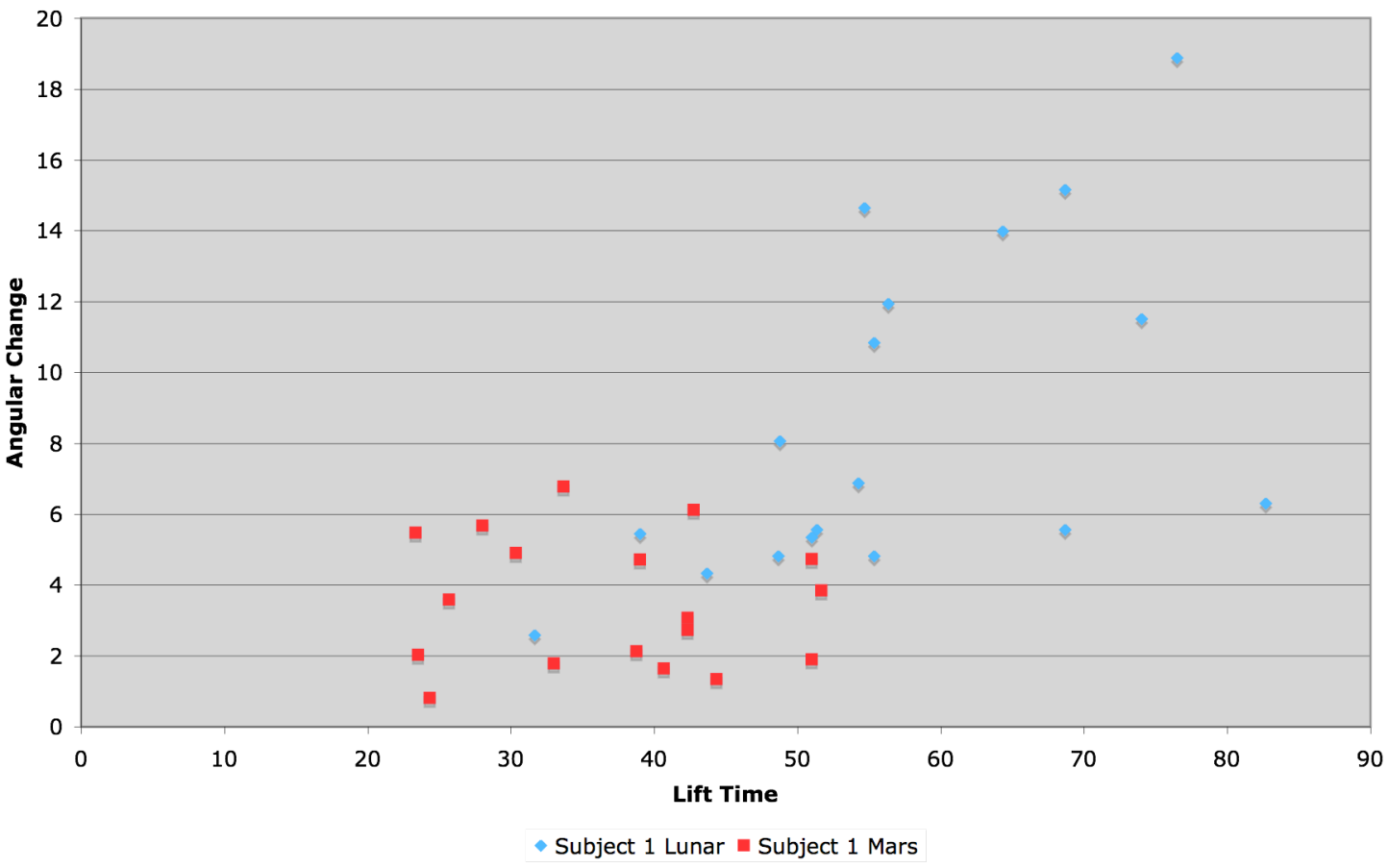


Subject 2 Lift Time vs. Angular Change

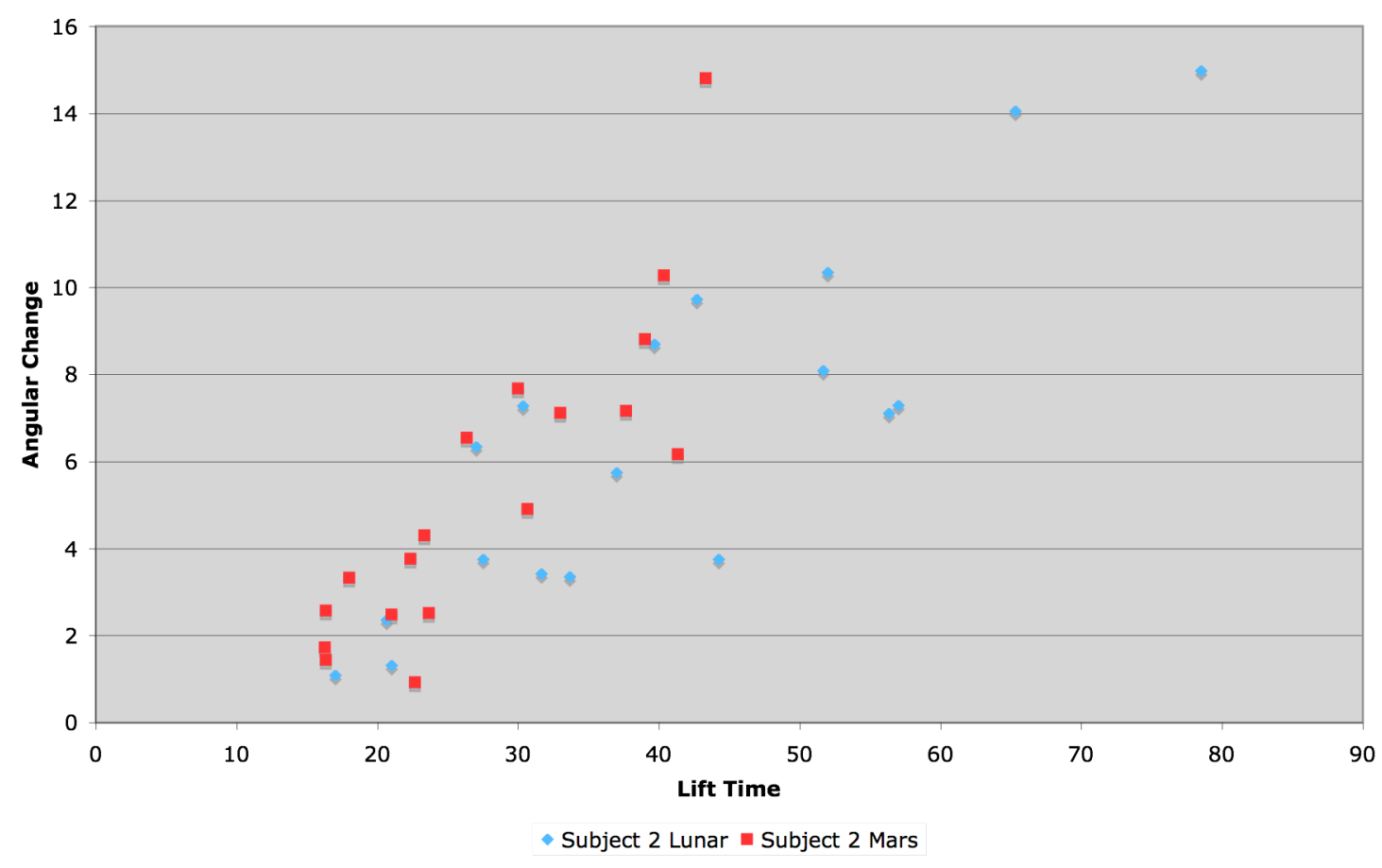


The following graphs show the angular change divided by the lift time for each trial. Once these values were calculated they were averaged for each loading condition.

Subject 1 Lunar vs. Mars

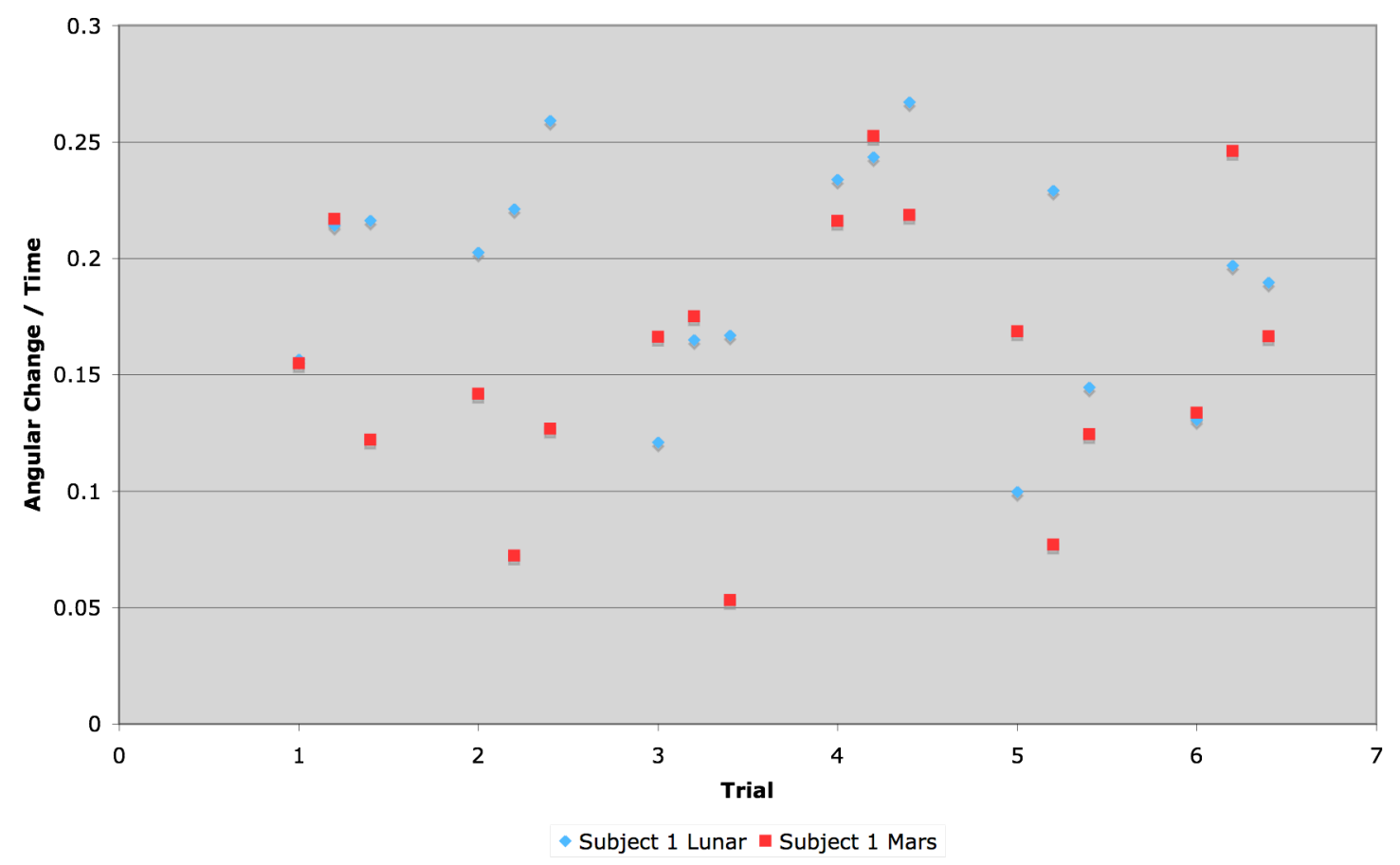


Subject 2 Lunar vs. Mars

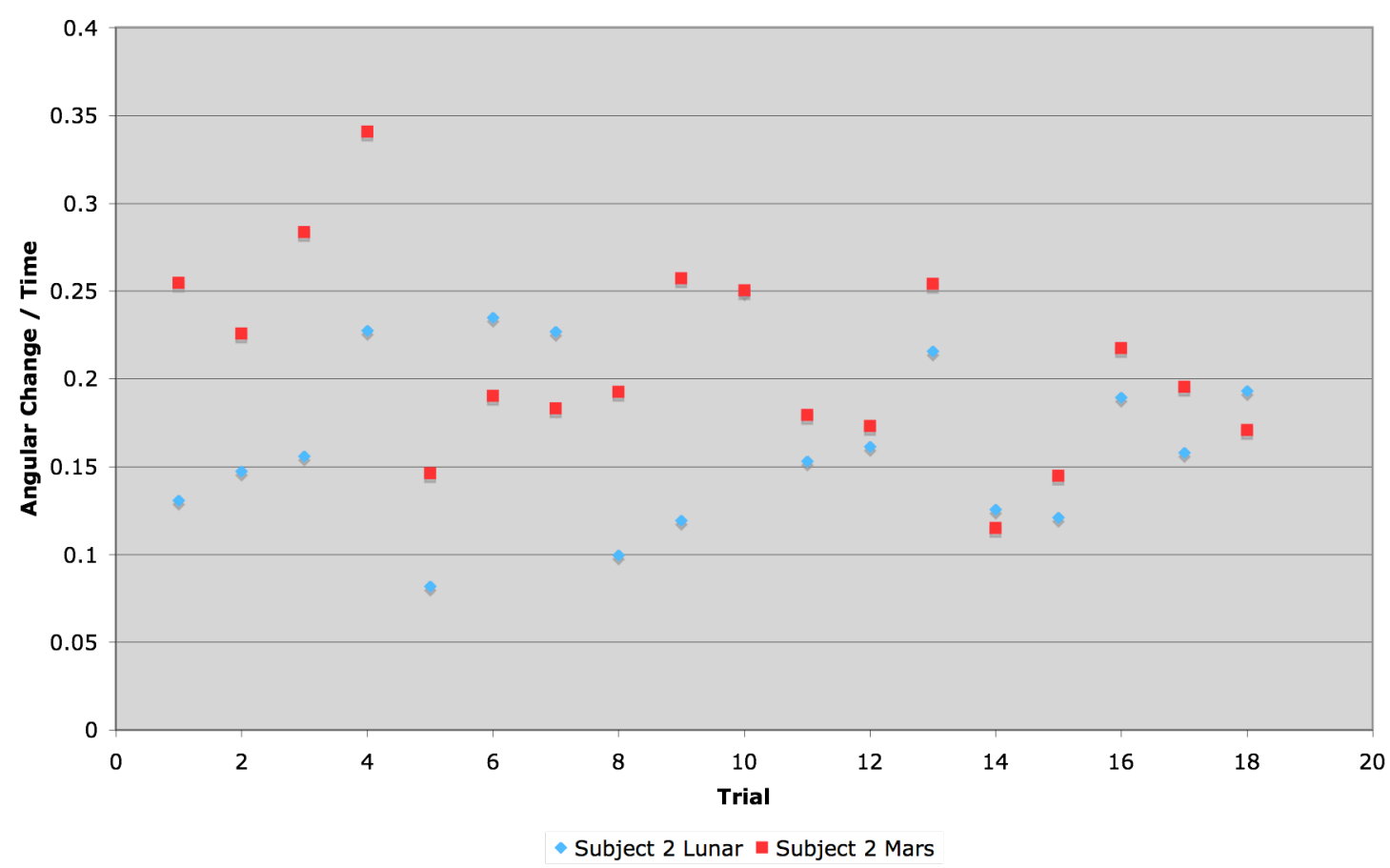

Subject 1 vs. Subject 2 Mars

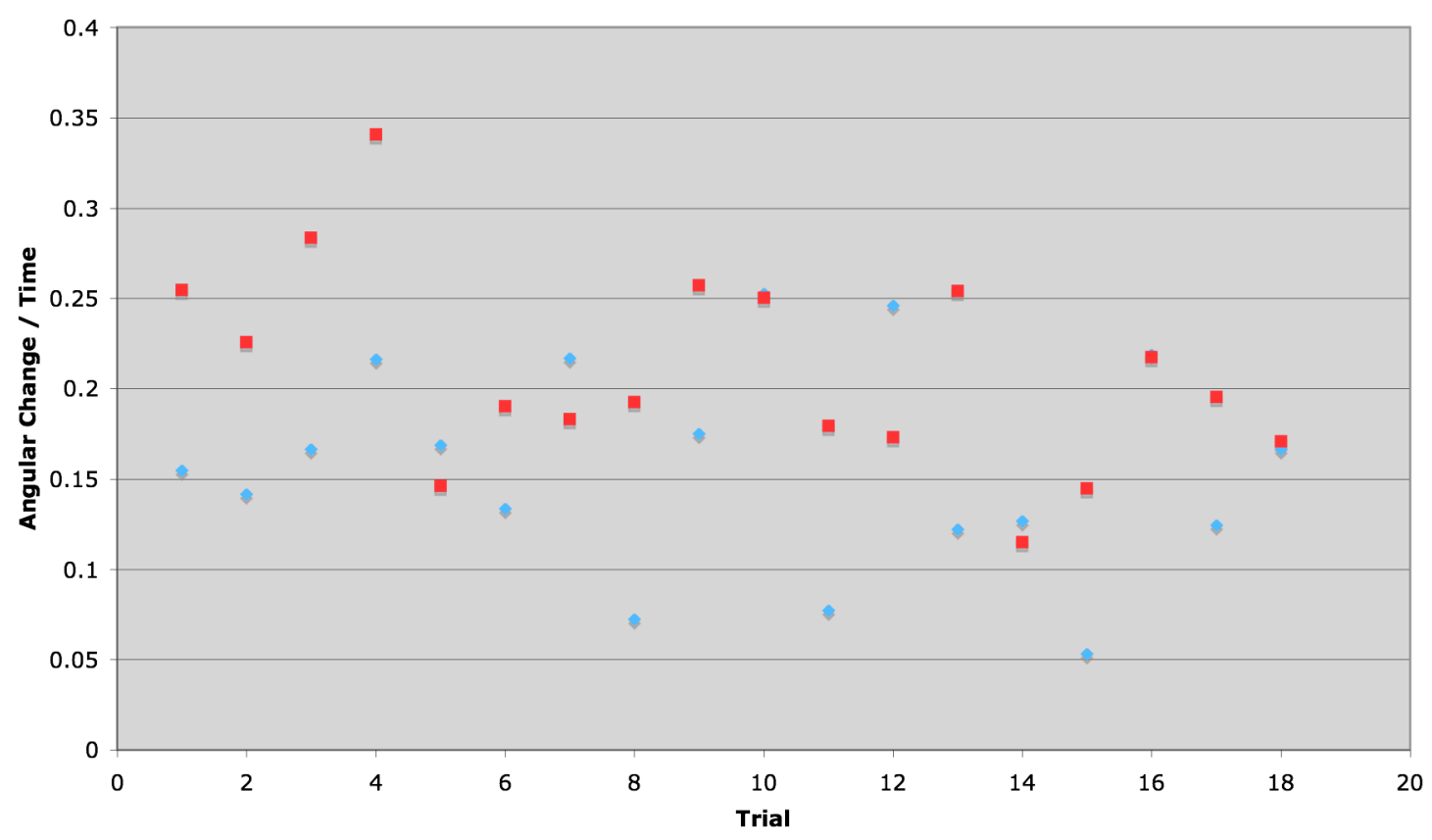

- Subject 1 Mars $\|$ Subject 2 Mars 
Lunar All Subjects

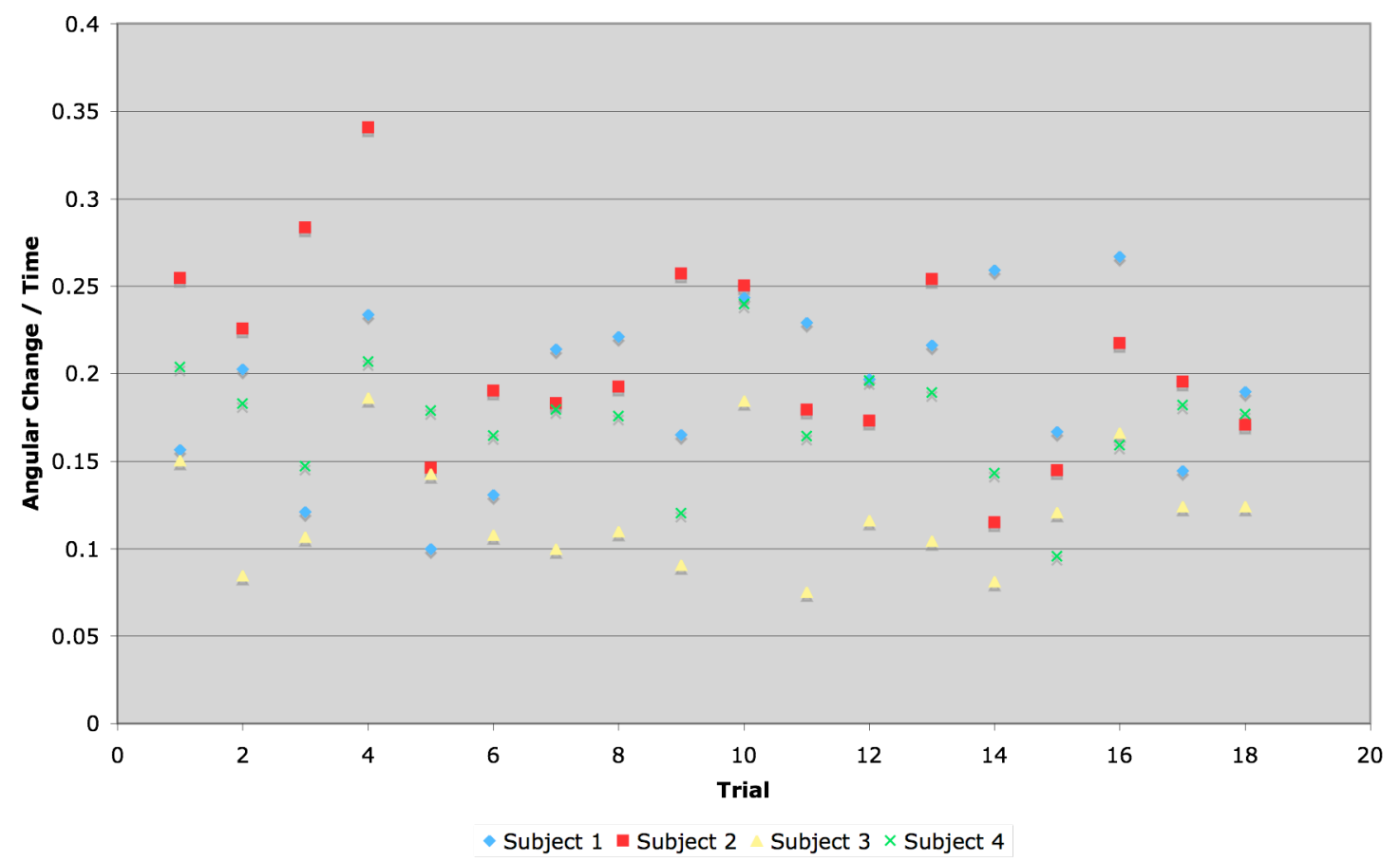

- Subject 1 - Subject 2 Subject $3 \times$ Subject 4 


\section{Appendix B: MATLAB Code}

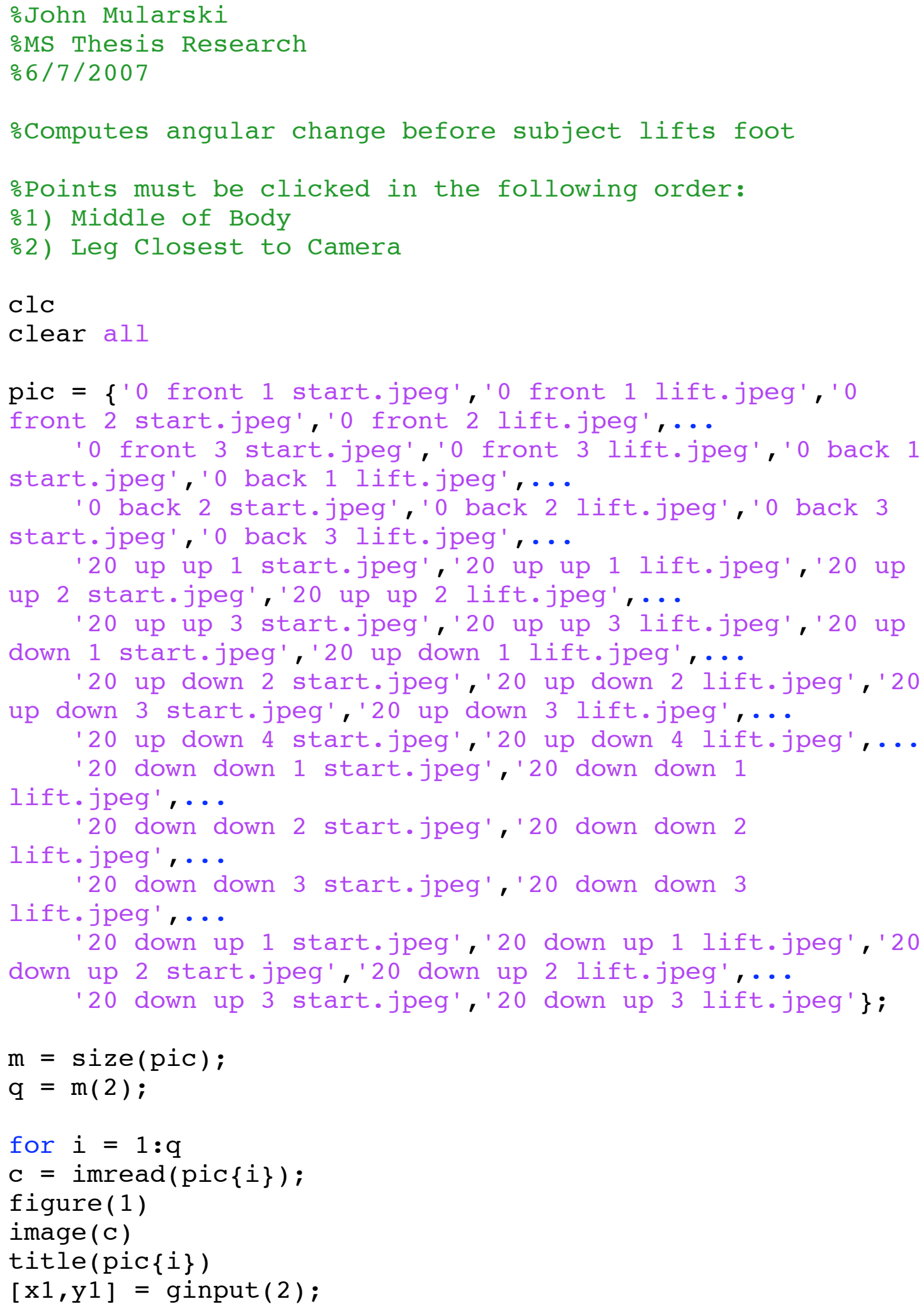




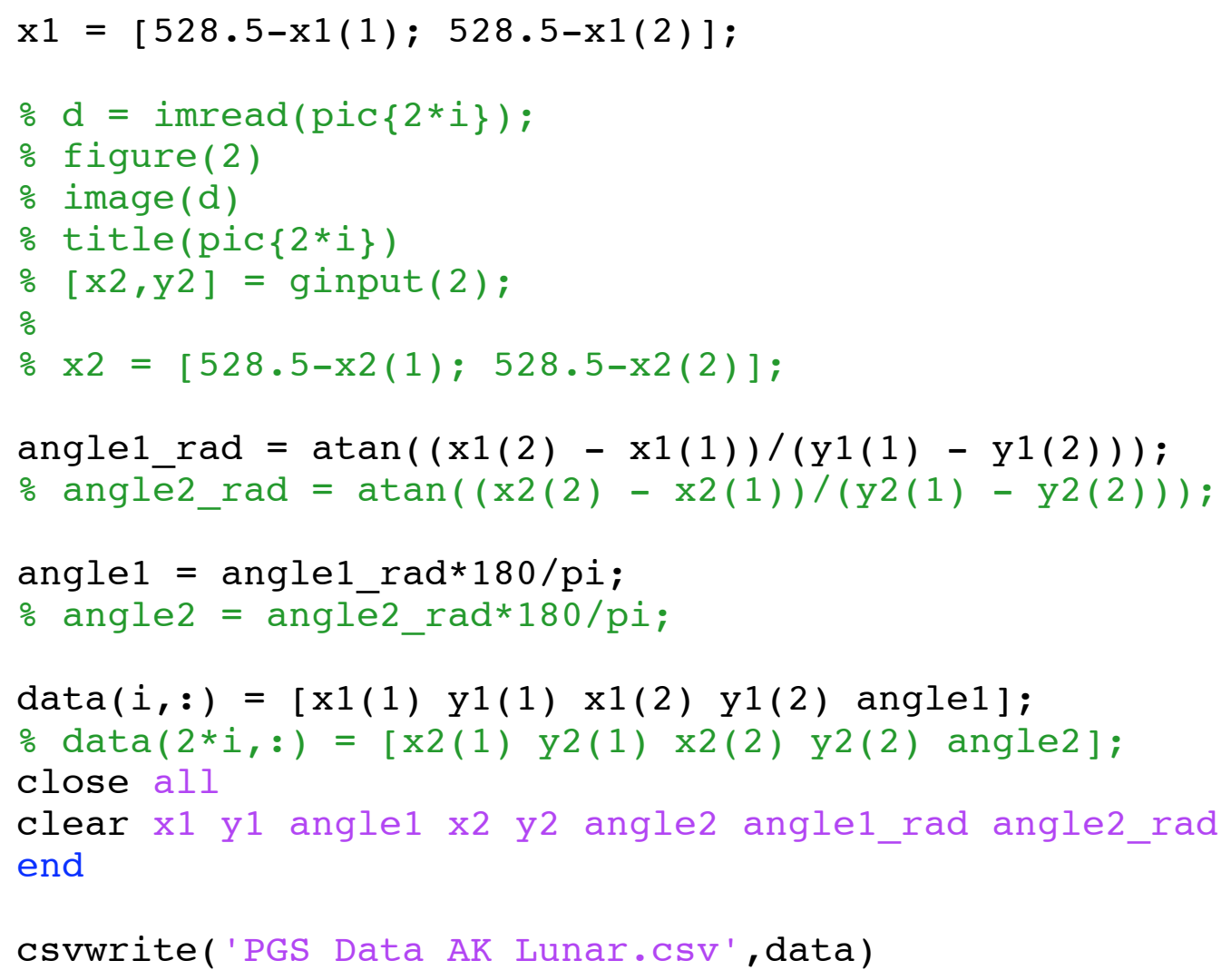


ঃJohn Mularski

$\%$ MS Thesis Research

\%6/13/2007

ঃComputes angular change before subject lifts foot

\%Points must be clicked in the following order:

\%) Middle of Body

○2) Leg Closest to Camera

$\mathrm{ClC}$

clear all

opic $=\{$ 'f11.jpeg' 'f12.jpeg' 'f13.jpeg' 'f14.jpeg'

'f21.jpeg' 'f22.jpeg' 'f23.jpeg' 'f24.jpeg' 'f31.jpeg'

'f32.jpeg' 'f33.jpeg' 'f34.jpeg'\};

opic $=\{$ 'b11.jpeg' 'b12.jpeg' 'b13.jpeg' 'b14.jpeg'

'b21.jpeg' 'b22.jpeg' 'b23.jpeg' 'b24.jpeg' 'b31.jpeg'

'b32.jpeg' 'b33.jpeg' 'b34.jpeg'\};

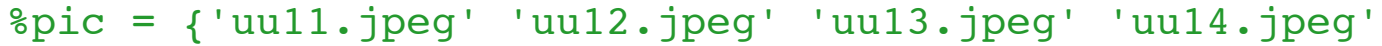

'uu21.jpeg' 'uu22.jpeg' 'uu23.jpeg' 'uu24.jpeg' 'uu31.jpeg'

'uu32.jpeg' 'uu33.jpeg' 'uu34.jpeg'\};

opic $=\{$ 'ud11.jpeg' 'ud12.jpeg' 'ud13.jpeg' 'ud14.jpeg'

'ud21.jpeg' 'ud22.jpeg' 'ud23.jpeg' 'ud24.jpeg' 'ud31.jpeg'

'ud32.jpeg' 'ud33.jpeg' 'ud34.jpeg' 'ud41.jpeg' 'ud42.jpeg'

'ud43.jpeg' 'ud44.jpeg'\};

opic $=\{$ 'dd11.jpeg' 'dd12.jpeg' 'dd13.jpeg' 'dd14.jpeg'

'dd21.jpeg' 'dd22.jpeg' 'dd23.jpeg' 'dd24.jpeg' 'dd31.jpeg'

'dd32.jpeg' 'dd33.jpeg' 'dd34.jpeg'\};

pic $=\{$ 'du11.jpeg' 'du12.jpeg' 'du13.jpeg' 'du14.jpeg'

'du21.jpeg' 'du22.jpeg' 'du23.jpeg' 'du24.jpeg' 'du31.jpeg'

'du32.jpeg' 'du33.jpeg' 'du34.jpeg'\};

$\mathrm{m}=\operatorname{size}(\mathrm{pic}) ;$

$\mathrm{q}=\mathrm{m}(2) ;$

for $i=1: q$

$\mathbf{c}=\operatorname{imread}(\operatorname{pic}\{i\})$;

figure (1)

image (c)

title (pic $\{i\})$

$[\mathrm{x} 1, \mathrm{y} 1]=\operatorname{ginput}(2)$;

$\mathrm{x} 1=[528.5-\mathrm{x} 1(1) ; 528.5-\mathrm{x} 1(2)] ;$

angle1_rad $=\operatorname{atan}((\mathrm{x} 1(2)-\mathrm{x} 1(1)) /(\mathrm{y} 1(1)-\mathrm{y} 1(2)))$;

angle1 = angle1_rad*180/pi; 


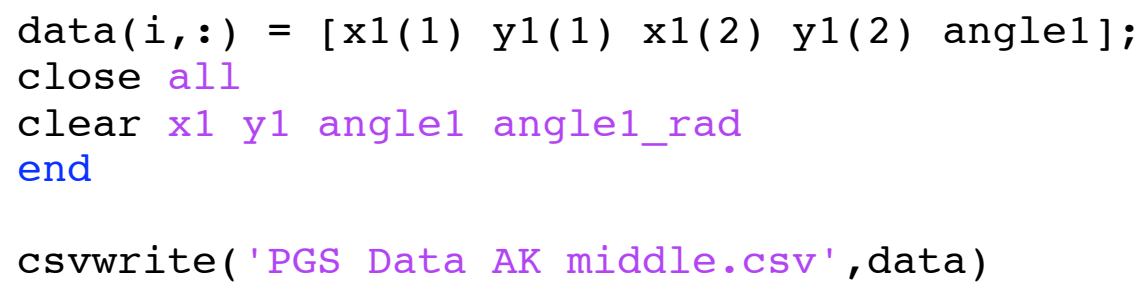




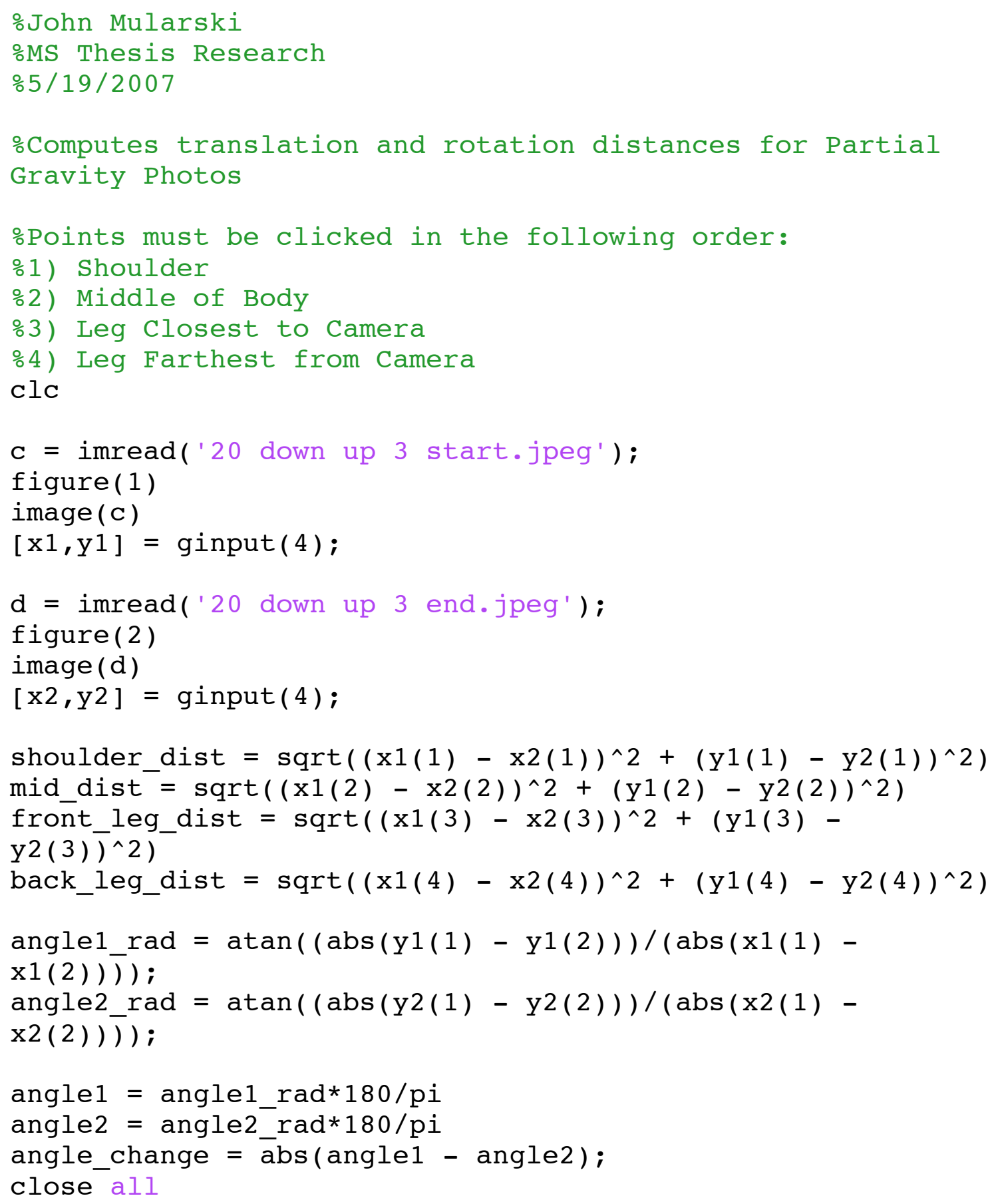




\section{Appendix C: IRB Paperwork}

\section{IRB Application}

\begin{tabular}{|c|c|}
\hline 0. & $\begin{array}{l}\text { Title: } \\
\text { Water Immersion Ballasted Partial Gravity Simulation for Lunar and Martian } \\
\text { EVA Simulation }\end{array}$ \\
\hline 1. & $\begin{array}{l}\text { Abstract: } \\
\text { This experiment will simulate the gravity conditions found on Mars and the } \\
\text { Moon, and assess the ability of humans to operate and perform routine tasks in } \\
\text { these partial gravity environments. Subjects will wear a weight harness that will } \\
\text { load them to the appropriate percentage of their weight on Earth. The experiment } \\
\text { will be conducted in the Neutral Buoyancy Research Facility (NBRF) based at the } \\
\text { Space Systems Lab (SSL). The NBRF is a } 25 \text {-foot deep } 367,000 \text {-gallon water } \\
\text { tank used for space simulation research. This research will seek to develop an } \\
\text { information base from which hardware can be designed for extravehicular } \\
\text { activities (EVAs) in reduced gravity conditions. This will include hatchway } \\
\text { design, load-carrying devices, and mobility aids. The tests will be conducted } \\
\text { through the use of SCUBA. The subjects will utilize a hookah diving rig to allow } \\
\text { unencumbered movement. Should the primary air supply cease functioning, } \\
\text { subjects will also be equipped with a } 3 \mathrm{ft}{ }^{3} \text { Spare-Air bottle. This will provide } \\
\text { approximately } 2 \text { - } 3 \text { minutes of breathing time while safety divers execute } \\
\text { emergency procedures. Depending on the severity of the situation this will } \\
\text { include the use of an alternate air source, jettisoning ballast, and subject extraction } \\
\text { from the tank. All diving operations will be performed under the auspices of the } \\
\text { University of Maryland Diving Control Board, and in accordance with the UMd } \\
\text { Diving Safety Manual. Subject involvement will be completely voluntary, } \\
\text { informed consent will be obtained before the start of the experiment, and all } \\
\text { subject data will be kept confidential. }\end{array}$ \\
\hline 2. & $\begin{array}{l}\text { Subject Selection: } \\
\text { The subjects will be SSL certified divers. As a condition of diving at the } \\
\text { University of Maryland, all of the subjects have current physical exams and } \\
\text { medical histories that demonstrate that they meet the established criteria to dive. } \\
\text { As part of the diver certification process, they have already been tested for scuba } \\
\text { diving skills and trained in required subjects, including CPR, first aid, and } \\
\text { emergency oxygen administration. Subjects will be recruited by an email sent to } \\
\text { all active SSL divers. Participation in the experiment will be completely } \\
\text { voluntary and any subject can withdraw at anytime for any reason. }\end{array}$ \\
\hline 3. & $\begin{array}{l}\text { Procedures: } \\
\text { SSL Facilities \& Procedures } \\
\text { All experimental sessions will be conducted at the NBRF. Sessions will be } \\
\text { conducted with safety as the primary focus. To this end SSL personnel will } \\
\text { monitor all sessions both underwater and on the deck. There are two porthole } \\
\text { cameras located in the tank, one in the north and one in the south. These two } \\
\text { cameras are adjustable in both position and zoom. If additional views are neec }\end{array}$ \\
\hline
\end{tabular}




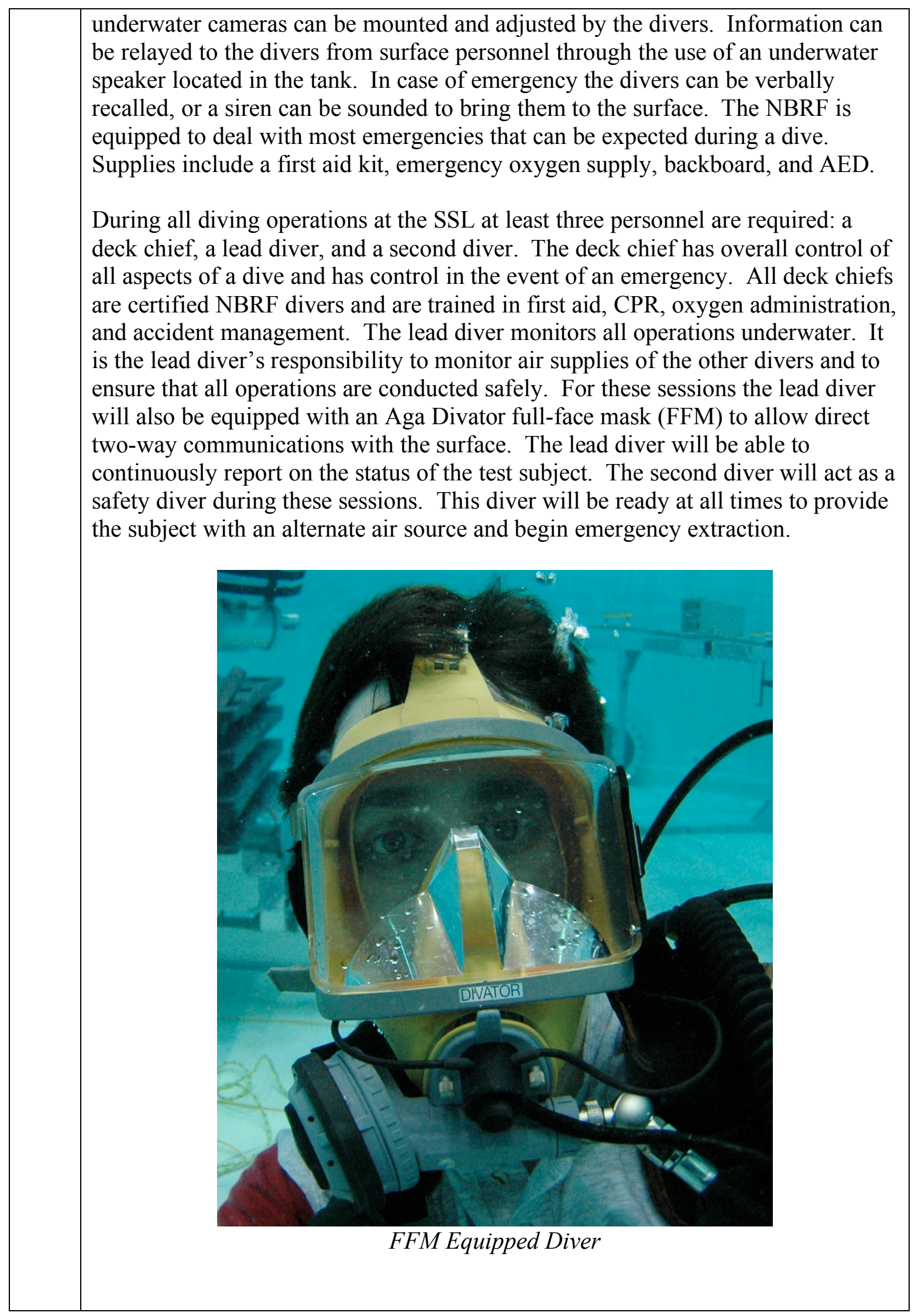




\begin{tabular}{|c|}
\hline 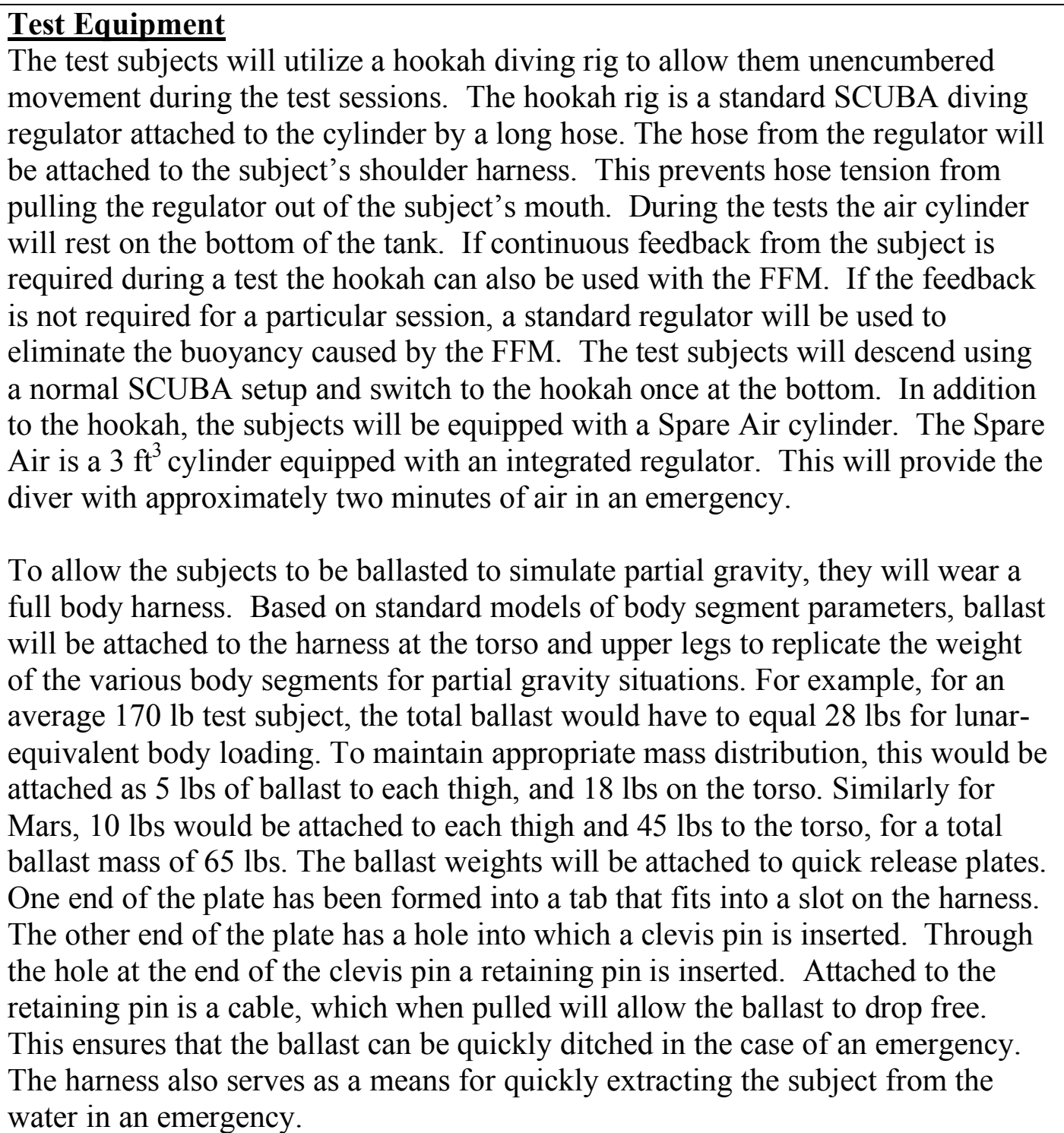 \\
\hline
\end{tabular}




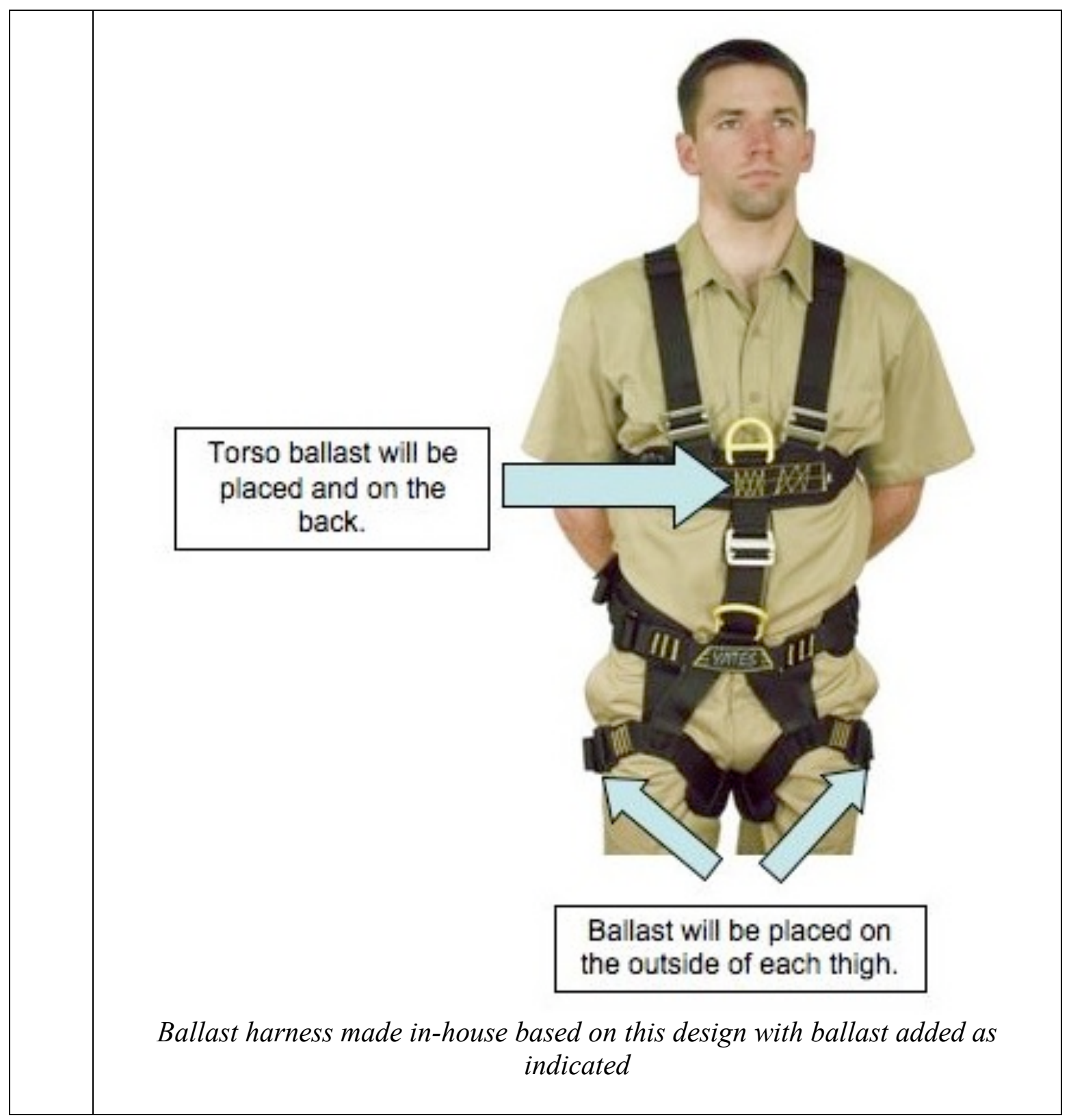




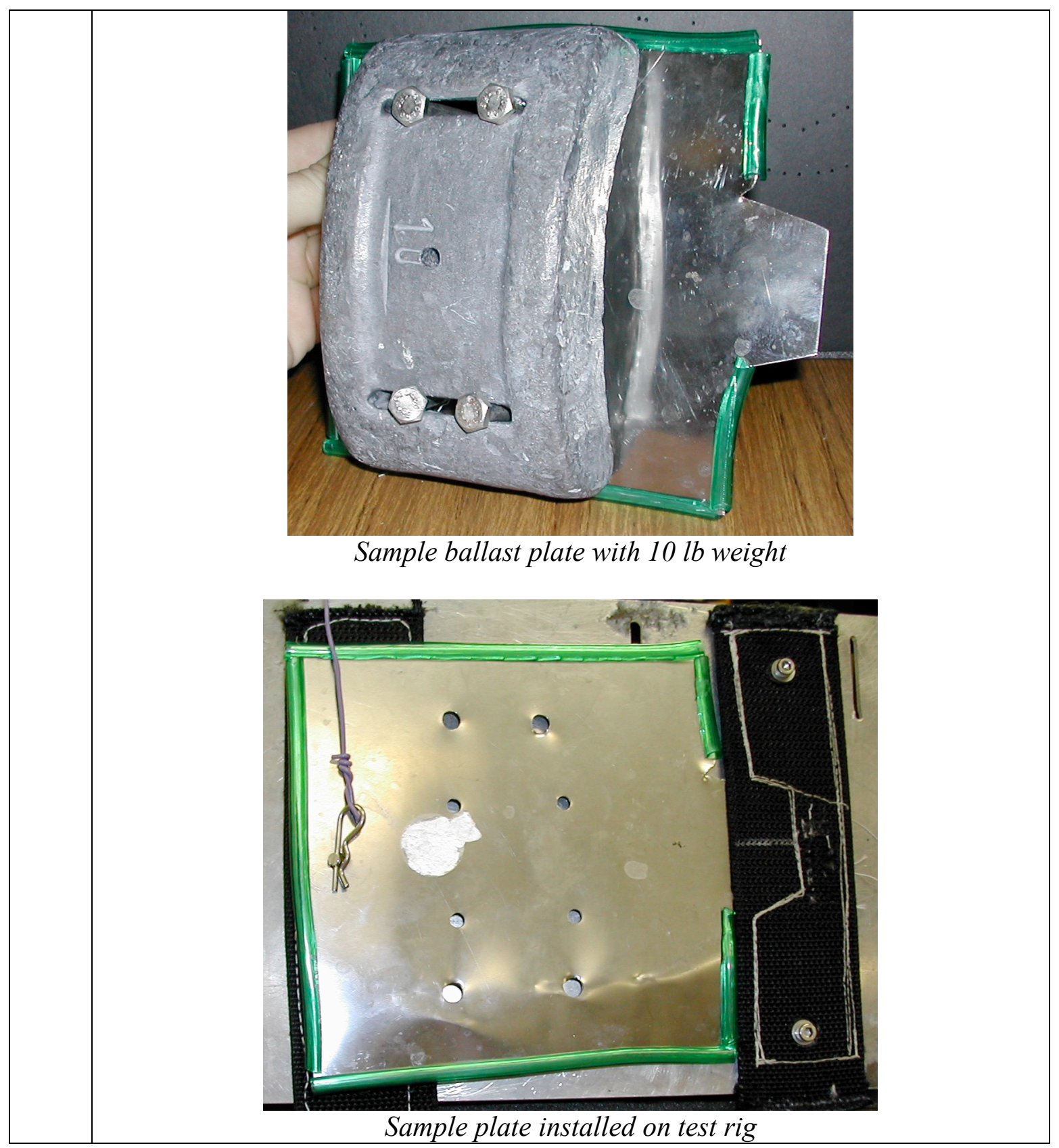




Plate shown after quick release activated
(Shown without weight for purposes of illustration)
(1)
Emergency Procedures
Primary Air Supply Interruption
If the subject's hookah air supply fails for any reason, a "bailout" to an alternate
air source will be performed. The subject has at least three alternate air supplies
to choose from. The first is the Spare Air cylinder attached to their harness,
which supplies them with several minutes of breathing air. This is an "interim"
supply, capable of providing air during an emergency ascent, or as a bridge to an
alternate air source. The second source is an "octopus" (safety) regulator offered
by a safety diver. As part of the test protocols, safety divers are required to stay
within close range of the test subject, and to be capable of handing them the spare
regulator within ten seconds following an emergency. All scuba divers are
practiced in the skill of switching from one regulator from their training courses.
Actually, any diver underwater can share their air supply through secondary
regulators or "buddy-breathing", but the safety diver is positioned to be the first
responder if a problem occurs. The third air source is the standard tank/buoyancy
compensator/regulator set-up, which the test subject wears while descending to
the test site and which is laid on the tank floor beside the test apparatus. Once
alternative air sources have been supplied and the subject is stabilized, the ballast
will be removed and the subject will nominally transfer back to the standard
SCUBA rig. This will then be used to ascend to the surface.
Emergency Requiring Immediate Extraction
If an emergency occurs that requires immediate extraction, the safety divers will
ditch the subject's ballast using the quick release mechanisms. After the ballast
has been removed one safety diver will immediately assist the subject to the
surface. The hookah hose is long enough to reach the surface without adjustment


under normal circumstances. If for any reason the hose does not reach, the second safety diver will carry the air cylinder supplying the hookah from the bottom of the tank to a point where the hose will reach. Once at the surface any necessary medical action will be taken and the deck chief will be informed of the situation.

Ballast Release Failure

A ballast release failure by itself is not an emergency. As long as the subject is breathing there is plenty of time to troubleshoot the problem. If during the troubleshooting the subject or safety divers run low on air, additional cylinders can be sent from the surface. Due to having a compressor on site, a virtually unlimited supply of air is available. Once the ballast release problem has been resolved, a normal ascent can be conducted. If for any reason the ballast release problem is not resolved, a number of resolution techniques are available. The subject can remove the entire harness system with the weights attached.

Alternately, even at the largest Mars ballast loads two divers would be able to swim the subject to the surface, where they could stand on the donning platform with their head out of the water while the weights are removed. A further alternative is to climb the access ladder to the surface, which runs the entire distance from the bottom of the tank to the top. Finally, if all other alternatives have failed, the subject can immediately extracted from the water using the overhead crane.

\section{Test Overview}

Subjects will participate in multiple sessions the first of which will be a familiarization session. First, the consent form will be presented to the subjects to be signed before the test goes further. Next, during this session the subjects will be weighed to determine the amount of ballast needed. Then the weight harness will be fitted to the subject and all emergency procedures will be explained. The subject and safety divers will then descend on SCUBA to the bottom of the tank. Once at the bottom the subject will remove their fins, switch to the hookah, and ballast will be attached. The subject will be allowed to become comfortable with the ballast before any experiments are conducted. This will be followed by a rehearsal of the emergency procedures. Subsequent sessions will be used for the data collection. Each of these subsequent sessions will focus on a particular activity. These sessions will include backpack stability, ease of ingress/egress, and package transport. Data for each session will be collected by videotape and subject debrief.

\section{Backpack Stability}

During these sessions weights will be placed in different location on the subjects back to simulate a space suit backpack. The location as well as the amount of weight will be varied during the session. The subject will be asked to perform simple tasks with each backpack configuration. These will include climbing slopes and ladders, bending to pick up rocks, recovery from a prone position, and walking. 


\begin{tabular}{|c|c|}
\hline & $\begin{array}{l}\text { Ingress/Egress } \\
\text { These sessions are being conducted to investigate the optimum size and shape of a } \\
\text { hatchway on a pressurized rover or habitat. The test apparatus will consist of an } \\
\text { adjustable frame that will simulate the hatchway. The subject will move through } \\
\text { hatch from one side to the other. The habitat/rover will not be simulated, so the } \\
\text { subject will not be entering an overhead environment. } \\
\text { Package Transport } \\
\text { The subjects will transport packages representing planetary surface experiments } \\
\text { between two points. This will be done using several different methods to include } \\
\text { baskets, attached handles, carts, and simply lifting the object from the bottom. }\end{array}$ \\
\hline 4. & $\begin{array}{l}\text { Risks and Benefits: } \\
\text { The main risks of the experiment are those inherent to SCUBA diving. These } \\
\text { include drowning, arterial gas embolism, decompression sickness, and barotrauma } \\
\text { to the ears. Since the subjects are all divers they are trained to deal with the risks. } \\
\text { The ballast system will add some risks unique from diving, namely the subject's } \\
\text { inability to ascend while wearing the weights. To mitigate this risk, the weights } \\
\text { will be mounted on quick release mechanisms and safety divers will be present at } \\
\text { all times to assist the subjects. }\end{array}$ \\
\hline 5. & $\begin{array}{l}\text { Confidentiality: } \\
\text { Data collected during debriefings will not be labeled with the subjects' name. The } \\
\text { debriefings will be labeled with a code that allows the principal and student } \\
\text { investigator to identify the subject. This is necessary to allow the debrief } \\
\text { comments to be linked to the videos. All debriefings will be stored in electronic } \\
\text { form on password-protected computers. Videos of each session will be stored on } \\
\text { tapes at the SSL. The tapes will become part of the SSL video archive. The tapes } \\
\text { will be labeled with the same code as the debriefings. The subject will only be } \\
\text { identifiable if recognized from the video. Subjects' identities will not be revealed } \\
\text { in any publication of this research. }\end{array}$ \\
\hline 6. & $\begin{array}{l}\text { Information and Consent Forms: } \\
\text { All subjects will be supplied with printed consent forms to be signed before the } \\
\text { commencement of experimental sessions. The consent form will include } \\
\text { information on the purpose, procedure, and risks involved with the experiment. } \\
\text { As divers at the SSL all of the subjects have already signed waivers informing } \\
\text { them of the risks inherent to SCUBA diving. When the consent form is provided } \\
\text { to the subjects they will be given the opportunity to ask questions. The consent } \\
\text { form will only be presented in English, as all subjects will be fluent English } \\
\text { speakers. }\end{array}$ \\
\hline 7. & $\begin{array}{l}\text { Conflict of Interest: } \\
\text { No private sector company is involved in this research. No financial or } \\
\text { employment conflict of interest is presented by this research. }\end{array}$ \\
\hline 8. & $\begin{array}{l}\text { HIPAA Compliance: } \\
\text { No HIPAA protected health information will be used in this experiment. }\end{array}$ \\
\hline 9. & $\begin{array}{l}\text { Research Outside of the United States: } \\
\text { Not Applicable }\end{array}$ \\
\hline
\end{tabular}




\section{0. $\quad$ Research Involving Prisoners: Not Applicable}

\section{CONSENT FORM}

\begin{tabular}{|c|c|}
\hline Project Title & $\begin{array}{l}\text { Water Immersion Ballasted Partial Gravity Simulation for Lunar and } \\
\text { Martian EVA Simulation }\end{array}$ \\
\hline $\begin{array}{l}\text { Why is this research } \\
\text { being done? }\end{array}$ & $\begin{array}{l}\text { This is a research project being conducted by Dr. David Akin and John } \\
\text { Mularski of the Space Systems Lab (SSL) at the University of Maryland, } \\
\text { College Park. We are inviting you to participate in this research } \\
\text { project because you are a diver certified at the SSL. The purpose of } \\
\text { this research project is to evaluate hardware designed for Lunar and } \\
\text { Martian EVA. This information will be used to design hardware to } \\
\text { improve the productivity of astronauts on Lunar and Martian EVA. }\end{array}$ \\
\hline $\begin{array}{l}\text { What will I be asked } \\
\text { to do? }\end{array}$ & $\begin{array}{l}\text { The procedures involved in the first session will begin with being } \\
\text { weighed and fitted into the harness. After all safety procedures have } \\
\text { been explained you will then descend on SCUBA to the bottom of the } \\
\text { tank to begin the test. The first session will be used simply to become } \\
\text { comfortable with the harness as well as the emergency procedures. } \\
\text { After practicing the emergency procedures the first session will be } \\
\text { completed. Subsequent sessions will be divided between backpack } \\
\text { stability, ingress/egress, and package transport. } \\
\text { Backpack Stability } \\
\text { During these sessions weights will be placed in different location on } \\
\text { your back to simulate a space suit backpack. The location as well as } \\
\text { the amount of weight will be varied during the session. You will be } \\
\text { asked to perform simple tasks with each backpack configuration. These } \\
\text { will include climbing slopes and ladders, bending to pick-up rocks, } \\
\text { recovery from a prone position, and walking. } \\
\text { Ingress/Egress } \\
\text { These sessions are being conducted to investigate the optimum size and } \\
\text { shape of a hatchway on a pressurized rover or habitat. The test } \\
\text { apparatus will consist of an adjustable frame that will simulate the } \\
\text { hatchway. You will move through hatch from one side to the other. The } \\
\text { habitat/rover will not be simulated, so there will always be direct } \\
\text { access to the surface in case of emergency. } \\
\text { Package Transport } \\
\text { You will transport packages representing planetary surface experiments } \\
\text { between two points. This will be done using several different methods to } \\
\text { include baskets, attached handles, carts, and simply lifting the object } \\
\text { from the bottom. } \\
\text { the safety divers will then remove the ballast and assist the subject to } \\
\text { the surface. }\end{array}$ \\
\hline
\end{tabular}




\begin{tabular}{|c|c|}
\hline Project Title & $\begin{array}{l}\text { Water Immersion Ballasted Partial Gravity Simulation for Lunar and } \\
\text { Martian EVA Simulation }\end{array}$ \\
\hline $\begin{array}{l}\text { What will I be asked } \\
\text { to do? }\end{array}$ & $\begin{array}{l}\text { All of the sessions will be video taped for later analysis and subjective } \\
\text { comments will be gathered during a debriefing after each session. All } \\
\text { videotapes will be kept in the archives of the Space Systems Lab and } \\
\text { may be used for documentation of test activities. } \\
\text { Each session will last approximately } 1 \text { hour in-water. The study will } \\
\text { have a total of } 4 \text { in-water sessions with briefings and debriefings. The } \\
\text { total time commitment should be approximately } 8 \text { hours. }\end{array}$ \\
\hline $\begin{array}{l}\text { What about } \\
\text { confidentiality? }\end{array}$ & $\begin{array}{l}\text { We will do our best to keep your personal information confidential. To } \\
\text { help protect your confidentiality, (1) your name will not be included on } \\
\text { the surveys and other collected data; (2) a code will be placed on the } \\
\text { survey and other collected data; (3) through the use of an identification } \\
\text { key, the researcher will be able to link your survey to your identity; and } \\
\text { (4) only the researcher will have access to the identification key. If we } \\
\text { write a report or article about this research project, your identity will be } \\
\text { protected to the maximum extent possible. Your information may be } \\
\text { shared with representatives of the University of Maryland, College Park } \\
\text { or governmental authorities if you or someone else is in danger or if we } \\
\text { are required to do so by law. }\end{array}$ \\
\hline $\begin{array}{l}\text { What are the risks of } \\
\text { this research? }\end{array}$ & $\begin{array}{l}\text { There may be some risks from participating in this research study. The } \\
\text { main risks of the experiment are those inherent to SCUBA diving. These } \\
\text { include drowning, arterial gas embolism, decompression sickness, and } \\
\text { barotrauma to the ears. The ballast system will add some risks unique } \\
\text { from diving, namely the inability to ascend while wearing the weights. } \\
\text { To mitigate this risk, the weights will be mounted on quick release } \\
\text { mechanisms and safety divers will be present at all times to } \\
\text { After any major illness, injury, or medical condition requiring } \\
\text { hospitalization for } 24 \text { hours or longer subjects must be cleared before } \\
\text { returning to diving. If the illness, injury or condition is pressure-related, } \\
\text { then the clearance must come from a physician trained in diving } \\
\text { medicine. }\end{array}$ \\
\hline $\begin{array}{l}\text { What are the benefits } \\
\text { of this research? }\end{array}$ & $\begin{array}{l}\text { This research is not designed to help you personally, but the results may } \\
\text { help the investigator learn more about ways to design hardware for } \\
\text { planetary exploration. We hope that, in the future, other people might } \\
\text { benefit from this study through improved understanding of design } \\
\text { limitations placed on this equipment by astronauts' movement in reduced } \\
\text { gravity. }\end{array}$ \\
\hline
\end{tabular}




\begin{tabular}{|c|c|}
\hline Project Title & $\begin{array}{l}\text { Water Immersion Ballasted Partial Gravity Simulation for Lunar and } \\
\text { Martian EVA Simulation }\end{array}$ \\
\hline $\begin{array}{l}\text { Do I have to be in } \\
\text { this research? } \\
\text { May I stop } \\
\text { participating at any } \\
\text { time? }\end{array}$ & $\begin{array}{l}\text { Your participation in this research is completely voluntary. You may } \\
\text { choose not to take part at all. If you decide to participate in this } \\
\text { research, you may stop participating at any time for any reason. If you } \\
\text { decide not to participate in this study or if you stop participating at any } \\
\text { time, you will not be penalized or lose any benefits to which you } \\
\text { otherwise qualify. The subject's desire to end one session, does not } \\
\text { disqualify them in anyway from participating in subsequent sessions. }\end{array}$ \\
\hline $\begin{array}{l}\text { Is any medical } \\
\text { treatment available if } \\
\text { I am injured? }\end{array}$ & $\begin{array}{l}\text { The University of Maryland does not provide any medical, } \\
\text { hospitalization or other insurance for participants in this research } \\
\text { study, nor will the University of Maryland provide any medical } \\
\text { treatment or compensation for any injury sustained as a result of } \\
\text { participation in this research study, except as required by law. }\end{array}$ \\
\hline $\begin{array}{l}\text { What if I have } \\
\text { questions? }\end{array}$ & $\begin{array}{l}\text { This research is being conducted by Dr. David Akin and John Mularski } \\
\text { of the Aerospace Engineering Department at the University of } \\
\text { Maryland, College Park. If you have any questions about the research } \\
\text { study itself, please contact: } \\
\text { Dr. David Akin } \\
\text { University of Maryland } \\
\text { Building 382 Room 2100D } \\
\text { College Park, MD 20742 } \\
\text { (email) dakin@ssl.umd.edu } \\
\text { (telephone) 301-405-1138 } \\
\text { or } \\
\text { John Mularski } \\
\text { University of Maryland } \\
\text { Building 382 Room 1100C } \\
\text { College Park, MD 20742 } \\
\text { (email) mularski@ssl.umd.edu } \\
\text { (telephone) 301-405-7353 }\end{array}$ \\
\hline & $\begin{array}{l}\text { If you have questions about your rights as a research subject or wish to } \\
\text { report a research-related injury, please contact: } \\
\text { Institutional Review Board Office } \\
\text { University of Maryland, College Park, Maryland, } 20742 \\
\text { (e-mail) irb@deans.umd.edu } \\
\text { (telephone) 301-405-0678 }\end{array}$ \\
\hline & $\begin{array}{l}\text { This research has been reviewed according to the University of } \\
\text { Maryland, College Park IRB procedures for research involving human } \\
\text { subjects. }\end{array}$ \\
\hline
\end{tabular}




\begin{tabular}{|c|c|c|}
\hline Project Title & \multicolumn{2}{|c|}{$\begin{array}{l}\text { Water Immersion Ballasted Partial Gravity Simulation for Lunar and } \\
\text { Martian EVA Simulation }\end{array}$} \\
\hline $\begin{array}{l}\text { Statement of Age of } \\
\text { Subject and Consent } \\
\text { [Please note: } \\
\text { Parental } \\
\text { consent always } \\
\text { needed } \\
\text { for minors.] }\end{array}$ & \multicolumn{2}{|c|}{$\begin{array}{l}\text { Your signature indicates that: } \\
\text { you are at least } 18 \text { years of age; } \\
\text { the research has been explained to you; } \\
\text { your questions have been fully answered; } \\
\text { you agree to be videotaped during the sessions; and } \\
\text { you freely and voluntarily choose to participate in this research } \\
\text { project. }\end{array}$} \\
\hline \multirow[t]{3}{*}{ Signature and Date } & NAME OF SUBJECT & \\
\hline & SIGNATURE OF SUBJECT & \\
\hline & DATE & \\
\hline
\end{tabular}




\section{Bibliography}

[1] University of Minnesota. "AEM Students to Participate in Microgravity Experiments." Aerospace Engineering \& Mechanics Department. http://www.aem.umn.edu/info/update/1999-00/micrograv.html

[2] Williams, R. K. and Billica, L. W. "Johnson Space Center Reduced Gravity Program and 1992 Highlights." $31^{\text {st }}$ Aerospace Sciences Meeting \& Exhibit, 1993.

[3] NASA Technical Reports Server. "Astronaut Alan Shepard with Modular Equipment Transporter aboard KC-135.” ID S70-53479.

[4] NASA. “Apollo 12 Technical Crew Debriefing.” Houston, Texas, 1969.

[5] Newman, D. J. "Human Locomotion and Energetics in Simulated Partial Gravity." Ph.D. diss., Massachusetts Institute of Technology, 1992.

[6] NASA Technical Reports Server. "Astronaut Alan Bean participates in lunar surface simulation." ID S69-56059.

[7] Griffin, T. M., Tolani, N. A., and Kram, R. "Walking in Simulated Reduced Gravity: Mechanical Energy Fluctuations and Exchange." Journal of Applied Physiology 86, no. 1 (1999): $383-390$.

[8] Carr, C. E. "The Bioenergetics of Walking and Running in Space Suits." Sc.D. diss., Massachusetts Institute of Technology, 2005.

[9] Kennedy, K. J. “JSC-CTSD Advanced Habitation Design Capabilities." Space 2006. San Jose, California. Sept. 2006.

[10] NASA Technical Reports Server. "Reduced Gravity Walking Simulator." ID GPN2000-001782.

[11] Spady, Jr., A. A. and Krasnow, W. D. "Exploratory Study of Man's SelfLocomotion Capabilities with a Space Suit in Lunar Gravity." NASA Technical Note, 1966.

[12] Wickman, L. A. and Luna, B. "Locomotion while Load-Carrying in Reduced Gravities." Aerospace Medical Association Annual Scientific Meeting. Anaheim, CA. 1995.

[13] Todd, B. and Reagan, M. "The NEEMO Undersea Analog: Another Type of Deep Space Exploration.” Space 2006. Long Beach, CA. 2006. 
[14] NOAA. "Aquarius Undersea Laboratory."

http://www.uncw.edu/aquarius/archive/1993_1996/aq_exterior2_high.jpg.

[15] NASA Technical Reports Server. “Apollo 14 Crew Training.” ID GPN-2000000962.

[16] NASA Technical Reports Server. "Astronauts Young and Duke study rock formations on simulated lunar traverse." ID S71-59355.

[17] The Mars Society. "The Mars Society - Flashline Arctic Research Station." http://www.marssociety.org/arctic/index.asp.

[18] The Mars Society. "The Mars Society: Mars Desert Research Station." http://www.marssociety.org/MDRS/index.asp.

[19] Ross, A. J., Kosmo, J. J., Janoiko, B. A., Bernard, C., Splawn, K., and Eppler, D. B. "Desert Research and Technology Studies 2005 Report." ICES 2006. Norfolk, VA. 2006.

[20] Knapik, J., Harman, E., and Reynolds, K. "Load Carriage using Packs: A Review of Physiological, Biomechanical and Medical Aspects.” Applied Ergonomics. Vol 27. No. 3. pgs. 207 -216. 1996.

[21] Space Systems Laboratory. "Facilities at the SSL." http://ssl/facilities/index.shtml.

[22] de Leva, P., "Adjustments to Zatsiorsky-Seluyanov's Segment Inertia Parameters." Journal of Biomechanics 29, no. 9 (1996): 1223 - 1230.

[23] Larson, W. J., and Pranke, L. K. Human Spaceflight: Mission Analysis and Design. 1999. pg. 709. McGraw-Hill.

[24] Akin, D., "Akin's Laws of Spacecraft Design.”

http://spacecraft.ssl.umd.edu/akins_laws.html 